
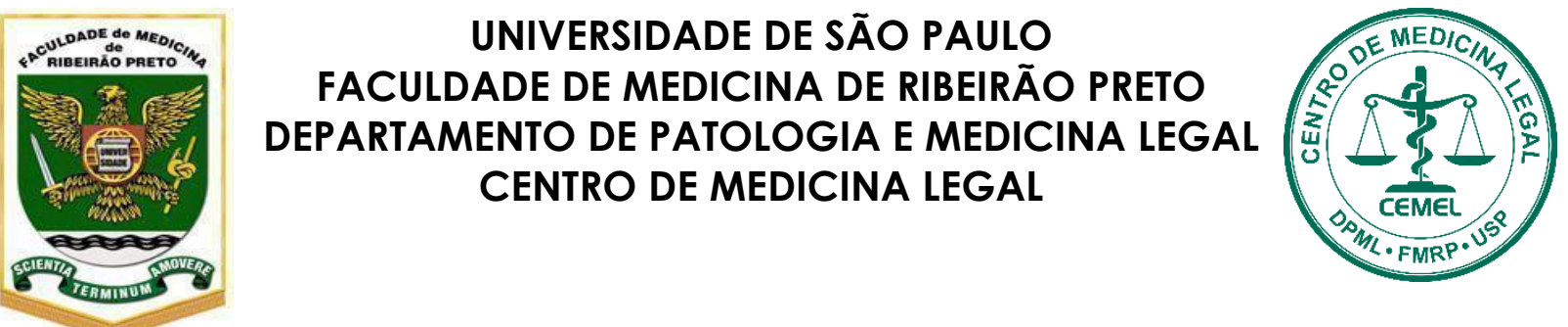

CAROLINA MELATO LINDEMANN

\title{
ESTUDO SOBRE O ENCAMINHAMENTO DE CADÁVERES PARA O SERVIÇO DE VERIFICAÇÃO DE ÓBITOS DO INTERIOR (SVOI): EFEITOS DO PARECER CONSULTA CREMESP $31.184 / 2015$
}

Ribeirão Preto 



\section{ESTUDO SOBRE O ENCAMINHAMENTO DE CADÁVERES PARA O SERVIÇO DE VERIFICAÇÃO DE ÓBITOS DO INTERIOR (SVOI): EFEITOS DO PARECER CONSULTA CREMESP 31.184/2015}

\section{Versão Corrigida}

Tese apresentada ao Departamento de Patologia e Medicina Legal da Faculdade de Medicina de Ribeirão Preto da Universidade de São Paulo para obtenção do título de Doutora em Patologia.

Área de Concentração: Patologia Experimental Orientador: Professor Doutor Marco Aurelio Guimarães

Ribeirão Preto

2021 
Autorizo a reprodução e divulgação total ou parcial deste trabalho, por qualquer meio convencional ou eletrônico, para fins de estudo ou pesquisa, desde que citada a fonte.

\section{FICHA CATALOGRÁFICA}

Lindemann, C.M. Estudo sobre o encaminhamento de cadáveres para o serviço de verificação de óbitos do interior (SVOI): efeitos do Parecer Consulta CREMESP 31.184/2015. Carolina Melato Lindemann. Orientador: Marco Aurelio Guimarães, $2021 \quad 00$ f.: il.; $30 \mathrm{~cm}$

Tese de Doutorado apresentada à Faculdade de Medicina de Ribeirão Preto - USP. Área de concentração: Patologia.

1. Necropsia 2. Causa Mortis 3. Mortalidade. 4. Óbito.

5. Diagnóstico. 6. Declaração de Óbito. 


\section{FOLHA DE APROVAÇÃO}

Nome: Lindemann, Carolina Melato.

Título: Estudo sobre o encaminhamento de cadáveres para o serviço de verificação de óbitos do interior (SVOI): efeitos do Parecer Consulta CREMESP $31.184 / 2015$.

Tese apresentada ao Departamento de Patologia e Medicina Legal da Faculdade de Medicina de Ribeirão Preto da Universidade de São Paulo para obtenção do título de Doutora em Patologia.

Área de Concentração: Patologia Experimental

Aprovado em: 1

Banca Examinadora

Prof. Dr. Instituição

Julgamento Assinatura

Prof. Dr. Instituição

Julgamento Assinatura

Prof. Dr. Instituição

Julgamento Assinatura

Prof. Dr. Instituição

Julgamento Assinatura

Prof. Dr. Instituição

Julgamento Assinatura 
À Fernanda, minha esposa, por todo o apoio, carinho e motivação que me deu para concluir este trabalho. Por ter segurado as pontas em casa e ter me segurado também, por ser tudo aquilo que nos une e nos fortalece.

Ao meu orientador, Marco Aurelio, que além da oportunidade e do caminho me deu os empurrões necessários para que o trabalho ficasse formal e ainda mantivesse o meu traço.

Ao professor Moacyr, por topar a ideia e por toda a paciência para me explicar de novo e de novo alguns cálculos e conceitos que eu queria entender.

À Regina e à Érika, do SVOI, por todo o apoio técnico e material (e pelo café!).

Às meninas de sempre, Luanah e Adriana, que já trilham comigo essa saga educacional há quase vinte anos, e à Fran, que chegou agora mas já se equiparou em força e parceria.

À Elisa, pelos dez anos de amizade e pela família que me deu.

À minha mãe, que em todo telefonema me perguntava "mas não acabou ainda?". Não, mãe, não acabou. Mesmo agora já penso na próxima pesquisa.

A todos aqueles que me ajudaram no mestrado, nas graduações, e mesmo achando loucura eu fazer tanta coisa ao mesmo tempo me apoiaram.

A todos os funcionários do CEMEL e do Departamento de Patologia da FMRP.

A todos os profissionais de saúde que comigo estiveram neste ano intenso e horrivel de pandemia. Que vocês estejam sempre protegidos, seguros, e que possam em breve ter merecidas férias com seus familiares e entes queridos. 
"Tudo deve ser levado em consideração. Se o fato não se ajusta à teoria, pior para a teoria!" Hercule Poirot - Agatha Christie (em tradução livre).

Christie, Agatha. The Mysterious Affair At Styles: A Hercule Poirot Novel Mystery. New York: Black Dog \& Leventhal Publishers, 224 pages. 2006. 


\section{RESUMO}

LINDEMANN, C.M. Estudo sobre o encaminhamento de cadáveres para o serviço de verificação de óbitos do interior (SVOI): efeitos do Parecer Consulta CREMESP 31.184/2015. Tese de Doutorado - Faculdade de Medicina de Ribeirão Preto, Universidade de São Paulo. Ribeirão Preto, Brasil, 2021.

Introdução. O encaminhamento indevido ou irregular de corpos para necropsia é um problema crônico enfrentado em vários centros de referência. O SVOI recebe corpos de pessoas que morreram sob cuidados médicos e/ou após longo período de morbidade, o que desobriga a realização de necropsia para fins de atestar o óbito. Porém, o serviço recebe semanalmente cadáveres com causa de morte presumíveis, inclusive provenientes de instituições hospitalares com equipe médica em tempo integral e, consequentemente, arca com o ônus de necropsias desnecessárias ou até incorretamente realizadas, como no caso de fetos mortos. Após o estabelecimento das novas regras sob o esclarecimento do Parecer Consulta 31.184/2015, ao final de 2017 foi contabilizada uma redução expressiva no número de necropsias - com consequente redução de custos públicos, institucionais, sociais e familiares. Essa redução imediata levantou uma dúvida: quais e que tipo de casos deixaram de dar entrada no SVOI? Objetivos. Realizar o levantamento retrospectivo de necropsias no SVOI para os anos de 2013-2014 e 2017-2018, e comparar os dados anteriores e posteriores à publicação do Parecer Consulta 31.184/2015 para verificação de possíveis diferenças entre o número de necropsias, perfil sociodemográfico e de diagnósticos de causa mortis nos casos de necropsias realizadas no SVOI, e assim avaliar a interferência do Parecer Consulta nas atividades do serviço. Ainda, objetivase analisar e discutir criticamente os aspectos médico-legais e bioéticos dos resultados a serem obtidos, indicando possíveis falhas dos processos e consequências para a gestão de recursos públicos. Métodos. Foram utilizados como fontes de dados os relatórios anuais de atividades do SVOI de Ribeirão Preto, os pedidos de necropsia, os Boletins de Ocorrência, as Declarações de Óbito e, por fim, os relatórios de necropsia contendo a causa do óbito e correlação diagnóstica de achados de macroscopia e microscopia, por vezes complementados com informações clínicas. As categorias de encaminhamento, faixa etária, local de óbito, cor de pele, sexo, e causa mortis segundo a CID-10 foram analisadas por estatística descritiva e análise de médias, e aplicado o Teste T de Student para amostras não pareadas. Resultados: Houve aumento de 5,29\% no numero de habitantes de Ribeirão Preto e de 12,13\% dos 
óbitos por causas naturais ocorridos na cidade, enquanto os encaminhamentos de corpos diminuíram $16,95 \%$ e o número de necropsias realizadas caiu 17,89\%. Não houve diferença quanto à cor de pele ou sexo dos necropsiados, mas quanto à idade foram expressivas as reduções de faixas etárias relativas à infância, sendo as necrópsias realizadas por óbitos perinatais $75,33 \%$ menores e as de crianças e adolescentes $63,83 \%$ menores. Apenas a faixa etária de 90 a 105 anos teve aumento de encaminhamentos $(28,47 \%)$, sendo que todas as outras faixas tiveram queda, ainda que não com significância estatística. Quanto ao local de óbito houve aumento de necropsiados provenientes de Casas de Repouso $(20,97 \%)$ e Domicílio $(37,67 \%)$, com diminuição de necropsiados provenientes de Hospitais de Financiamento Misto $(48,64 \%)$, Hospitais Particulares $(47,68 \%)$, Pronto Atendimento Público (35,25\%), Maternidade Pública (59,38\%) e, principalmente, de Maternidade Particular (81,55\%). A diminuição de encaminhamentos de Hospitais Públicos não foi estatisticamente significativa. Quando ao diagnóstico de causa de morte após necropsia, tiveram seu número significativamente reduzido os óbitos fetais ou perinatais $(83,59 \%)$, as doenças infecciosas $(47,48 \%)$, as doenças do sistema nervoso $(46,43 \%)$ e as neoplasias (22,58\%). Conclusões. O Parecer Consulta 31.184/2015 teve efeito de redução sobre o número de necropsias realizadas no SVOI. O maior impacto foi sobre encaminhamentos de pacientes após internação hospitalar com diagnóstico de septicemia e de óbitos fetais/perinatais. Não há respaldo legal ou ético para o encaminhamento de cadáveres para os SVO após internação que resultou em diagnóstico de causa de morte, seja sindrômico ou de foco indeterminado. O preenchimento da Declaração de Óbito pelo médico que acompanhou o paciente em vida evita diagnósticos irregulares e necropsias desnecessárias. Não é possível afirmar que o não encaminhamento desses pacientes resultou no preenchimento adequado das DO nos demais serviços da rede municipal de saúde. Faz-se necessária a implantação do preenchimento eletrônico da DO, de modo a guiar o preenchimento e promover a melhoria da correlação diagnóstica entre campos. Com um sistema nacional de prontuários médicos seria também possível delinear causas básicas e intermediárias de morte com base nas informações de saúde antigas e recentes daquele paciente.

Palavras-chave: 1. Necropsia 2. Causa Mortis. 3. Mortalidade. 4. Óbito. 5. Diagnóstico. 6. Declaração de Óbito. 


\begin{abstract}
LINDEMANN, C.M. Study on the referral of corpses to the city death verification service (SVOI): effects of the CREMESP Consultation Report 31.184 / 2015. Tesis presented to Ribeirão Preto Medical School, University of São Paulo. Ribeirão Preto, Brazil, 2021., São Paulo, 2021.
\end{abstract}

Introduction. The improper or irregular referral of bodies for necropsy is a chronic problem faced in several referral centers. The SVOI receives the bodies of people who died under medical care and / or after a long period of morbidity, which exempts necropsy for the purpose of attesting death. However, the institute receives corpses with a presumed cause of death on a weekly basis, including those coming from hospital institutions with full-time medical staff and, consequently, bears the burden of unnecessary or even incorrectly performed necropsies, as in the case of dead fetuses. After the establishment of the new rules under the clarification of Consultation Report 31.184 / 2015, at the end of 2017 a significant reduction in the number of autopsies was recorded - with a consequent reduction in public, institutional, social and family costs. This raised a question: which and what types of cases failed to file with SVOI? Objectives. Retrospectively survey necropsies at SVOI for the years 2013-2014 and 2017-2018, and compare the data before and after the publication of Consultation Report 31.184 / 2015 to verify possible differences between the number of necropsies, sociodemographic profile and diagnoses of causa mortis in cases of necropsies performed at SVOI, and thus assess the interference of the Opinion Consultation in the activities of the service. Still, the objective is to critically analyze and discuss the medico-legal and bioethical aspects of the results to be obtained, indicating possible failures of the processes and consequences for the management of public resources. Methods. Data sources were used in the annual activity reports of the SVOI of Ribeirão Preto, necropsy requests, police reports, death certificates and, finally, necropsy reports containing the cause of death and diagnostic correlation of findings macroscopy and microscopy, sometimes supplemented with clinical information. The categories of referral, age group, place of death, skin color, sex, and cause of death according to ICD-10 were analyzed using descriptive statistics and analysis of means, and the Student's T-Test was applied to unpaired samples. Results: There was a $5.29 \%$ increase in the number of inhabitants of Ribeirão Preto and $12.13 \%$ of deaths from natural causes that occurred in the city, while the referrals of bodies decreased by 
$16.95 \%$ and the number of autopsies performed fell by $17.89 \%$. There was no difference in skin color or sex of the necropsied individuals, but in terms of age, there were significant reductions in age groups related to childhood, with necropsies performed for perinatal deaths $75.33 \%$ lower and those of children and adolescents $63.83 \%$ smaller. Only the age group from 90 to 105 years old had an increase in referrals (28.47\%), and all other groups had a decrease, although the only other age group with statistical significance was 60-69 years old (-10,05\%). As for the place of death, there was an increase in necropsies from Nursing Homes (20.97\%) and Deaths at Home (37.67\%), with a decrease in necropsies from Mixed Financed Hospitals (48.64\%), Private Hospitals (47.68\%), Public Emergency Service (35.25\%), Public Maternity (59.38\%) and, mainly, Private Maternity (81.55\%). The decrease in referrals from Public Hospitals was not statistically significant. Regarding the diagnosis of cause of death after necropsy, fetal or perinatal deaths (83.59\%), Infectious Diseases (47.48\%), nervous system diseases $(46.43 \%)$ and neoplasms $(22.58 \%)$ were significantly reduced.

Conclusions. Consultation Report 31.184 / 2015 had a reducing effect on the number of necropsies performed at SVOI. The greatest impact was on referrals of patients after hospitalization with diagnosis of septicemia and fetal/perinatal deaths. There is no legal or ethical support for forwarding corpses to the SVO after hospitalizations that resulted in a diagnosis of cause of death, whether syndromic or of undetermined focus. Filling out the Death Certificate by the doctor who accompanied the patient while alive avoids irregular diagnoses and unnecessary necropsies. It is not possible to affirm that the non-referral of these patients resulted in the adequate completion of the DO in other services of the municipal health network. It is necessary to implement the electronic writing of the DO in order to guide the filling and promote the improvement of the diagnostic correlation between fields. With a national system of medical records, it would also be possible to outline basic and intermediate causes of death based on previous health information of that patient.

Keywords: 1. Necropsy 2. Cause of death. 3. Mortality. 4. Death. 5. Diagnosis. 6. Death certificate 
Figura 1. Óbitos em Ribeirão preto por causas naturais, causas externas, óbitos totais e encaminhamentos ao SVOI nos anos de 2013, 2014, 2017, 2018.

Figura 2. Distribuição do total de pacientes encaminhados ao SVOI nos anos de 2013. 2014, 2017 e 2018.

Figura 3. Médias de distribuição dos encaminhamentos totais nos anos de interesse com detalhamento dos pacientes redestinados.

Figura 4. Proporção entre pacientes redestinados ao $I M L$, ao hospital de origem ou liberados por médico da família.

Figura 5. Porcentagem de encaminhamentos, necropsias realizadas pelo SVOI e necropsias recusadas pelo serviço em relação ao total de óbitos em Ribeirão Preto.

Figura 6. Porcentagem de encaminhamentos, necropsias realizadas pelo SVOI e necropsias recusadas pelo serviço em relação às mortes por causas naturais ocorridas no município de Ribeirão Preto.

Figura 7. Porcentagem de necropsias realizadas pelo SVOI e de necropsias redestinadas em relação ao total de encaminhamentos para o serviço.

Figura 8. Porcentagem de necropsias transferidas ao IML, devolvidas ao hospital ou liberadas por médico da família em relação ao total de pacientes redestinados.

Figura 9. Distribuição por cor de pele dos pacientes segundo o relatório de necropsia dos anos de 2013, 2014, 2017 e 2018 em valores brutos.

Figura 10. Distribuição por cor de pele dos pacientes segundo o relatório de necropsia comparados, em porcentagem, ao total de moradores de Ribeirão preto no ano base de 2010.

Figura 11. Distribuição por sexo dos pacientes necropsiados pelo SVOI nos anos de 2013, 20142017 e 2018 em valores brutos.

Figura 12. Distribuição por idade do total de pacientes encaminhamentos nos anos de 2013, 2014, 2017 e 2018.

Figura 13. Médias de encaminhamentos dos anos anteriores e subsequentes ao Parecer Consulta, distribuídos por idade. 
Figura 14. Distribuição por idade do total de necropsias realizadas no SVOI nos anos de 2013, 2014, 2017, 2018.

Figura 15. Médias de necropsias realizadas no SVOI nos anos anteriores e subsequentes ao Parecer Consulta, distribuídos por idade.

Figura 16. Distribuição por idade do total de necropsias recusadas pelo SVOI nos anos de 2013, 2014, 2017, 2018 e redestinadas a outros serviços.

Figura 17. Médias de necropsias recusadas pelo SVOI e redestinadas a outros serviços nos anos de anteriores e subsequentes ao Parecer Consulta.

Figura 18. Distribuição por grupos etários do total encaminhadas nos anos de 2013, 2014, 2017, 2018.

Figura 19. Médias de necropsias realizadas no SVOI nos anos anteriores e subsequentes ao Parecer Consulta, distribuídos por faixa etária.

Figura 20. Distribuição por grupos etários do total de necropsias realizadas pelo SVOI nos anos de 2013, 2014, 2017, 2018.

Figura 21. Médias de necropsias realizadas pelo SVOI nos anos anteriores e subsequentes ao Parecer Consulta, distribuídos por grupos etários.

Figura 22. Distribuição por grupos etários do total de necropsias recusadas pelo SVOI nos anos de 2013, 2014, 2017, 2018 e redestinadas a outros serviços.

Figura 23. Médias de necropsias recusadas pelo SVOI e redestinadas a outros serviços nos anos anteriores e subsequentes ao Parecer Consulta, distribuídos por grupos etários.

Figura 24. Total de necropsias realizadas pelo SVOI nos anos de interesse, distribuídas por local de óbito.

Figura 25. Total de necropsias realizadas pelo SVOI nos anos de interesse, distribuídas por local de óbito.

Figura 26. Médias de necropsias realizadas pelo SVOI com encaminhamentos feitos por maternidades públicas e particulares em anos anteriores e subsequentes ao Parecer Consulta.

Figura 27. Total de necropsias realizadas nos anos de interesse, distribuídas por categorias relacionadas às causas terminais de morte constantes na Declaração de Óbito.

Figura 28. Médias de necropsias realizadas nos anos de interesse, distribuídas por categorias relacionadas às causas terminais de morte constantes na Declaração de Óbito.

Figura 29. Médias das categorias da CID-10 com redução significativa comparando os anos anteriores e subsequentes ao Parecer Consulta. ..... 
Tabela 1. Total de habitantes de Ribeirão Preto, total de óbitos ocorridos na cidade e total de encaminhamentos ao SVOI e de necropsias realizadas nos anos de interesse.

Tabela 2. Total de habitantes de Ribeirão Preto, total de óbitos ocorridos na cidade e total de encaminhamentos ao SVOI e de necropsias realizadas nos anos de interesse organizadas por médias dos anos anteriores e subsequentes ao Parecer Consulta.

Tabela 3. Pacientes recebidos e não necropsiados em 2013. 2014, 2017 e 2018.

Tabela 4. Médias de encaminhamentos entre os anos anteriores e subsequentes ao Parecer Consulta, com a aplicação do teste T de Student.

Tabela 5. Proporção de exames solicitados, realizados ou não, comparados aos dados do DATASUS e do IBGE na forma de médias dos anos anteriores e subsequentes ao Parecer Consulta.

Tabela 6. Distribuição por cor de pele dos pacientes segundo o relatório de necropsia dos anos de 2013, 2014, 2017 e 2018 em valores brutos.

Tabela 7. Distribuição por cor de pele dos pacientes segundo o relatório de necropsia comparados, em porcentagem, ao total de moradores de Ribeirão preto no ano base de 2010.

Tabela 8. Distribuição por sexo dos pacientes necropsiados pelo SVOI nos anos de 2013, 20142017 e 2018 em valores brutos.

Tabela 9. Distribuição por idade do total de encaminhamentos nos anos de 2013, 2014, 2017, 2018.

Tabela 10. Médias de encaminhamentos dos anos anteriores e subsequentes ao Parecer Consulta, distribuídos por faixas idade.

Tabela 11. Distribuição por idade do total de necropsias realizadas no SVOI nos anos de 2013, 2014, 2017, 2018.

Tabela 12. Médias de necropsias realizadas no SVOI nos anos anteriores e subsequentes ao Parecer Consulta, distribuídos por idade.

Tabela 13. Distribuição por idade do total de necropsias recusadas pelo SVOI nos anos de 2013, 2014, 2017, 2018 e redestinadas a outros serviços.

Tabela 14. Médias de necropsias recusadas pelo SVOI e redestinadas a outros serviços nos anos de anteriores e subsequentes ao Parecer Consulta. 
Tabela 15. Distribuição por grupos etários do total de encaminhamentos nos anos de 2013, 2014, 2017, 2018.

Tabela 16. Médias de necropsias realizadas no SVOI nos anos anteriores e subsequentes ao Parecer Consulta, distribuídos por faixa etária.

Tabela 17. Distribuição por grupos etários do total de necropsias realizadas pelo SVOI nos anos de 2013, 2014, 2017, 2018.

Tabela 18. Médias de necropsias realizadas pelo SVOI nos anos anteriores e subsequentes ao Parecer Consulta, distribuídos por grupos etários.

Tabela 19. Distribuição por grupos etários do total de necropsias recusadas pelo SVOI nos anos de 2013, 2014, 2017, 2018 e redestinadas a outros serviços.

Tabela 20. Médias de necropsias recusadas pelo SVOI e redestinadas a outros serviços nos anos anteriores e subsequentes ao Parecer Consulta, distribuídos por grupos etários.

Tabela 21. Total de necropsias realizadas pelo SVOI nos anos de interesse, distribuídas por local de óbito.

Tabela 22. Médias de necropsias realizadas pelo SVOI nos anos anteriores e subsequentes à publicação do Parecer Consulta, distribuídas por local de óbito, salientando a diferença em porcentagem e estatística.

Tabela 23. Médias de encaminhamentos feitos por maternidades públicas e particulares em anos anteriores e subsequentes à publicação do Parecer Consulta.

Tabela 24. Total de necropsias realizadas nos anos de interesse, distribuídas por categorias relacionadas às causas terminais de morte constantes na Declaração de Óbito.

Tabela 25. Médias de necropsias realizadas nos anos de interesse, distribuídas por categorias relacionadas às causas terminais de morte constantes na Declaração de Óbito.

Tabela 26. Médias das categorias da CID-10 com redução significativa comparando os anos anteriores e subsequentes ao Parecer Consulta. 


\section{Lista de Siglas}

\begin{tabular}{|c|c|}
\hline CEE & Comissão Especial De Estudos \\
\hline CEMEL & Centro De Medicina Legal \\
\hline CEP & Comitê De Ética Em Pesquisa \\
\hline CLT & Consolidação Das Leis Do Trabalho \\
\hline CONEP & Comissão Nacional De Ética Em Pesquisa \\
\hline COVID-19 & Coronavirus Disease 2019 \\
\hline CREMESP & Conselho Regional De Medicina Do Estado De São Paulo \\
\hline DATASUS & $\begin{array}{l}\text { Portal De Informações Em Saúde Pública Do Sistema Único } \\
\text { De Saúde Brasileiro }\end{array}$ \\
\hline DIPE & $\begin{array}{l}\text { Diagnósticos Incongruentes Ou De Preenchimento } \\
\text { Equivocado }\end{array}$ \\
\hline DO & Declaração De Óbito \\
\hline DOE & Diário Oficial Do Estado \\
\hline DOU & Diário Oficial Da União \\
\hline ESF & Estratégia De Saúde Da Família \\
\hline FMRP/USP & $\begin{array}{l}\text { Faculdade De Medicina De Ribeirão Preto / Universidade } \\
\text { De São Paulo }\end{array}$ \\
\hline GC & Garbage Codes (Códigos Lixo) \\
\hline IBGE & Instituto Brasileiro De Geografia E Estatística \\
\hline ILP & Instituição De Longa Permanência. \\
\hline IML & Instituto Médico Legal \\
\hline PC & Parecer Consulta \\
\hline SAMU & Serviço De Atendimento Móvel De Urgência \\
\hline SIM & Sistema De Informação Sobre Mortalidade \\
\hline SINASC & Sistema De Informação Sobre Nascidos Vivos \\
\hline SVO & Serviço De Verificação De Óbitos \\
\hline SVOC & Serviço De Verificação De Óbitos Da Capital \\
\hline SVOI & Serviço De Verificação De Óbitos Do Interior \\
\hline TCLE & Termo De Consentimento Livre E Esclarecido \\
\hline UBS & Unidade Básica De Saúde \\
\hline IPA & Unidade De Pronto Atendimento \\
\hline
\end{tabular}




\section{Sumário}

1. Introdução

1.1 A Declaração de Óbito e o Serviço de Verificação de Óbito (SVO) no

Estado de São Paulo.

1.2 Um panorama sobre as necropsias ........................................................ 4

1.3 O Parecer Consulta 31.184/2015 do CREMESP (PC) ................................ 6

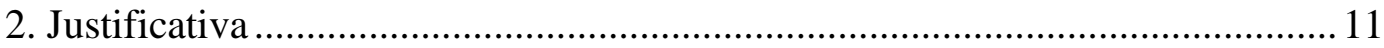

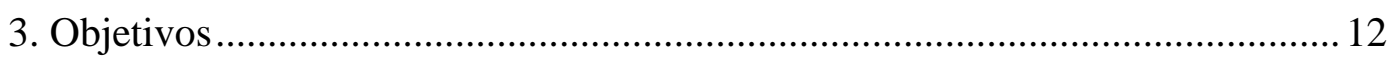

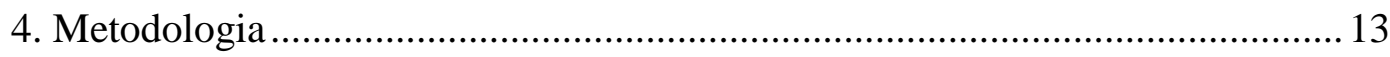

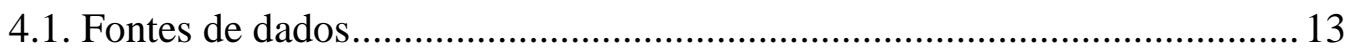

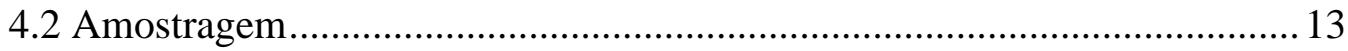

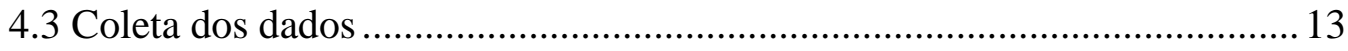

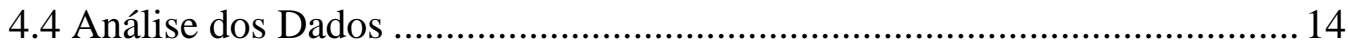

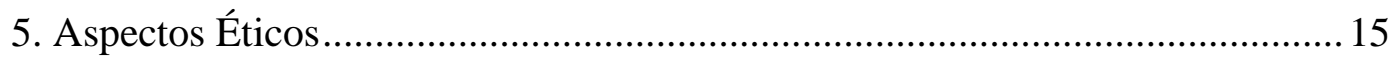

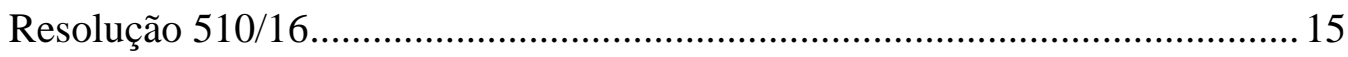

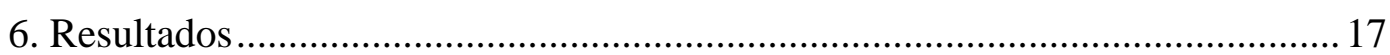

6.1 Resultados quanto a população, óbitos e encaminhamentos ...................... 17

6.2 Características Sociodemográficas dos pacientes encaminhados............... 25

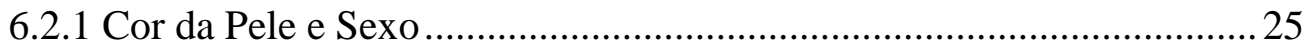

6.2.2 Idade e Grupo Etário...................................................................... 27

6.3 Análise de Local de Óbito e Causa Mortis .................................................. 38

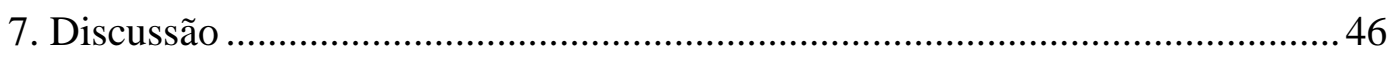

7.1 Características Sociodemográficas dos pacientes examinados................... 47

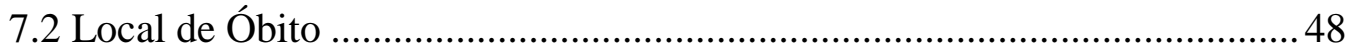

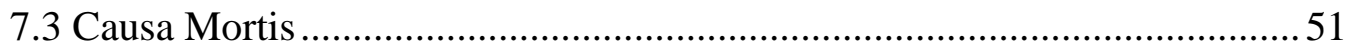

7.4 Diagnósticos Incongruentes ou de Preenchimento Equivocado (DIPE) ..... 54

7.5 Implicações sobre a Gestão de Recursos para a Saúde Pública........................ 57

7.6 Implicações legais, bioéticas e de impacto social da realização necropsias

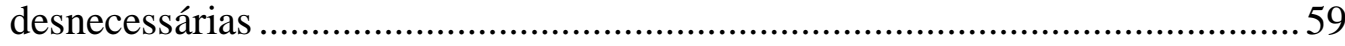

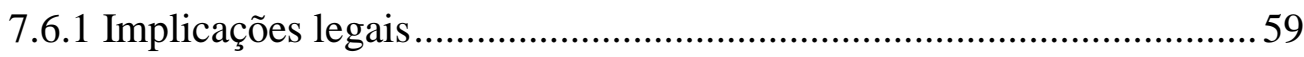

7.6.2 Implicações bioéticas e de impacto social ......................................... 62

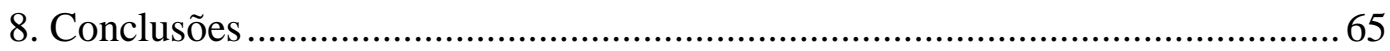

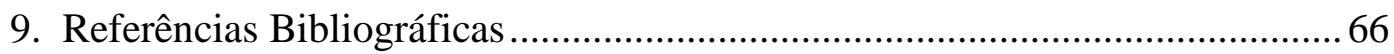

Anexo 1 - Parecer Consulta CREMESP 31.184/2015 .772

Anexo 2 - Declaração de Óbito fornecida pelo Ministério da Saúde.................. 766

Anexo 3 - Carta de Aceite do Projeto de Pesquisa pelo Comitê de Ética em pesquisa do HC-FMRP ............................................................................ 



\section{Introdução}

\subsection{A Declaração de Óbito e o Serviço de Verificação de Óbito (SVO) no Estado de São Paulo}

A Organização Mundial da Saúde define o óbito como "a ausência definitiva de todo sinal de vida em um momento qualquer após o nascimento, sem possibilidade de ressuscitação" (MINISTÉRIO DA SAÚDE, 2009). Carezzato redefine óbito como "o desaparecimento permanente de todo sinal de vida em um ser que era previamente autônomo e competente na realização de suas funções orgânicas de acordo com seu estágio de desenvolvimento, sem possibilidade de ressuscitação ou manutenção artificial de processos fisiológicos, salvo no caso de morte cerebral" (CAREZZATO, 2016). Consideramos essa segunda definição mais atual e abrangente, englobando inclusive os óbitos fetais.

Em 1976 o Ministério da Saúde instituiu um formulário único de Declaração de Óbito (DO) em todo o território nacional como documento base do Sistema de Informações sobre Mortalidade -SIM, com dois objetivos principais. O primeiro, de caráter legal, é o de ser o documento oficial no Brasil para lavratura da Certidão de Óbito pelos Cartórios de Registro Civil (Lei dos Registros Públicos - Lei 6.015/73), que por sua vez é necessária para a autorização de funeral, sepultamento ou cremação de seres humanos. O segundo é de estabelecer um documento padrão para a coleta dos dados sobre mortalidade e, portanto, para o cálculo das estatísticas epidemiológicas do país. O médico é responsável ética e juridicamente pela assinatura da DO e pelo preenchimento das informações registradas em todos os campos do documento, inclusive os de identificação do indivíduo (MINISTÉRIO DA SAÚDE, 2009).

O Serviço de Verificação de Óbito (SVO) é o órgão público oficial encarregado pela realização de necropsias em pessoas que morreram sem diagnóstico definido ou sem assistência médica (MINISTÉRIO DA SAÚDE, 2009). Nos casos de morte natural, o SVO deverá estabelecer a causa de morte e a doença de base, viabilizando a obtenção de dados epidemiológicos indispensáveis para 
a implementação de políticas de saúde pública, podendo guiar medidas preventivas e o rastreamento de causas de morte evitáveis, como casos de moléstias infectocontagiosas, de morte materno-infantil ou ainda de transtornos genéticos que possam acometer outros membros de uma mesma família. Também é responsável pela identificação de eventuais casos de morte não natural inicialmente considerados como morte natural quando da descoberta do cadáver ou da chegada do paciente ao serviço médico de urgência, encaminhando o corpo ao Instituto Médico Legal para exame pericial obrigatório. Além disso, possibilita o ensino médico e a pesquisa científica (SERVIÇO DE VERIFICAÇÃO DE ÓBITOS DA CAPITAL, 2021).

Atualmente o SVOI de São Paulo, em Ribeirão Preto, funciona no edifício do Centro de Medicina Legal (CEMEL), que foi inaugurado em 2005, subordinado à Secretaria de Segurança Pública do Estado de São Paulo (SSP-SP) e à FMRP, através do Departamento de Patologia e Medicina Legal. O acordo de criação, firmado em 1996 (Proc. CS5389-91 DOE Seção I - 106 (122) 28/6/96), prevê a cooperação técnico-científica mútua entre o Núcleo de Perícias Médico-Legais de Ribeirão Preto (NPML/RPO) e a Universidade nas áreas de perícia e pesquisa no campo da Medicina Legal, objetivando o aperfeiçoamento das investigações criminais, das pesquisas científicas na área forense e do ensino prático de Medicina Legal aos alunos da Faculdade de Medicina de Ribeirão Preto da Universidade de São Paulo - FMRP/USP (SERVIÇO DE VERIFICAÇÃO DE ÓBITOS DO INTERIOR, 2021).

A Lei $n^{\circ}$ 5.452, de 22 de dezembro de 1986, a mais recente no que diz respeito aos serviços do Estado de São Paulo, "Reorganiza os Serviços de Verificação de Óbitos no Estado de São Paulo" e define as funções e atribuições do SVO (SÃO PAULO, 1986):

Artigo $1^{\circ}$ - Os Serviços de Verificação de Óbitos no Estado de São Paulo ficam reorganizados nos termos desta lei.

Artigo $2^{\circ}$ - Os Serviços de Verificação de Óbitos têm por finalidade:

L- esclarecer a "causa mortis" em casos de óbito por moléstia mal definida ou sem assistência médica: 
11 - prestar colaboração técnica, didática e científica aos Departamentos de Patologia das Faculdades de Medicina, órgãos afins ou outros interessados, participando de seus trabalhos e podendo funcionar nas suas dependências e instalações.

Artigo $3^{\circ}$ - Compete aos Serviços de Verificação de Óbitos:

I - realizar as necropsias de pessoas falecidas de morte natural sem assistência médica ou com atestado de óbito de moléstia mal definida, inclusive os que Ihe forem encaminhados pelo Instituto Médico Legal do Estado - IML, fornecendo os respectivos atestados de óbito:

II - proceder ao registro de óbito e expedir guia de sepultamento, dentro dos prazos legais, para corpos necropsiados e não reclamados. Nesse caso, o sepultamento poderá ser feito 48 horas após a necropsia, salvo no caso de cadáveres putrefatos, hipótese em que poderá ser feito imediatamente:

III - remover para o IML os casos suspeitos de morte violenta verificados antes ou no decorrer da necropsia e aqueles, de morte natural, de identificação desconhecida, enviando, sempre que couber, comunicação à autoridade policial;

IV - fiscalizar o embarque de cadáveres, ossadas ou restos exumados, para fora de cada município, expedindo os competentes "livre trânsito", nos casos de morte natural;

$\checkmark$ - realizar e/ou fiscalizar embalsamamentos e formolizações de acordo com a legislação sanitária e convenções internacionais em vigor;

$\mathrm{VI}$ - lacrar as urnas funerárias que se destinam ao Exterior, nos casos de morte natural.

VII - fazer as necessárias comunicações à fundação Sistema Estadual de Análise de Dados - SEADE e, quando solicitado, a outros órgãos interessados, nos casos em que, após exames complementares, for modificado ou completado o diagnóstico da causa básica da morte;

Parágrafo único - As atribuições a que se referem os incisos IV e VI, quando se tratar de morte violenta, serão de competência do IML.

(...)

Artigo $7^{\circ}$ - Os oficiais de Registro Civil dos municípios onde haja Serviço de Verificação de Óbitos não registrarão atestados de óbito com moléstia mal definida, encaminhando os interessados ao SVO, que providenciará necropsia. Se, após esta, a moléstia não for esclarecida, os cartórios de Registro Civil registrarão o atestado expedido pelo Serviço.

A referida lei estende-se aos cuidados de acondicionamento de 
cadáveres e regulamenta a administração dos SVO da capital e do interior (SÃO PAULO, 1986).

\subsection{Um panorama sobre as necropsias}

Quanto mais próximas da realidade forem as estatísticas de mortalidade, mais adequadas serão as políticas públicas para a melhoria da coletividade. As necropsias apresentam importante papel no auxílio a essas estatísticas, que são de extrema valia para o diagnóstico de saúde em uma população (BLOSSER, ZIMMERMAN \& STAUFFER, 1998; FERNANDEZ - SEGOVIANO \& ESTEBAN, 1999; HASUO et al, 1989; MCPHEE, 1996b). A necropsia é um exame imprescindível na averiguação das enfermidades do paciente falecido nos casos em que a causa de morte é desconhecida, estando a sua realização em outras circunstâncias, como nos casos de pacientes com diagnósticos definidos, reservada a auditorias de qualidade hospitalar, perícias médico-forenses, pesquisas científicas e ao ensino de profissões da área da saúde (CAREZZATO, 2016). Historicamente sua realização permitiu a elucidação de doenças e seus mecanismos fisiopatológicos ao longo dos séculos e diversas vezes auxiliou no desenvolvimento de medidas terapêuticas através da análise pós-morte do efeito das moléstias sobre os órgãos (KAJIWARA \& ZUCOLOTO, 1991). As necropsias também auxiliam na elucidação

de casos complicados de interesse judicial (CORDNER, 1993), e demonstram amplo potencial de contribuição para as necessidades modernas da pesquisa científica.

Nas últimas décadas tem-se abordado na literatura científica a função central do exame necroscópico nas medidas para controle de qualidade do trabalho médico (GUT, FERREIRA \& MONTENEGRO, 1999; JUVIN et al, 2000; CHUTE, BALLARD \& NEMETZ, 1991; GAMBINO, 1984). O achados necroscópicos ainda são considerados o padrão ouro para a análise da precisão do diagnóstico clínico, sendo um importante e indispensável recurso para auditoria das discrepâncias diagnósticas (SHOJANIA, 2004; LARDENOYE et al, 2002; NADROUS et al, 2003; NEWTON et al, 2004; BELZEBERG \& RIVKIND, 1998; TRELSTEAD et al, 1996).

É inegável a influência das novas tecnologias sobre a precisão diagnóstica e, consequentemente, sobre as taxas de cura e sobrevida, analisadas 
isoladamente. Em adição, a expectativa de vida da população mundial (ainda que com as disparidades entre países) aumenta ano a ano também pela associação de políticas sanitárias com o conhecimento advindo do progresso de diversos campos científicos, integrando a área da saúde com as ciências sociais e o planejamento urbano.

A tecnologia evoluiu em ritmo exponencial nas últimas décadas, principalmente nas áreas de informação, de saúde e na interface das duas, com novos dispositivos diagnósticos e terapêuticos, novos fármacos e com a possibilidade da troca instantânea de informações. Onde antes era necessário viajar para realizar uma radiografia, hoje temos aparelhos de ultrassonografia portáteis e acopláveis a tablets e smartphones, além de grandes centros hospitalares com sistema integrado, em que as imagens anatômicas obtidas por Tomografia Computadorizada ou Ressonância Nuclear Magnética têm seu laudo emitido pelo radiologista dentro da próxima hora e logo as equipes responsáveis pelo paciente se reúnem para planejar o tratamento. Nos laboratórios de análises clínicas são contados e dosados inúmeros elementos do sangue e secreções em minutos por meio de espectometria e técnicas imunomoleculares. A imunologia e a patologia diagnósticas foram revolucionadas pelo advento da microscopia eletrônica e, posteriormente, com a associação de outras técnicas como a imunofluorescência, imunohistoquímica, do desenvolvimento da biologia estrutural e da química computacional, entre outros.

Além do impacto do aprimoramento diagnóstico, diversas outras razões para a diminuição do número de necropsias vêm sendo discutidas desde a década de 1970. Questões relativas ao corte de custos têm seu papel, notadamente quando os administradores hospitalares não têm formação em ciências da saúde ou não vêm retorno financeiro em tal procedimento (BAYERGARNER, FINK \& LAMPS, 2002, KING, 1984) (SINARD \& BLOOD, 2001; LUNDBERG, 1984; CHERNOF, 1996). Culturalmente, existe a oposição religiosa à realização do exame (BIERIG, 1996; GELLER, 1984), social (KING \& MEEHAN, 1973); a aversão ao cadáver e o medo da morte (PAPADODIMA, 2008). Por último, a falha de comunicação entre diversos setores hospitalares (patologia, clínica médica, cirurgia, pediatria, etc.) leva à falta de conhecimento pelos profissionais da atenção primária, secundária e terciária de saúde em reação aos casos 
encaminhados pelo próprio setor, o que pode causar a falsa impressão de que não se obtêm dados úteis a partir do exame e que sejam aplicáveis à prática clínica cotidiana (FEINSTEIN, 1996; SETLOW, 1996; ZARBO, BAKER \& HOWANITZ, 1999; CAREZZATO, 2016).

\subsection{O Parecer Consulta 31.184/2015 do CREMESP (PC)}

Os sistemas de informação de saúde pública devem prover a comunidade com informações para guiar seus programas e políticas públicas de saúde (NAGHAVI, 2010). No Brasil esse papel é desempenhado pelo DATASUS, que depende para isso da completude dos dados de mortalidade para o estudo epidemiológico e o desenvolvimento de estratégias em saúde.

O encaminhamento indevido ou irregular de corpos para necropsia é um problema crônico enfrentado em vários centros de referência, à parte dos casos em que há dúvida sobre a natureza violenta ou não da causa de morte ou em que há múltiplas causas de morte, em que a dúvida é inerente ao processo desde a descoberta do cadáver. O Brasil é um dos únicos países em que a causa mortis é pressuposta antes do exame necroscópico, funcionando com dois sistemas separados para averiguação da causa de morte - os Institutos de Medicina Legal (IML) e os Serviços de Verificação de Óbito (SVO) - sendo que o destino inicial do cadáver é muitas vezes decidido pelo Delegado de Polícia (Mendo et al., 2019).

Numa tentativa de uniformizar o encaminhamento de corpos e o preenchimento da declaração de óbito, o Ministério da Saúde vem publicando manuais revisados e atualizados, sendo o mais recente de 2006, que foi revisado em 2009 - e 2011. Da mesma forma procedeu o Conselho Regional de Medicina do Estado de São Paulo (CREMESP), com seu último manual publicado em 2015 (LAURENTI E MELLO JORGE, 2015), que serve de referência aos procedimentos adotados pelo SVOI.

Desde o início do seu funcionamento no CEMEL, em 2005, o SVOI recebe corpos de pessoas que morreram sob cuidados médicos e/ou após longo período de morbidade, o que desobriga a realização de necropsia para fins de atestar o óbito, estando o médico responsável habilitado a preencher a D.O. Porém, o 
serviço recebe semanalmente cadáveres com causa de morte presumíveis, inclusive provenientes de instituições hospitalares com equipe médica em tempo integral e, consequentemente, arca com o ônus de necropsias desnecessárias ou até incorretamente realizadas, como no caso de fetos mortos.

Transcrevem-se e discutem-se abaixo trechos da Resolução CFM nº 1779/2005 (bl56) publicada no DOU de 5/12/2005, Seção I p. 121.

Art. $1^{\circ} \mathrm{O}$ preenchimento dos dados constantes na Declaração de Óbito é da responsabilidade do médico que atestou a morte.

Art. $2^{\circ}$ Os médicos, quando do preenchimento da Declaração de Óbito, obedecerão às seguintes normas:

\section{1) Morte natural:}

I. Morte sem assistência médica:

a) Nas localidades com Serviço de Verificação de Óbitos (SVO):

A Declaração de Óbito deverá ser fornecida pelos médicos do SVO;

b) Nas localidades sem SVO:

A Declaração de Óbito deverá ser fornecida pelos médicos do serviço público de saúde mais próximo do local onde ocorreu o evento; na sua ausência, por qualquer médico da localidade.

II. Morte com assistência médica:

a) A Declaração de Óbito deverá ser fornecida, sempre que possível, pelo médico que vinha prestando assistência ao paciente.

b) A Declaração de Óbito do paciente internado sob regime hospitalar deverá ser fornecida pelo médico assistente e, na sua falta por médico substituto pertencente à instituição.

c) A declaração de óbito do paciente em tratamento sob regime ambulatorial deverá ser fornecida por médico designado pela instituição que prestava assistência, ou pelo SVO;

d) A Declaração de Óbito do paciente em tratamento sob regime domiciliar (Programa Saúde da Família, internação domiciliar e outros) deverá ser fornecida pelo médico pertencente ao programa ao qual o paciente estava cadastrado, ou pelo SVO, caso o médico não consiga correlacionar o óbito com o quadro clínico concernente ao acompanhamento do paciente. 


\section{2) Morte fetal:}

Em caso de morte fetal, os médicos que prestaram assistência à mãe ficam obrigados a fornecer a Declaração de Óbito quando a gestação tiver duração igual ou superior a 20 semanas ou o feto tiver peso corporal igual ou superior a 500 (quinhentos) gramas e/ou estatura igual ou superior a $25 \mathrm{~cm}$.

\section{3) Mortes violentas ou não naturais:}

A Declaração de Óbito deverá, obrigatoriamente, ser fornecida pelos serviços médico-legais.

Parágrafo único. Nas localidades onde existir apenas 1 (um) médico, este é o responsável pelo fornecimento da Declaração de Óbito.

Os itens A, C e D, por si, deveriam garantir que portadores de doenças crônicas, com múltiplas comorbidades ou idosos acompanhados pelos núcleos de saúde da família não fossem encaminhados para o SVOI, exceto em casos em que há dúvida plausível sobre o diagnóstico ou sobre natureza da causa de morte, sendo a Declaração de Óbito assinada pelo médico de família local ou outro profissional médico responsável pelo paciente.

“a) A Declaração de Óbito deverá ser fornecida, sempre que possivel, pelo médico que vinha prestando assistência ao paciente c) A declaração de óbito do paciente em tratamento sob regime ambulatorial deverá ser fornecida por médico designado pela instituição que prestava assistência, ou pelo SVO;

d) A Declaração de Óbito do paciente em tratamento sob regime domiciliar (Programa Saúde da Família, internação domiciliar e outros) deverá ser fornecida pelo médico pertencente ao programa ao qual o paciente estava cadastrado, ou pelo SVO, caso o médico não consiga correlacionar o óbito com o quadro clínico concernente ao acompanhamento do paciente."

Nota-se que nos três itens o fornecimento da DO pelo SVO é uma alternativa em relação a uma primeira opção prioritária que é o fornecimento por parte de quem prestava assistência inicialmente à pessoa que evoluiu a óbito. 


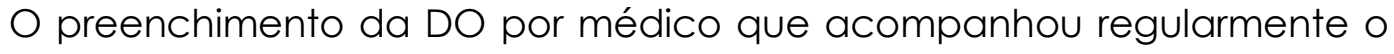
paciente em vida evitaria diagnósticos irregulares e vagos como senilidade, parada cardíaca e falência múltipla de órgãos.

Da mesma forma, além de se enquadrar em todos os itens do artigo II, o item 2 asseguraria que fetos mortos ou bebês que viessem a falecer durante ou logo após o parto tivessem suas certidões preenchidas pelo obstetra, pediatra ou demais médicos presentes na assistência ao parto.

"Em caso de morte fetal, os médicos que prestaram assistência à mãe ficam obrigados a fornecer a Declaração de Óbito quando a gestação tiver duração igual ou superior a 20 semanas ou o feto tiver peso corporal igual ou superior a 500 (quinhentos) gramas e/ou estatura igual ou superior a $25 \mathrm{~cm} . "$

Há, ainda, corroborando esse item, a questão conceitual sobre o processo de parto, que é para todos os fins um processo fisiológico (MINISTÉRIO DA SAÚDE 2) inerente à espécie humana - e, em geral, aos demais mamíferos - enquanto o exame necroscópico se enquadra na definição de exame anatomopatológico. Assim, pode o patologista avaliar o resultado do processo fisiopatológico que gerou aquele cadáver, sem que possa adequadamente preencher os campos referentes ao processo de parto, no qual não estava presente..

Assim, sendo produzida por obstetra, a DO seria não só correta como útil epidemiologicamente, com seus campos de correlação diagnóstica adequadamente preenchidos, pois diferenciariam as anoxias neonatais (diagnóstico comumente dado pelo patologista) em anoxia por descolamento prematuro de placenta, por imaturidade pulmonar, entre outros que só poderiam ser verificados durante o acompanhamento da gestação e do trabalho de parto.

O item B tipifica grande parte do volume de corpos encaminhados ao SVOI até o ano de 2016. Naturalmente, alguns pacientes vieram a óbito dentro dos primeiros minutos de atendimento ou a caminho do hospital, mas há aqueles encaminhados para necropsia após algum período de internação com diagnóstico e tratamento acordado entre os médicos. 
"A Declaração de Óbito do paciente internado sob regime hospitalar deverá ser fornecida pelo médico assistente e, na sua falta por médico substituto pertencente à instituição".

Tendo em vista que a redução do encaminhamento indevido/irregular de corpos para o SVOI evitaria os custos institucionais, sociais e familiares de uma necropsia, foi solicitado ao Conselho Regional de Medicina do Estado de São Paulo (CREMESP) pela Diretoria do CEMEL e SVOI o Parecer Consulta 31.184/2015, anexo 1 deste documento. Após aprovação e redação em diferentes instâncias do CREMESP e sua publicação oficial, O PC foi apresentado em reunião às diretorias clínicas e Secretaria da Saúde de Ribeirão Preto em 2016, sendo estabelecido que não seriam recebidos os corpos de encaminhamento equivocado, sendo esses devolvidos à instituição de origem, com efeito a partir de janeiro de 2017.

Depois do estabelecimento das novas regras sob o esclarecimento do Parecer Consulta 31.184/2015, ao final de 2017 foi contabilizada uma redução expressiva no número de necropsias - com consequente redução de custos públicos, institucionais, sociais e familiares. Estima-se que a economia em reais pode chegar a $R \$ 900.000$, aproximadamente, com mais de 300 necropsias evitadas. Contudo, essa redução imediata levantou uma dúvida: quais e que tipo de casos deixaram de dar entrada no SVOl?

O presente estudo visou esclarecer a questão levantada com base em dados de necropsias do SVOI anteriores e posteriores à aplicação do Parecer Consulta 31.184/2015. 


\section{Justificativa}

Este estudo visa levantar e comparar o número de necropsias no SVOI-SP nos anos anteriores e posteriores à publicação do Parecer Consulta 31.184/2015 para verificar possíveis diferenças entre o número de necropsias, perfil sociodemográfico dos indivíduos e de diagnósticos dos pacientes encaminhados ao SVOI para investigação de causa de morte, avaliando assim a interferência do Parecer Consulta nas atividades do serviço. A queda abrupta no número de necropsias após a publicação do Parecer, levanta questões como:

1- $\quad$ Eram necessários os procedimentos realizados anteriormente?

2- Os encaminhamentos de corpos para o SVOI eram realizados corretamente?

3- Qual o perfil dos pacientes que deixaram de ser encaminhados e suas circunstâncias de morte?

4- Houve doença ou diagnóstico com percentual significativamente aumentado ou reduzido nos laudos de necropsia de 2017 e 2018 em comparação com os de 2013 e 2014 ?

Este projeto, além de seu caráter científico, possui a característica de geração de dados de importância para saúde pública, tendo em vista a contribuição sociodemográfica, epidemiológica e possivelmente econômica para o município de Ribeirão Preto, para o Governo do Estado, para a União e para a Universidade em que está alocado o SVOI, podendo o Parecer Consulta $31.184 / 2015$ futuramente ser expandido para outras localidades. Procuramos também analisar e discutir criticamente os aspectos médico-legais e bioéticos dos resultados a serem obtidos, indicando possíveis falhas dos processos e consequências para a gestão de recursos públicos. 


\section{Objetivos}

A) Realizar o levantamento retrospectivo do número de necropsias no SVOI para os anos de 2013 e 2014, assim como as características sociodemográficas dos casos (sem identificação individual) e diagnósticos finais para emissão das DOs;

B) Realizar o levantamento retrospectivo do número de necropsias no SVOI para o ano de 2017 e 2018, assim como as características sociodemográficas dos casos (sem identificação individual) e diagnósticos finais para emissão das DOs;

C) Realizar a comparação dos dados anteriores e subsequentes à publicação do Parecer Consulta 31.184/2015 para verificar possíveis diferenças entre o número de necropsias, perfil sociodemográfico e de diagnósticos nos casos de necropsias realizadas no SVOI para avaliação da interferência desse documento nas atividades do serviço;

D) Responder às perguntas 1, 2, 3 e 4 levantadas no tópico 2 (1-Eram necessários os procedimentos realizados anteriormente? 2-Os encaminhamentos de corpos para o SVOI eram realizados corretamente? 3-Qual o perfil dos pacientes que deixaram de ser encaminhados e suas circunstâncias de morte? 4-Houve doença ou diagnóstico com percentual significativamente aumentado ou reduzido nos laudos de necropsia de 2017 e 2018 em comparação com os de 2013 e 2014?).

E) Analisar e discutir criticamente os aspectos médico-legais e bioéticos dos resultados a serem obtidos, indicando possíveis falhas dos processos e consequências para a gestão de recursos públicos; 


\section{Metodologia}

\subsection{Fontes de dados}

Foram utilizados como fontes de dados os relatórios anuais de atividades do SVOI de Ribeirão Preto, os pedidos de necropsia, os Boletins de Ocorrência, as Declarações de Óbito e, por fim, os relatórios de necropsia contendo a causa do óbito e correlação diagnóstica de achados de macroscopia e microscopia, por vezes complementados com informações clínicas.

O modelo da Declaração de Óbito fornecida pelo Ministério da Saúde pode ser conferido no anexo 2 (MINISTÉRIO DA SAÚDE, 2009).

\subsection{Amostragem}

Foram utilizados todos os registros de procedimentos realizados pelo SVOI (portanto de mortes de causa natural não esclarecida, ou seja, não-violentas) dos respectivos anos de interesse para este estudo, incluindo óbitos fetais, perinatais e infantis em que seja possível realizar o exame necroscópico.

Nos relatórios anuais de atividades do SVOI de Ribeirão Preto constam e foram analisados, ainda, os casos não examinados pelo SVOI, que foram transferidos ao IML, devolvidos ao hospital de origem ou liberados por médico da família que preencheu e assinou a Declaração de Óbito

\subsection{Coleta dos dados}

A coleta dos dados deu-se por revisão e análise de cada registro de necropsia amostrado para o estudo. Lembramos que foram coletados conforme 
constavam nesses documentos e que esses podem variar da autodesignação do indivíduo em vida para os itens gênero e cor da pele.

Foram coletados os seguintes dados:

- Pessoais: idade, gênero, cor de pele.

- Complementares: local de ocorrência do óbito (hospital, domicílio, outros), dados informados no boletim de ocorrência dados, clínicos e de exames eventualmente encaminhados com o corpo, e hospital de origem do encaminhamento para necropsia, quando o óbito ocorreu em estabelecimento de saúde.

- Causa imediata ou terminal de morte, ou seja, campo 1-A da Declaração de Óbito.

\subsection{Análise dos Dados}

Todos os dados obtidos foram transferidos para planilhas do programa Excel ${ }^{\circledR}$, agrupados por categorias de análise estabelecidas para atender aos objetivos propostos, e submetidos às análises estatísticas necessárias de acordo com a viabilidade dos dados obtidos.

As categorias de encaminhamento, faixa etária, local de óbito, cor de pele, sexo, e causa mortis segundo a Classificação Estatística Internacional de Doenças e Problemas Relacionados à Saúde (CID-10) foram analisadas por estatística descritiva e análise de médias, sobre as quais foi aplicado o Teste T de Student para amostras não pareadas. Nessa etapa contou-se com a colaboração do Prof. Dr. Moacyr Lobo da Costa Jr., docente aposentado da Escola de Enfermagem de Ribeirão Preto da Universidade de São Paulo (EERPUSP) e docente colaborador junto ao CEMEL/FMRP-USP.

Nas análises em que foi aplicado o Teste T, são considerados significativos os valores resultantes menores que 0,05. 


\section{Aspectos Éticos}

Este projeto foi autorizado pelo ao Comitê de Ética em Pesquisa (CEP) em acordo com a Resolução 510/16 (CONSELHO NACIONAL DE SAÚDE, 2016) que trata da pesquisa em seres humanos no âmbito das Ciências Humanas e Sociais.

Considerando-se que a Medicina Legal e a Bioética apresentam inserção tanto dentro da área das Ciências das Saúde como das Ciências Humanas e Sociais, o presente trabalho não teve de ser registrado nem avaliado pelo Sistema CEP/CONEP, por força do disposto na Resolução no 510 de 7 de abril de 2016 do Conselho Nacional de Saúde.

Os exames necroscópicos realizados no SVOI são obrigatórios por lei e os dados gerados são de interesse público. A autorização para sua utilização depende somente da Diretoria do Serviço e dispensa o uso de Termo de Consentimento Livre e Esclarecido (TCLE), já que a identidade de cada paciente não foi utilizada nesta análise de dados secundários. $\bigcirc$ trabalho foi desenvolvido sob autorização da diretoria do SVOI, entidade responsável administrativamente pelo armazenamento e sigilo dos dados. A autorização encontra-se no Anexo 3 deste documento.

Em momento algum a equipe entrou em contato com familiares ou responsáveis pelos pacientes dos casos em análise, nem foram divulgadas imagens ou informações que pudessem identificá-los. Somente os pesquisadores da equipe deste projeto tiveram acesso aos dados. Trata-se, portanto, de análise de dados secundários.

\section{Resolução 510/16}

Considerando que a pesquisa em ciências humanas e sociais exige respeito e garantia do pleno exercício dos direitos dos participantes, devendo ser concebida, avaliada e realizada de modo a prever e evitar possíveis danos aos participantes;

Considerando que as Ciências Humanas e Sociais têm especificidades nas suas 
concepções e práticas de pesquisa, na medida em que nelas prevalece uma acepção pluralista de ciência da qual decorre a adoção de múltiplas perspectivas teórico-metodológicas, bem como lidam com atribuições de significado, práticas e representações, sem intervenção direta no corpo humano, com natureza e grau de risco específico;

Art. 10 (...) Parágrafo único. Não serão registradas nem avaliadas pelo sistema CEP/CONEP:

I - pesquisa de opinião pública com participantes não identificados;

II - pesquisa que utilize informações de acesso público, nos termos da Lei no 12.527 , de 18 de novembro de 2011;

III - pesquisa que utilize informações de domínio público;

IV - pesquisa censitária;

$\checkmark$ - pesquisa com bancos de dados, cujas informações são agregadas, sem possibilidade de identificação individual; e

VI - pesquisa realizada exclusivamente com textos científicos para revisão da literatura científica;

VII - pesquisa que objetiva o aprofundamento teórico de situações que emergem espontânea e contingencialmente na prática profissional, desde que não revelem dados que possam identificar o sujeito; $e$

VIII - atividade realizada com o intuito exclusivamente de educação, ensino ou treinamento sem finalidade de pesquisa científica, de alunos de graduação, de curso técnico, ou de profissionais em especialização.

Em termos de análise Bioética, atende ao princípios fundamentais de nãomaleficência, tendo em vista que não causa nenhum prejuízo ou danos aos sujeitos de pesquisa ou suas famílias; não fere o princípio da autonomia, pois somente serão utilizados os relatórios de exames não identificados de pessoas que já faleceram e foram compulsoriamente necropsiadas; e, por fim, respeita o princípio da justiça, sendo sua execução de interesse público para garantir o direito de que familiares tenham acesso à causa de morte de seus entes queridos para providências quer na esfera de prevenção em saúde, assim como na esfera judicial. 


\section{Resultados}

\subsection{Resultados quanto a população, óbitos e encaminhamentos}

A média de habitantes da cidade de Ribeirão Preto aumentou 5,29 \% entre os anos deste estudo, segundo estimativas feitas pelo IBGE e pela Prefeitura Municipal. A média de óbitos totais de 2017 e 2018 é 12,13 \% maior do que a média de óbito de 2013 e 2014, apesar de o aumento populacional ser de 5,29 \%. Ao analisar a natureza dos óbitos, temos aumento de 13,77 \% na média de óbitos de causas naturais nos anos 2017 e 2018 quando comparados à média de 2013 e 2014, enquanto houve queda de 3,5\% nos óbitos por causa externa.

A tabela 1 mostra a distribuição dos óbitos ocorridos na cidade de Ribeirão Preto segundo o SIM/DATASUS (SISTEMA DE INFORMAÇÃO SOBRE MORTALIDADE, BRASIL), O total de habitantes estimados pelo IBGE (INSTITUTO BRASILEIRO DE GEOGRAFIA E ESTATÍSTICA) e o total de encaminhamentos ao SVOI nos anos de interesse.

\begin{tabular}{|l|c|c|c|c|}
\cline { 2 - 5 } \multicolumn{1}{c|}{} & $\begin{array}{l}\text { Ano de } \\
\mathbf{2 0 1 3}\end{array}$ & $\begin{array}{l}\text { Ano de } \\
\mathbf{2 0 1 4}\end{array}$ & $\begin{array}{l}\text { Ano de } \\
\mathbf{2 0 1 7}\end{array}$ & $\begin{array}{l}\text { Ano de } \\
\mathbf{2 0 1 8}\end{array}$ \\
\hline População pelo IBGE & $\mathbf{6 4 9 . 5 5 6}$ & $\mathbf{6 5 8 . 0 5 9}$ & $\mathbf{6 8 2 . 3 0 2}$ & $\mathbf{6 9 4 . 5 4 3}$ \\
\hline Total de Óbitos em Ribeirão Preto & 5618 & 5788 & 6415 & 6374 \\
\hline Óbitos por Causas Externas & 535 & 552 & 518 & 531 \\
\hline Óbitos por Causas Naturais & 5083 & 5236 & 5897 & 5843 \\
\hline Pacientes Encaminhados ao SVOI & 1063 & 1079 & 934 & 845 \\
\hline Necropsias Realizadas pelo SVOI & $\mathbf{1 0 0 8}$ & $\mathbf{1 0 2 1}$ & $\mathbf{8 7 6}$ & $\mathbf{7 9 0}$ \\
\hline
\end{tabular}

Tabela 1 - Total de habitantes de Ribeirão Preto, total de óbitos ocorridos na cidade e total de encaminhamentos ao SVOI e de necropsias realizadas nos anos de interesse.

Contrariando o aumento populacional e o número de óbitos ocorridos no município, houve queda significativa no número de pacientes encaminhados ao SVOI e, também de necropsias realizadas pelo SVOI. A média de encaminhamentos dos anos anteriores à publicação do Parecer Consulta caiu de 1071 pacientes para 889,5 nos anos subsequentes, e a média de necropsias realizadas pelo SVOI caiu de 1014,5 para 833, representando diminuições de 
$16,95 \%$ e $17,89 \%$ respectivamente.

Como mostrado na tabela 2, o teste T de 0,0264 indica que essa queda nas médias de necropsias realizadas é significativa. A média de pacientes redestinados, ou seja, transferidos ao IML, liberados por médico contactado pela família ou devolvidos ao hospital de origem, foi igual nos dois períodos, mas com diferenças significativas intragrupos. Dos 56,5 casos, em média, nos anos anteriores ao PC, apenas 0,5 foram devolvidos ao hospital de origem, enquanto nos anos subsequentes ao PC essa média foi de 19,0, um aumento de $3700 \%$. A média de transferências de pacientes ao IML diminuiu 37,14 \%, de 52,5 para 33 pacientes. A média de pacientes liberados por médico da família se manteve a mesma nos dois períodos, sendo 5,5 pacientes no período anterior ao PC e 4,5 no período subsequente (tabela 4 ).

A tabela 2 mostra a mesma distribuição organizada por médias dos anos anteriores e subsequentes ao Parecer Consulta.

\begin{tabular}{|l|c|c|c|c|}
\cline { 2 - 5 } \multicolumn{1}{c|}{} & $\begin{array}{c}\text { Média } \\
\text { anterior }\end{array}$ & $\begin{array}{c}\text { Média } \\
\text { subsequente }\end{array}$ & Diferença & Teste T \\
\hline $\begin{array}{l}\text { População pelo } \\
\text { IBGE }\end{array}$ & 653.808 & 688.423 & $+5,29 \%$ & 0,0217 \\
\hline $\begin{array}{l}\text { Total de Óbitos em } \\
\text { Ribeirão Preto }\end{array}$ & 5703 & 6394,5 & $+12,13 \%$ & 0,0078 \\
\hline $\begin{array}{l}\text { Óbitos por Causas } \\
\text { Externas }\end{array}$ & 543,5 & 524,5 & $-3,50 \%$ & 0,1089 \\
\hline $\begin{array}{l}\text { Óbitos por Causas } \\
\text { Naturais }\end{array}$ & 5159,5 & 5870 & $+13,77 \%$ & 0,0064 \\
\hline $\begin{array}{l}\text { Pacientes } \\
\text { Encaminhados ao } \\
\text { SVOI }\end{array}$ & 1071 & 889,5 & $-16,95 \%$ & 0,0284 \\
\hline $\begin{array}{l}\text { Necropsias } \\
\text { Realizadas pelo SVOI }\end{array}$ & 1014,5 & 833 & $-17,89 \%$ & 0,0264 \\
\hline
\end{tabular}

Tabela 2 - Total de habitantes de Ribeirão Preto, total de óbitos ocorridos na cidade e total de encaminhamentos ao SVOI e de necropsias realizadas nos anos de interesse organizadas por médias dos anos anteriores e subsequentes ao Parecer Consulta.

A Figura 1 mostra o total de óbitos em Ribeirão Preto e sua proporção segundo a natureza do óbito, ou seja, causa natural ou externa. Também mostra a distribuição dos encaminhamentos totais ao serviço nos anos de interesse. 


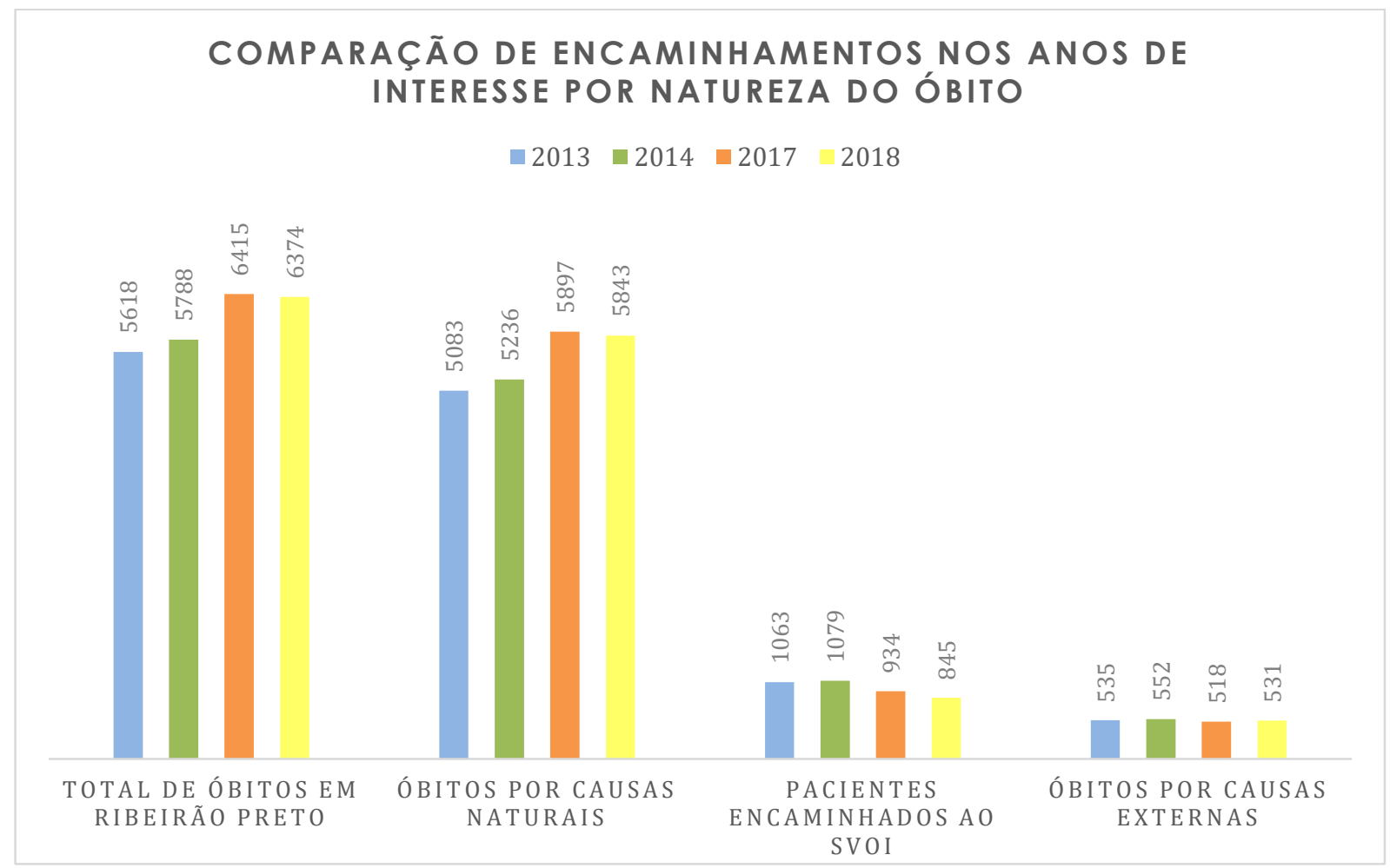

Figura 1- Óbitos em Ribeirão preto por causas naturais, causas externas, óbitos totais e encaminhamentos ao SVOI nos anos de 2013, 2014, 2017, 2018.

A Figura 2 mostra a diferença entre pacientes encaminhados e necropsias realizadas nos anos de interesse.

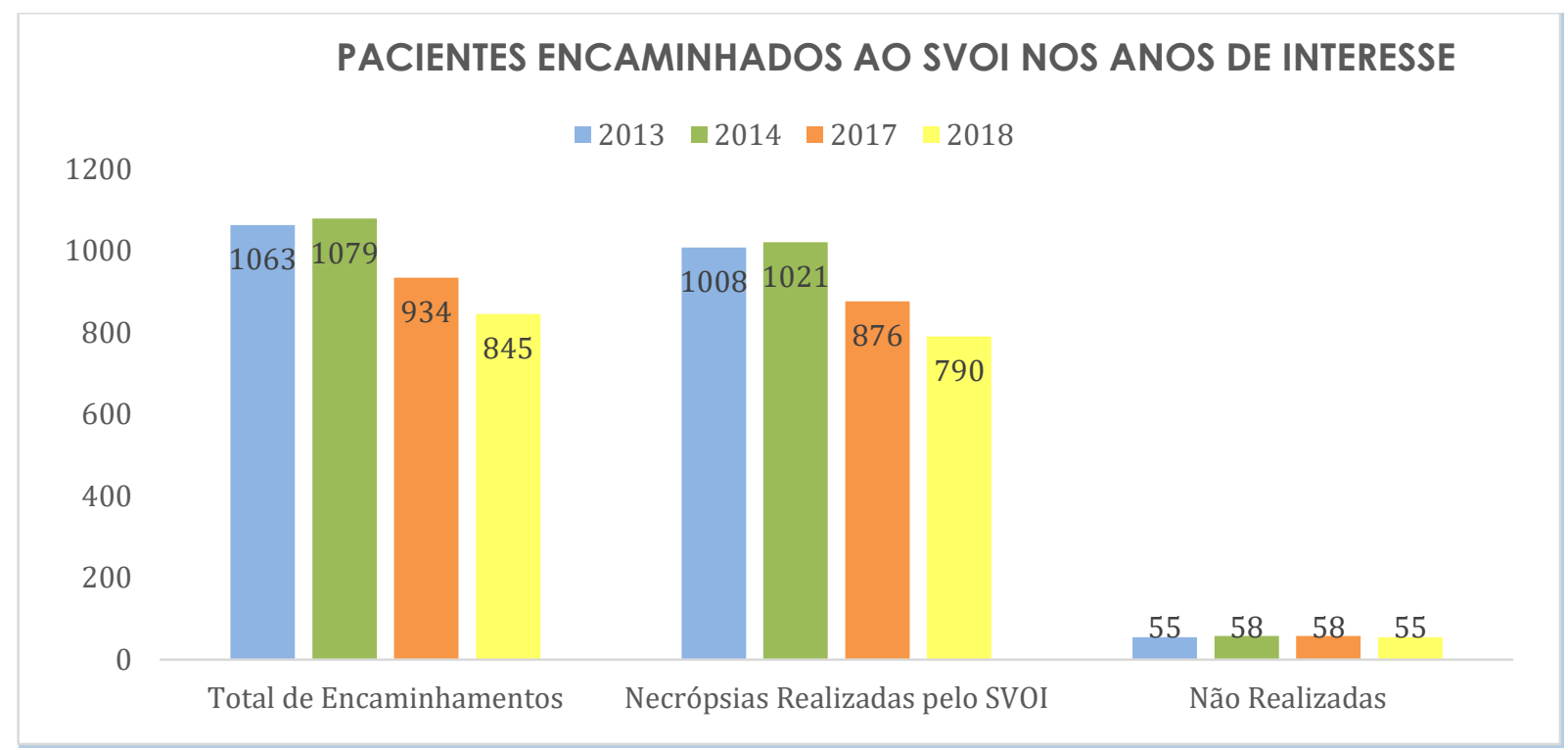

Figura 2. Distribuição do total de pacientes encaminhados ao SVOI nos anos de 2013. 2014, 2017 e 2018 
A tabela 3 apresenta o detalhamento das necropsias não realizadas, em que pacientes foram redestinados a outros serviços, ou seja: liberados por médico contactado pela família e que já acompanhava o paciente, transferidas ao IML ou devolvidas ao hospital de origem.

\begin{tabular}{|l|c|c|c|c|}
\cline { 2 - 5 } \multicolumn{1}{c|}{} & 2013 & 2014 & 2017 & 2018 \\
\hline Devolvidas ao Hospital & 0 & 1 & 19 & 19 \\
\hline Liberada & 4 & 7 & 4 & 5 \\
\hline Transferidas ao IML & 51 & 54 & 35 & 31 \\
\hline Total de Necropsias Redestinadas & 55 & 58 & 58 & 55 \\
\hline
\end{tabular}

Tabela 3. Pacientes recebidos e não necropsiados em 2013. 2014, 2017 e 2018.

A tabela 4 mostra as médias de encaminhamentos entre os anos de interesse, com a aplicação do teste T de Student. Os valores significativos são menores do que 0,05, e estão marcados em verde os parâmetros que tiveram diminuição entre os anos, em preto os que não tiveram alteração significativa e em vermelho os que tiveram aumento.

\begin{tabular}{|l|c|c|c|c|}
\hline & $\begin{array}{c}\text { Média } \\
\text { Anterior }\end{array}$ & $\begin{array}{c}\text { Média } \\
\text { Subsequente }\end{array}$ & Diferença & Teste T \\
\hline Total de Encaminhamentos & 1071 & 889,5 & $-16,95 \%$ & 0,028409 \\
\hline Realizadas pelo SVOI & 1014,5 & 833 & $-17,89 \%$ & 0,026449 \\
\hline Não realizadas & 56,5 & 56,0 & $0 \%$ & - \\
\hline Devolvidas ao Hospital & 0,5 & 19 & $+3700 \%$ & 0,000365 \\
\hline Liberadas & 5,5 & 4,5 & $-18,18 \%$ & 0,295876 \\
\hline Transferidas para IML & 52,5 & 33 & $-37,14 \%$ & 0,008021 \\
\hline
\end{tabular}

Tabela 4. Médias de encaminhamentos entre os anos anteriores e subsequentes ao Parecer Consulta, com a aplicação do teste T de Student.

A figura 3 apresenta as médias de distribuição dos encaminhamentos totais nos anos de interesse com detalhamento dos pacientes redestinados. 


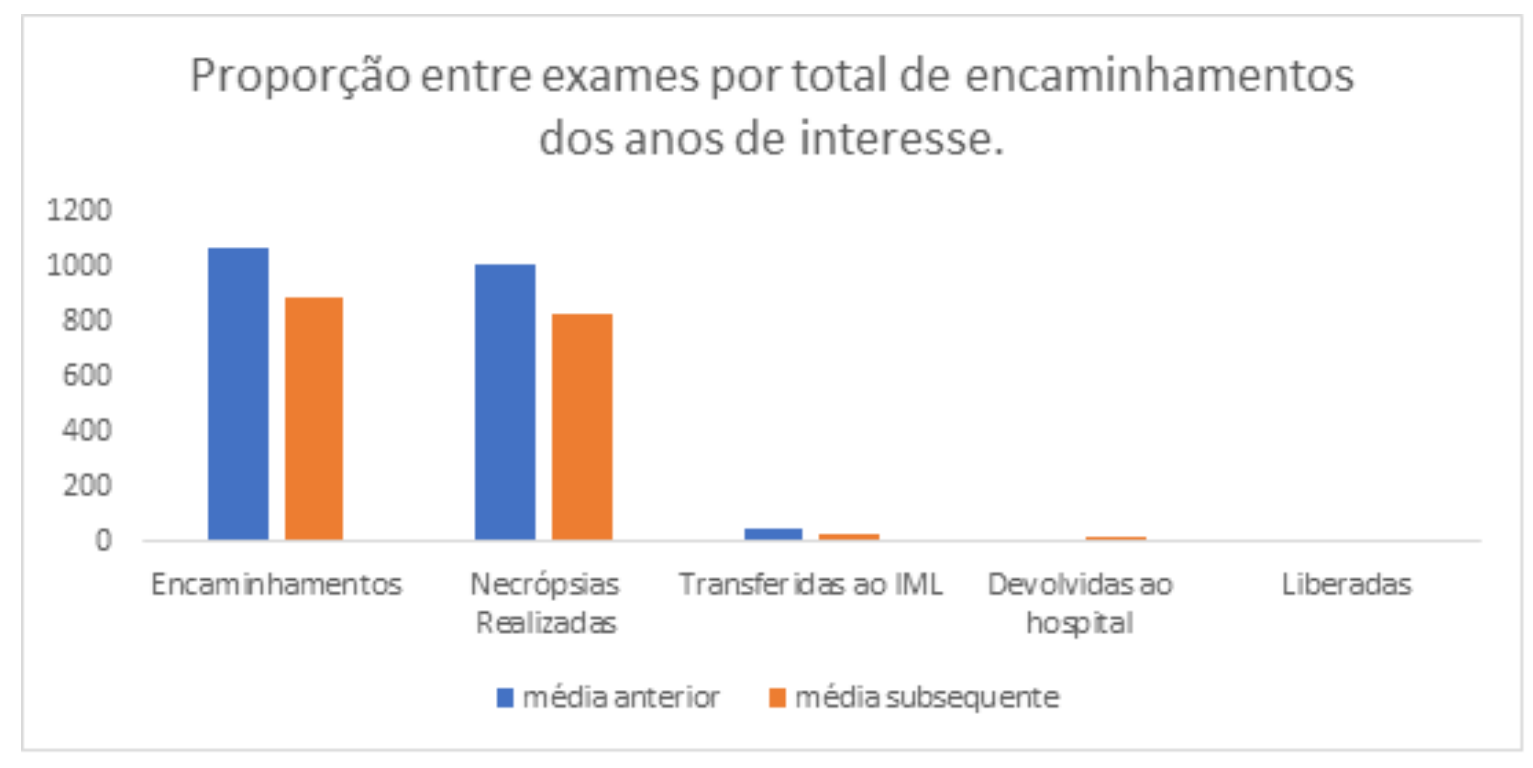

Figura 3. Médias de distribuição dos encaminhamentos totais nos anos de interesse com detalhamento dos pacientes redestinados.

A figura 4 apresenta a proporção entre pacientes redestinados ao $I M L$, ao hospital de origem ou liberados por médico da família.

\section{Proporção entre médias de exames redestinados \\ por total de necrópsias não realizadas}

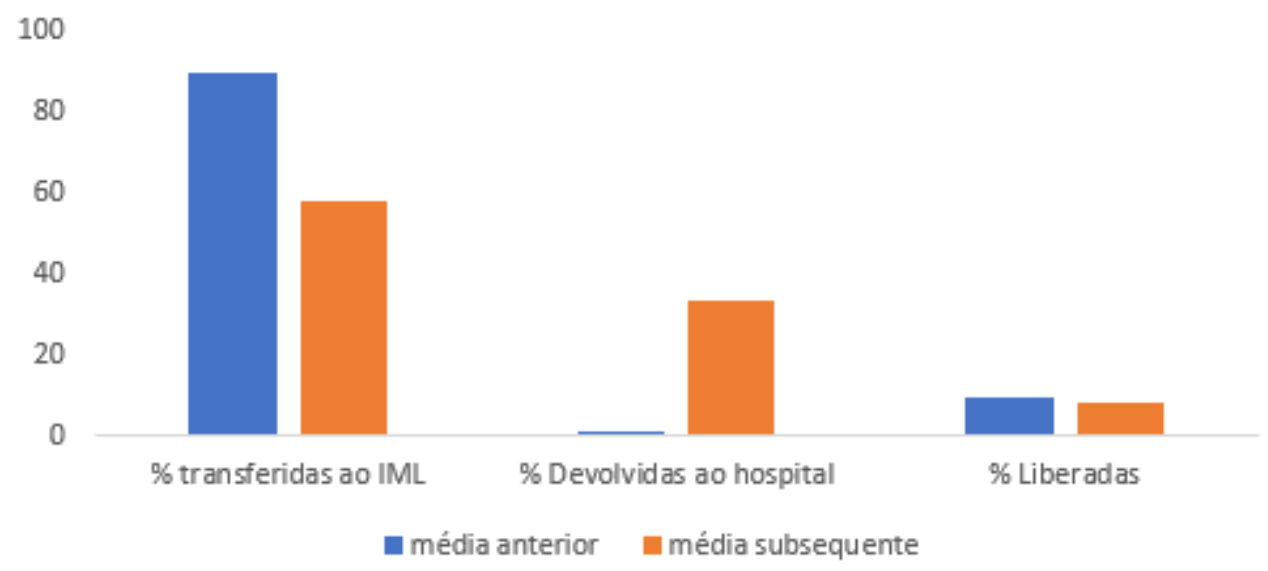

Figura 4. Proporção entre pacientes redestinados ao IML, ao hospital de origem ou liberados por médico da família.

A tabela 5 e as figuras de 5 a 8 apresentam as proporções de exames comparados aos dados do DATASUS e do IBGE na forma de médias dos anos anteriores e subsequentes ao Parecer Consulta. 


\begin{tabular}{|l|c|c|}
\hline $\begin{array}{c}\text { Comparação de médias de óbitos, encaminhamentos, } \\
\text { necropsias e transferências. }\end{array}$ & $\begin{array}{c}\text { Média } \\
\text { anterior }\end{array}$ & $\begin{array}{c}\text { Média } \\
\text { subsequente }\end{array}$ \\
\hline $\begin{array}{l}\text { Razão de encaminhamentos por total de óbitos em Ribeirão } \\
\text { Preto }\end{array}$ & 18,7 & 13,91 \\
\hline $\begin{array}{l}\text { Razão de necropsias realizadas pelo SVOI por total de óbitos } \\
\text { em Ribeirão Preto }\end{array}$ & 17,79 & 13,03 \\
\hline $\begin{array}{l}\text { Razão de necropsias não realizadas pelo SVOI por total de } \\
\text { óbitos em Ribeirão Preto }\end{array}$ & 0,99 & 0,93 \\
\hline $\begin{array}{l}\text { Porcentagem de falecidos devolvidos ao hospital de origem } \\
\text { por total de óbitos em Ribeirão Preto }\end{array}$ & 0,01 & 0,3 \\
\hline
\end{tabular}

\begin{tabular}{|l|c|c|}
\hline $\begin{array}{l}\text { Razão de encaminhamentos por total de óbitos por causas } \\
\text { naturais em Ribeirão Preto }\end{array}$ & 20,75 & 15,15 \\
\hline $\begin{array}{l}\text { Razão de necropsias realizadas pelo SVOI por total de óbitos } \\
\text { por causas naturais em Ribeirão Preto }\end{array}$ & 19,65 & 14,2 \\
\hline $\begin{array}{l}\text { Razão de necropsias não realizadas pelo SVOI por total de } \\
\text { óbitos por causas naturais em Ribeirão Preto }\end{array}$ & 1,09 & 0,96 \\
\hline $\begin{array}{l}\text { Porcentagem de falecidos devolvidos ao hospital de origem } \\
\text { por total de óbitos por causas naturais em Ribeirão Preto }\end{array}$ & 0,01 & 0,32 \\
\hline
\end{tabular}

\begin{tabular}{|l|c|c|}
\hline $\begin{array}{l}\text { Porcentagem de transferências ao IML do total de falecidos } \\
\text { redestinados }\end{array}$ & 89,47 & 58,35 \\
\hline $\begin{array}{l}\text { Porcentagem de devoluções ao hospital de origem do total } \\
\text { de falecidos redestinados }\end{array}$ & 0,86 & 33,65 \\
\hline $\begin{array}{l}\text { Porcentagem de necropsias liberadas por médico de família } \\
\text { do total de falecidos redestinados }\end{array}$ & 9,67 & 7,99 \\
\hline
\end{tabular}

\begin{tabular}{|l|c|c|}
\hline $\begin{array}{l}\text { Porcentagem de necropsias realizadas pelo SVOI do total de } \\
\text { encaminhamentos. }\end{array}$ & 94,72 & 93,65 \\
\hline $\begin{array}{l}\text { Porcentagem de necropsias não realizadas pelo SVOI do total } \\
\text { de encaminhamentos. }\end{array}$ & 5,28 & 6,23 \\
\hline $\begin{array}{l}\text { Porcentagem de transferências ao IML em relação ao total de } \\
\text { encaminhamentos }\end{array}$ & 5,275 & 6,36 \\
\hline $\begin{array}{l}\text { Porcentagem de devoluções ao hospital de origem em } \\
\text { relação ao total de encaminhamentos }\end{array}$ & 0,045 & 2,14 \\
\hline
\end{tabular}

Tabela 5. Proporção de exames solicitados, realizados ou não, comparados aos dados do DATASUS e do IBGE na forma de médias dos anos anteriores e subsequentes ao Parecer Consulta. 


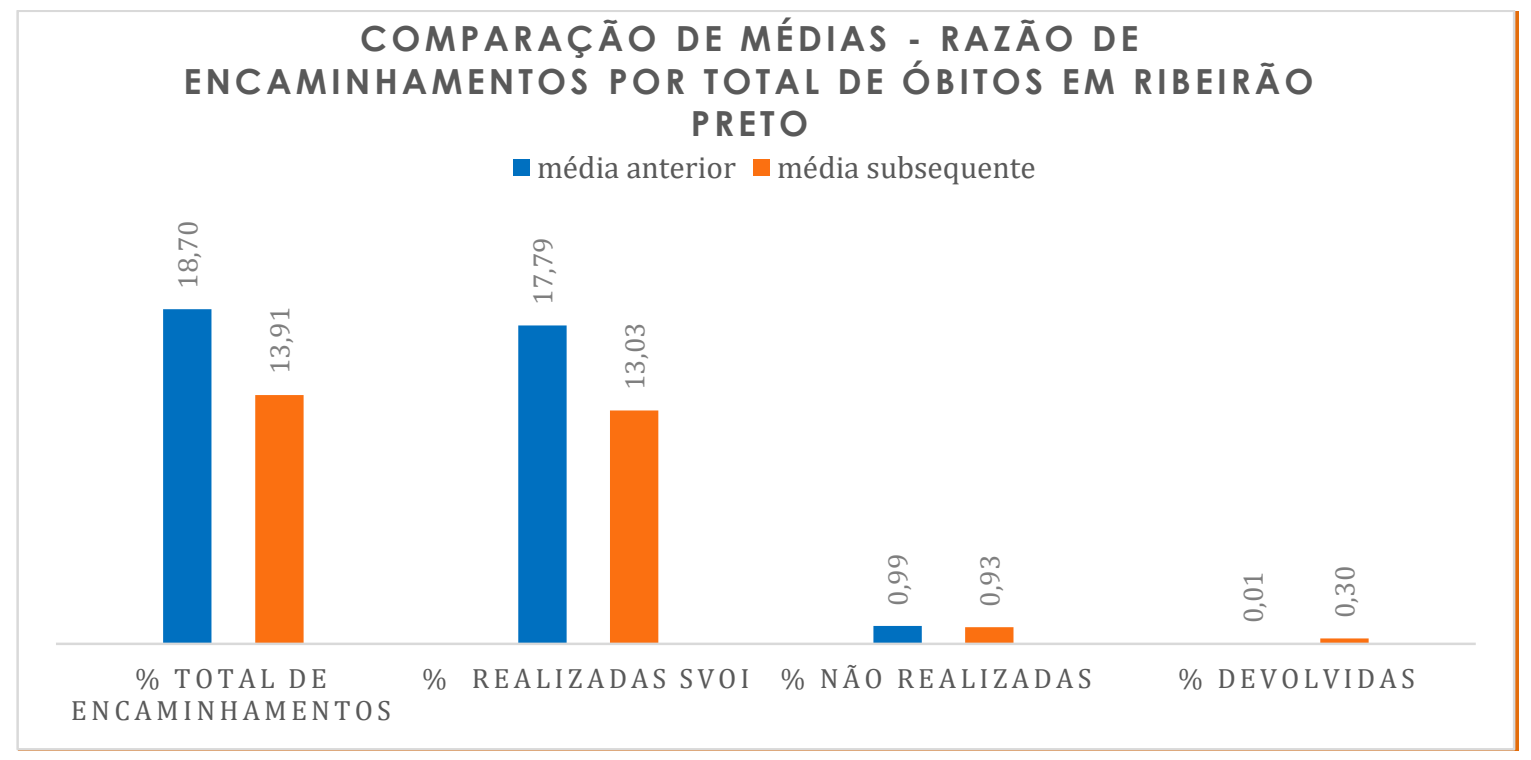

Figura 5. Porcentagem de encaminhamentos, necropsias realizadas pelo SVOI e necropsias recusadas pelo serviço em relação ao total de óbitos em Ribeirão Preto.

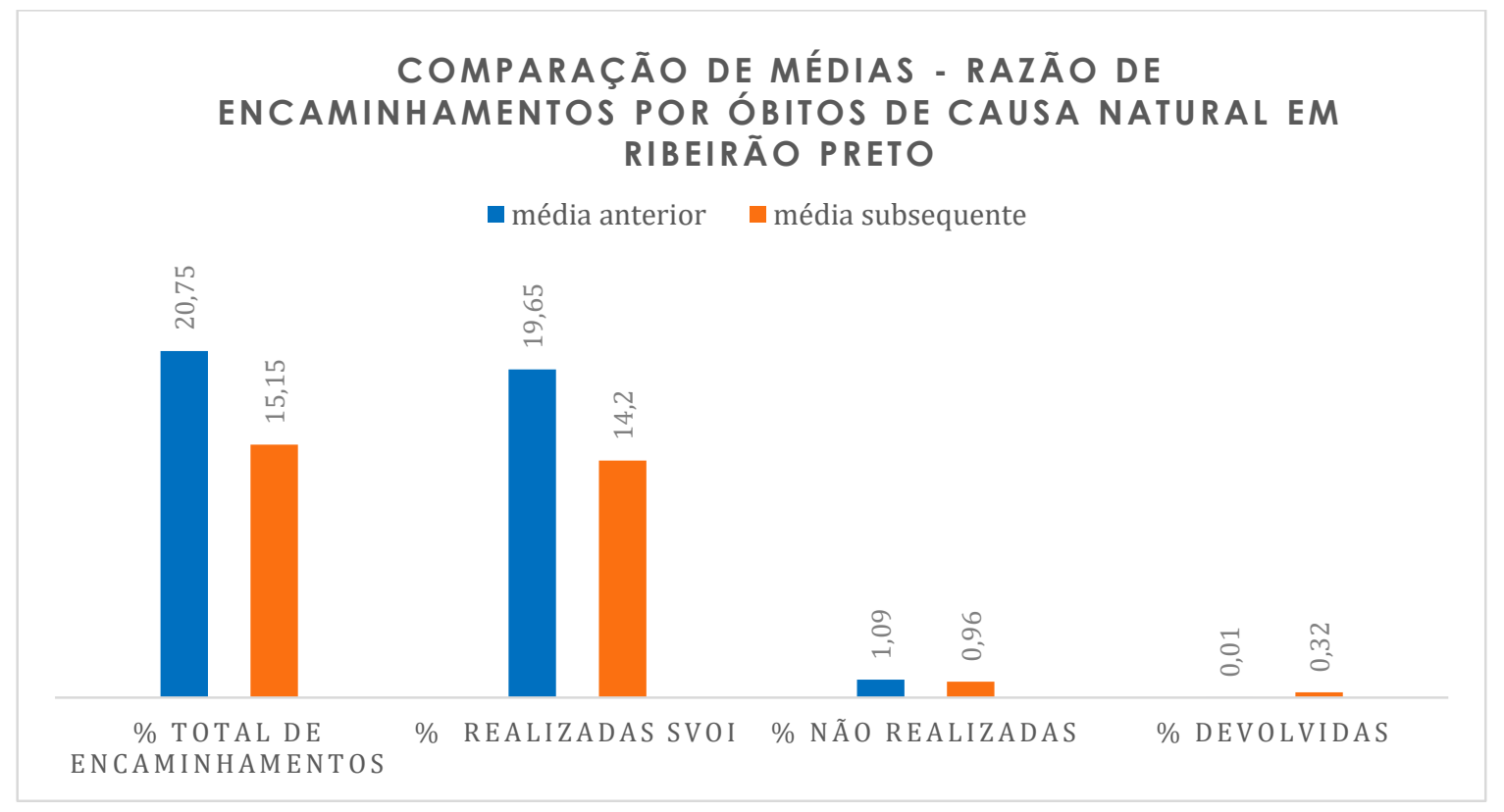

Figura 6. Porcentagem de encaminhamentos, necropsias realizadas pelo SVOI e necropsias recusadas pelo serviço em relação às mortes por causas naturais ocorridas no município de Ribeirão Preto. 


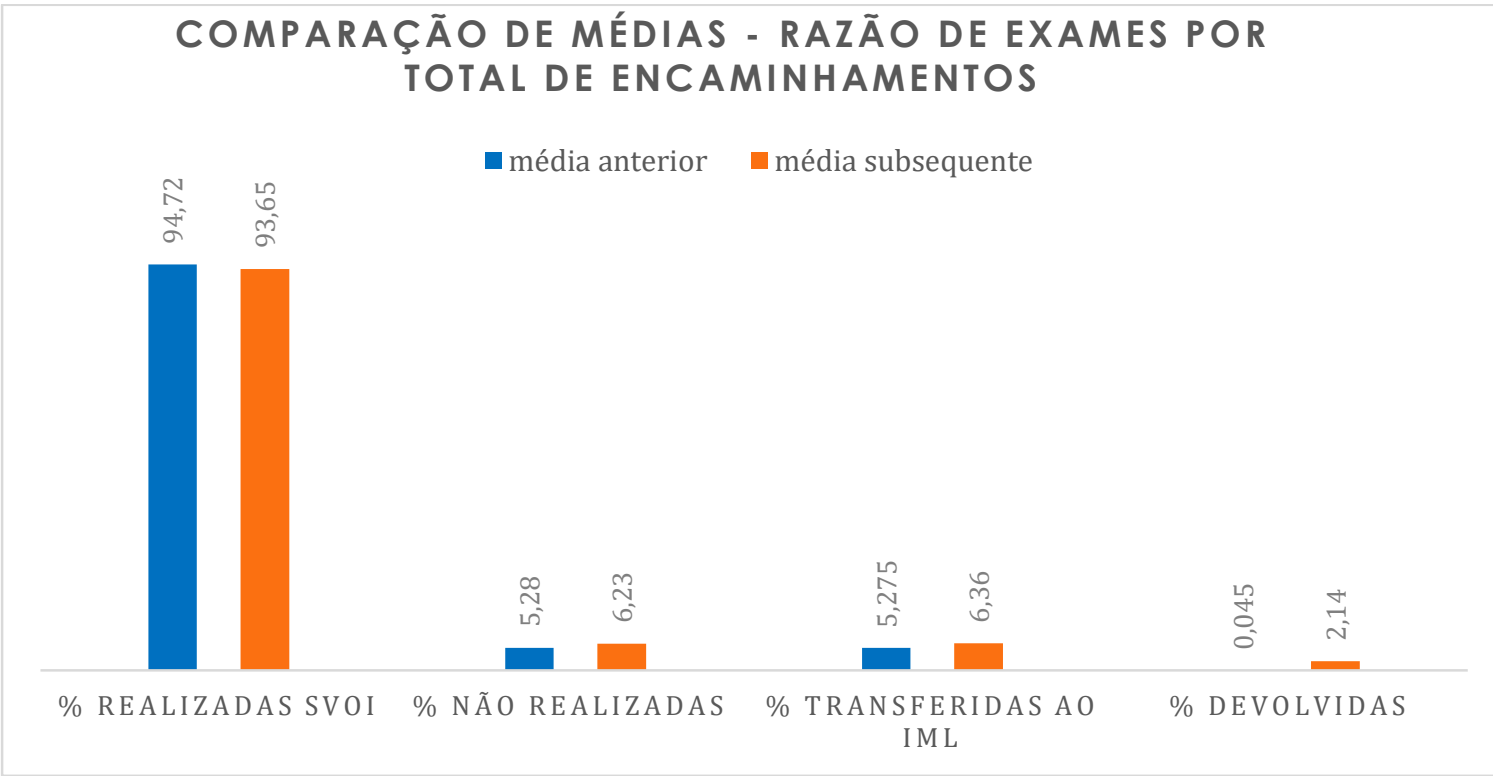

Figura 7. Porcentagem de necropsias realizadas pelo SVOI e de necropsias redestinadas em relação ao total de encaminhamentos para o serviço.

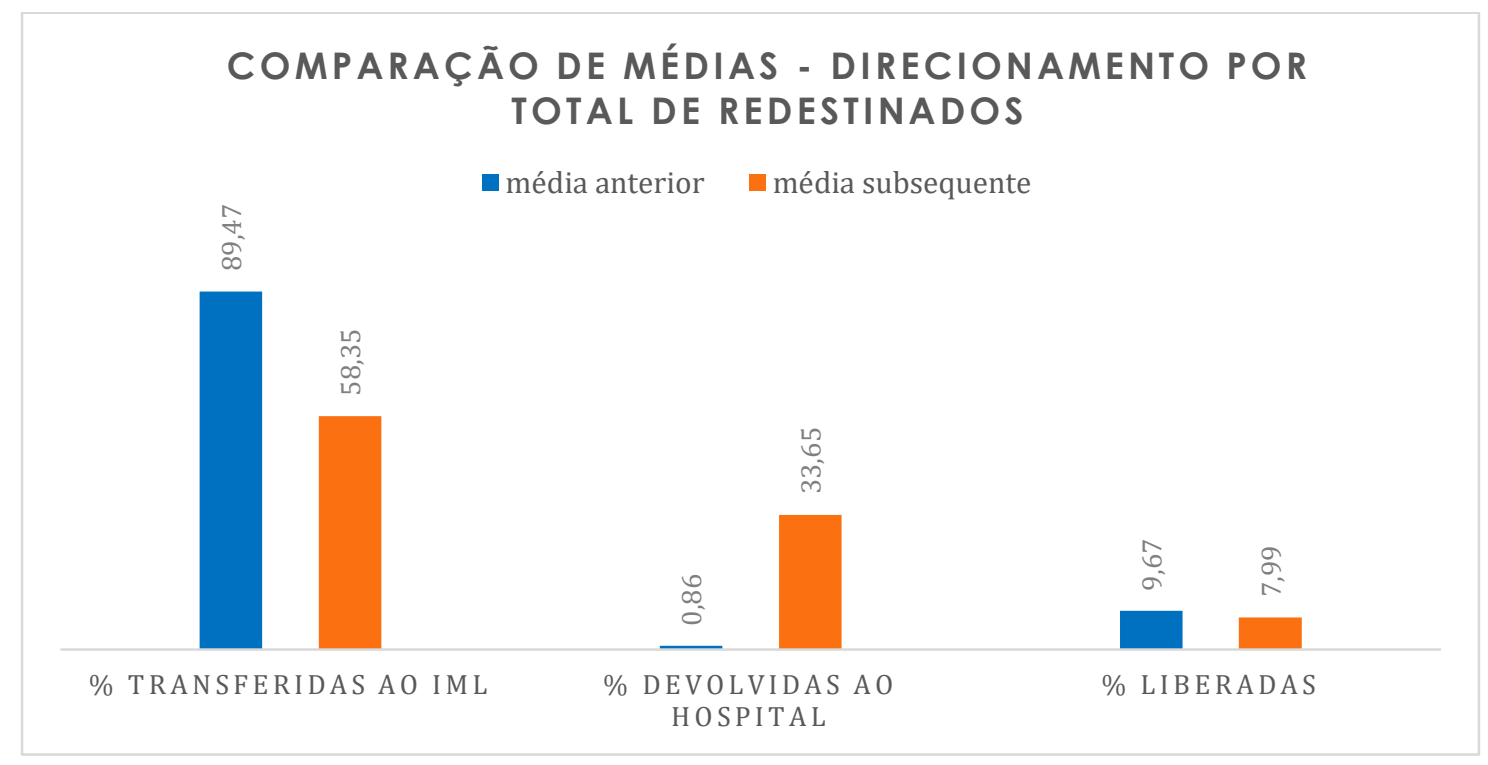

Figura 8. Porcentagem de necropsias transferidas ao IML, devolvidas ao hospital ou liberadas por médico da família em relação ao total de pacientes redestinados. 


\subsection{Características Sociodemográficas dos pacientes encaminhados.}

\subsubsection{Cor da Pele e Sexo}

A tabela 6 e a figura 9 apresentam a distribuição por cor de pele dos pacientes segundo o relatório de necropsia dos anos de 2013 - 2014 e 2017 - 2018 em valores brutos.

\begin{tabular}{|l|l|l|l|l|}
\hline COR DA PELE & $\begin{array}{l}\text { Ano de } \\
\mathbf{2 0 1 3}\end{array}$ & $\begin{array}{l}\text { Ano de } \\
\mathbf{2 0 1 4}\end{array}$ & $\begin{array}{l}\text { Ano de } \\
\mathbf{2 0 1 7}\end{array}$ & $\begin{array}{l}\text { Ano de } \\
\mathbf{2 0 1 8}\end{array}$ \\
\hline Amarela & 5 & 7 & 9 & 6 \\
\hline Branca & 768 & 806 & 674 & 622 \\
\hline Parda & 116 & 103 & 103 & 101 \\
\hline Preta & 106 & 95 & 88 & 58 \\
\hline Ignorada & 2 & 3 & 2 & 3 \\
\hline Campo não preenchido & 11 & 7 & 0 & 0 \\
\hline Total & $\mathbf{1 0 0 8}$ & $\mathbf{1 0 2 1}$ & $\mathbf{8 7 6}$ & $\mathbf{7 9 0}$ \\
\hline
\end{tabular}

Tabela 6. Distribuição por cor de pele dos pacientes segundo o relatório de necropsia dos anos de 2013, 2014, 2017 e 2018 em valores brutos.

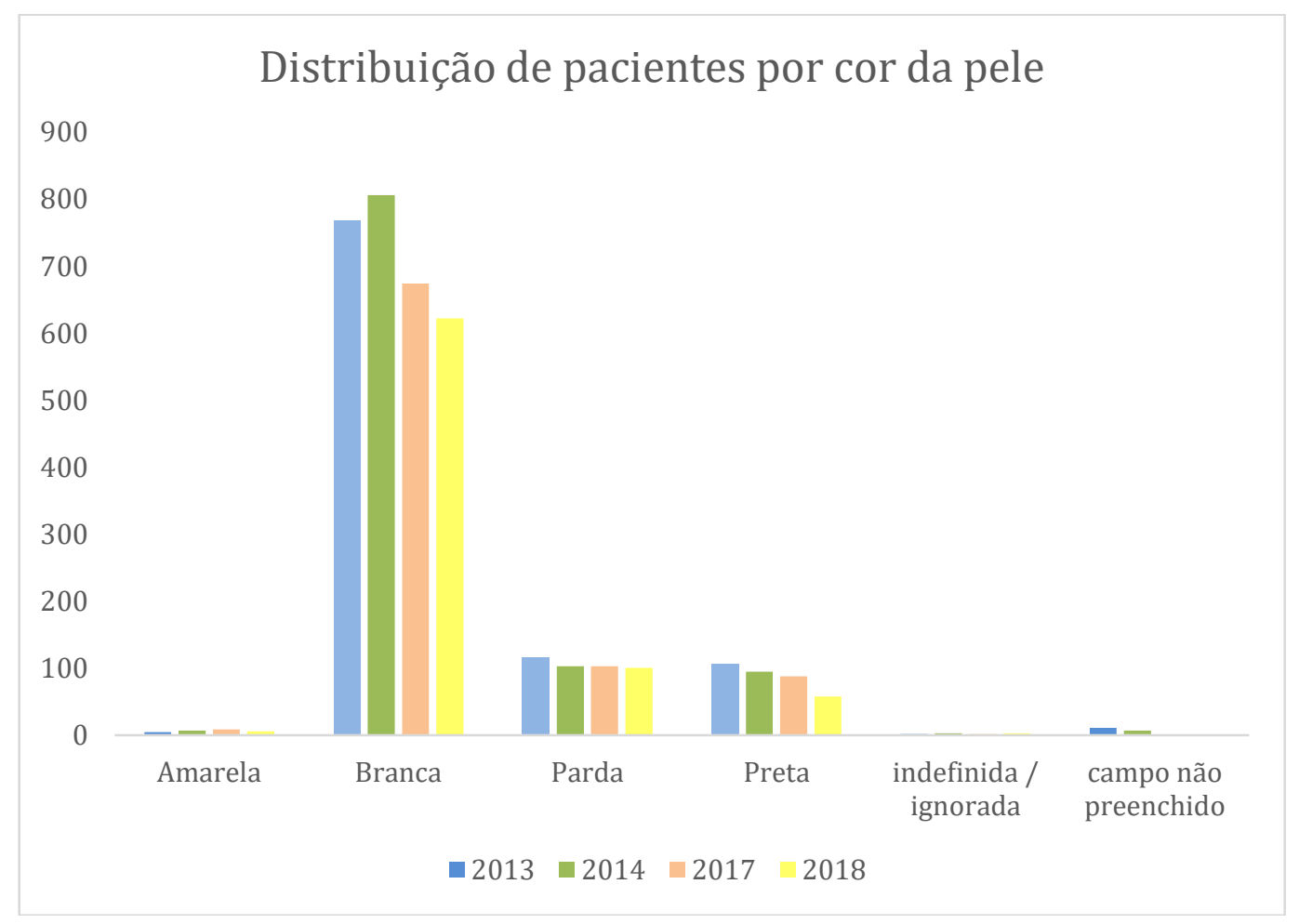

Figura 9. Distribuição por cor de pele dos pacientes segundo o relatório de necropsia dos anos de 2013, 2014, 2017 e 2018 em valores brutos.

A tabela 7 e a figura 10 apresentam a distribuição por cor de pele dos 
pacientes segundo o relatório de necropsia, comparando em porcentagem o total de necropsias realizadas pelo SVOI em relação ao total de moradores de Ribeirão preto no ano base de 2010. Esse ano foi selecionado e acrescentado à tabela porque dados mais recentes encontrados em censo demográfico para esse parâmetro, segundo o Atlas para o Desenvolvimento Humano no Brasil (2020), são do ano de 2010.

\begin{tabular}{|l|c|c|c|c|c|c|}
\hline Cor de Pele & $\begin{array}{c}\text { Moradores de } \\
\text { Ribeirão Preto em } \\
2010-\text { IBGE }\end{array}$ & $\begin{array}{c}\text { SVOI } \\
2010\end{array}$ & $\begin{array}{c}\text { SVOI } \\
2013\end{array}$ & $\begin{array}{c}\text { SVOI } \\
2014\end{array}$ & $\begin{array}{c}\text { SVOI } \\
2017\end{array}$ & $\begin{array}{c}\text { SVOI } \\
2018\end{array}$ \\
\hline Branca & $69,76 \%$ & $75,40 \%$ & $76,2 \%$ & $78,9 \%$ & $76,9 \%$ & $78,7 \%$ \\
\hline Preta ou Parda & $29,29 \%$ & $22,7 \%$ & $22 \%$ & $19,4 \%$ & $21,8 \%$ & $20,1 \%$ \\
\hline Outras & $1,05 \%$ & $0,7 \%$ & $0,5 \%$ & $0,7 \%$ & $1 \%$ & $0,8 \%$ \\
\hline Não Informado & $0 \% 5$ & $1,2 \%$ & $1,3 \%$ & $1 \%$ & $0,2 \%$ & $0,4 \%$ \\
\hline
\end{tabular}

Tabela 7. Distribuição por cor de pele dos pacientes segundo o relatório de necropsia comparados, em porcentagem, ao total de moradores de Ribeirão preto no ano base de 2010.

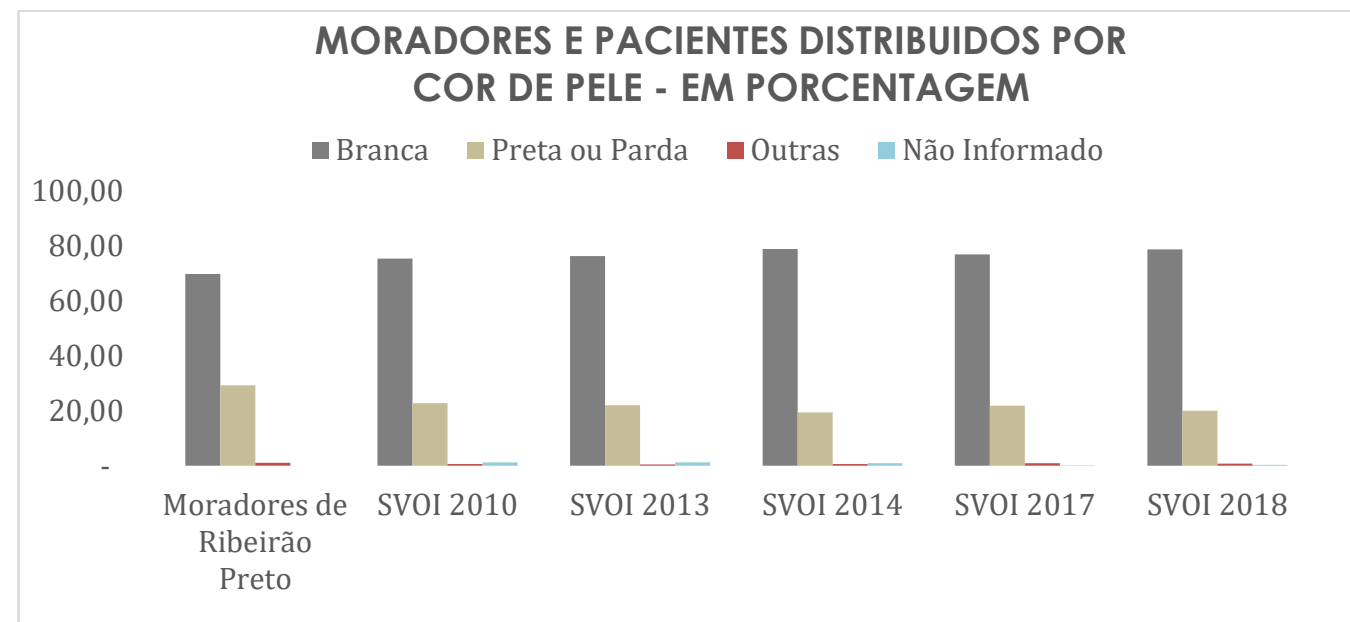

Figura 10. Distribuição por cor de pele dos pacientes segundo o relatório de necropsia comparados, em porcentagem, ao total de moradores de Ribeirão preto no ano base de 2010.

A tabela 8 e a figura 11 apresentam a distribuição por sexo dos pacientes necropsiados pelo SVOI nos anos de 2013, 20142017 e 2018 em valores brutos.

\begin{tabular}{|r|l|l|l|l|}
\hline \multicolumn{1}{|r|}{ SEXO } & Ano de 2013 & Ano de 2014 & Ano de 2017 & Ano de 2018 \\
\hline Masculino & 554 & 564 & 478 & 439 \\
\hline Feminino & 454 & 454 & 398 & 351 \\
\hline Ignorado & 0 & 3 & 0 & 0 \\
\hline TOTAL & $\mathbf{1 0 0 8}$ & $\mathbf{1 0 2 1}$ & $\mathbf{8 7 6}$ & $\mathbf{7 9 0}$ \\
\hline
\end{tabular}

Tabela 8. Distribuição por sexo dos pacientes necropsiados pelo SVOI nos anos de 2013, 20142017 e 2018 em valores brutos. 


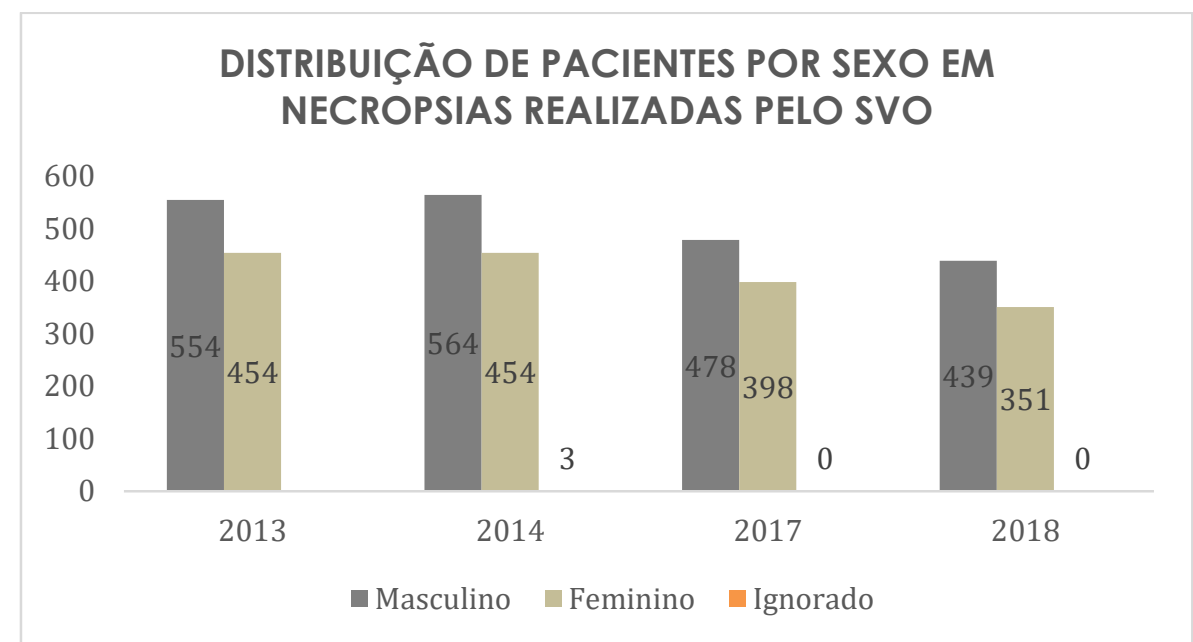

Figura 11. Distribuição por sexo dos pacientes necropsiados pelo SVOI nos anos de 2013, 20142017 e 2018 em valores brutos.

\subsubsection{Idade e Grupo Etário}

As tabelas 9 a 14 e as figuras 12 a 17 apresentam a distribuição por faixa etária dos pacientes nos anos de 2013, 2014, 2017 e 2018 em valores brutos, sendo as tabelas 9 e 10 referentes ao total de encaminhamentos, a tabela 11 e 12 referentes apenas às necropsias realizadas pelo SVOI e as tabelas 13 e 14 referentes aos pacientes redirecionados.

\begin{tabular}{|l|c|c|c|c|}
\hline $\begin{array}{l}\text { Total de } \\
\text { Encaminhamentos }\end{array}$ & $\begin{array}{c}\text { Ano de } \\
\mathbf{2 0 1 3}\end{array}$ & $\begin{array}{c}\text { Ano de } \\
\mathbf{2 0 1 4}\end{array}$ & $\begin{array}{c}\text { Ano de } \\
\mathbf{2 0 1 7}\end{array}$ & $\begin{array}{c}\text { Ano de } \\
\mathbf{2 0 1 8}\end{array}$ \\
\hline FM ou NM & 69 & 92 & 25 & 22 \\
\hline Rn-0 a 28d & 28 & 40 & 13 & 3 \\
\hline $1-12$ meses & 12 & 12 & 1 & 5 \\
\hline 1 a 9 anos & 4 & 7 & 4 & 5 \\
\hline 10 a 19 & 8 & 5 & 4 & 3 \\
\hline $20-29$ & 21 & 8 & 11 & 7 \\
\hline $30-39$ & 39 & 23 & 31 & 30 \\
\hline $40-49$ & 84 & 75 & 73 & 55 \\
\hline $50-59$ & 147 & 131 & 127 & 110 \\
\hline $60-69$ & 184 & 184 & 168 & 163 \\
\hline $70-79$ & 209 & 200 & 196 & 178 \\
\hline $80-89$ & 190 & 204 & 172 & 184 \\
\hline $90-105$ & 58 & 79 & 96 & 80 \\
\hline ignorado/ em branco & 10 & 19 & 13 & 0 \\
\hline Total & 1063 & 1079 & 934 & 845 \\
\hline
\end{tabular}

Tabela 9. Distribuição por idade do total de encaminhamentos nos anos de 2013, 2014, 2017, 2018. 


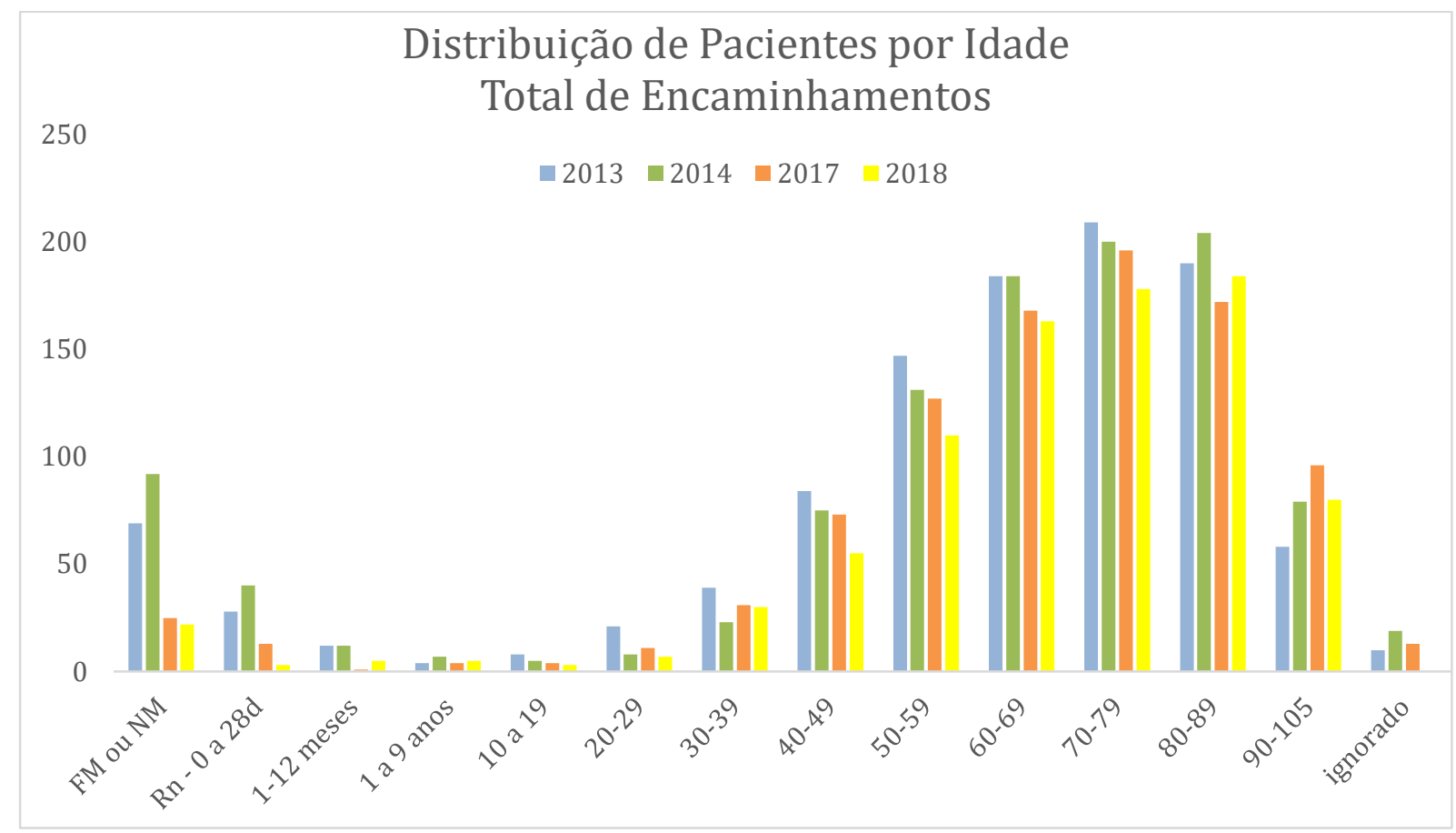

Figura 12. Distribuição por idade do total de pacientes encaminhamentos nos anos de 2013, 2014, 2017 e 2018.

\begin{tabular}{lcccc}
\hline Total de Encaminhamentos & $\begin{array}{c}\text { Média } \\
\text { anterior }\end{array}$ & $\begin{array}{c}\text { Média } \\
\text { subsequente }\end{array}$ & Diferença & Teste T \\
\hline FM ou NM & 80,5 & 23,5 & $-70,81 \%$ & 0,01619 \\
RN - 0 a 28d & 34 & 8 & $-76,47 \%$ & 0,03980 \\
1-12 meses & 12 & 3 & $-75,00 \%$ & 0,02300 \\
1 a 9 anos & 5,5 & 4,5 & $-18,18 \%$ & 0,2959 \\
10 a 19 & 6,5 & 3,5 & $-46,15 \%$ & 0,0991 \\
20-29 & 14,5 & 9 & $-37,93 \%$ & 0,2518 \\
$30-39$ & 31 & 30,5 & $-1,61 \%$ & 0,4780 \\
$40-49$ & 79,5 & 64 & $-19,50 \%$ & 0,1317 \\
$50-59$ & 139 & 118,5 & $-14,75 \%$ & 0,1106 \\
$60-69$ & 184 & 165,5 & $-10,05 \%$ & 0,00889 \\
$70-79$ & 204,5 & 187 & $-8,56 \%$ & 0,1121 \\
$80-89$ & 197 & 178 & $-9,64 \%$ & 0,0877 \\
90-105 & 68,5 & 88 & $28,47 \%$ & 0,1388 \\
Ignorado / em branco & 14,5 & 6,5 & $-55,17 \%$ & 0,2090 \\
\hline Total & 1071 & 889,5 & $-16,95 \%$ & 0,02841 \\
\hline
\end{tabular}

Tabela 10. Médias de encaminhamentos dos anos anteriores e subsequentes ao Parecer Consulta, distribuídos por faixas idade. 


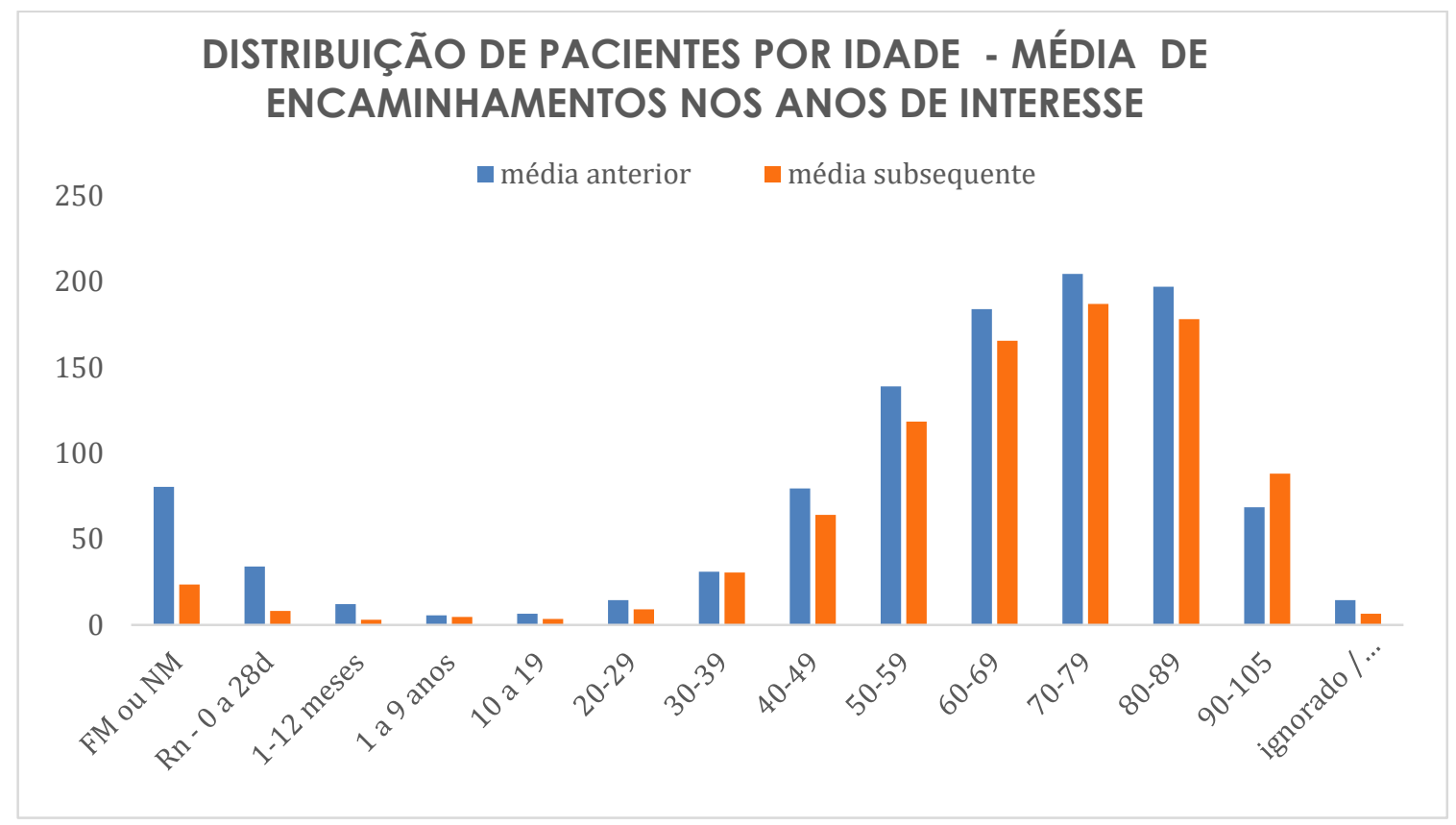

Figura 13. Médias de encaminhamentos dos anos anteriores e subsequentes ao Parecer Consulta, distribuídos por idade.

\begin{tabular}{lcccc}
\hline $\begin{array}{c}\text { Necropsias Realizadas } \\
\text { pelo SVOI }\end{array}$ & $\begin{array}{c}\text { Ano de } \\
\mathbf{2 0 1 3}\end{array}$ & $\begin{array}{c}\text { Ano de } \\
\mathbf{2 0 1 4}\end{array}$ & $\begin{array}{c}\text { Ano de } \\
\mathbf{2 0 1 7}\end{array}$ & $\begin{array}{c}\text { Ano de } \\
\mathbf{2 0 1 8}\end{array}$ \\
\hline FM ou NM & 69 & 92 & 24 & 19 \\
Rn- 0 a 28d & 27 & 39 & 10 & 3 \\
1-12 meses & 12 & 11 & 1 & 3 \\
l a 9 anos & 4 & 7 & 2 & 4 \\
10 a 19 & 8 & 5 & 4 & 3 \\
$20-29$ & 19 & 8 & 10 & 7 \\
$30-39$ & 37 & 21 & 28 & 23 \\
$40-49$ & 82 & 70 & 67 & 50 \\
$50-59$ & 140 & 122 & 120 & 106 \\
$60-69$ & 181 & 178 & 159 & 157 \\
$70-79$ & 197 & 196 & 190 & 169 \\
$80-89$ & 179 & 197 & 170 & 169 \\
90-105 & 53 & 75 & 91 & 77 \\
lgnorado / em branco & 0 & 0 & 0 & 0 \\
\hline Total & 1008 & $\mathbf{1 0 2 1}$ & $\mathbf{8 7 6}$ & $\mathbf{7 9 0}$ \\
\hline
\end{tabular}

Tabela 11. Distribuição por idade do total de necropsias realizadas no SVOI nos anos de 2013 , 2014, 2017, 2018. 


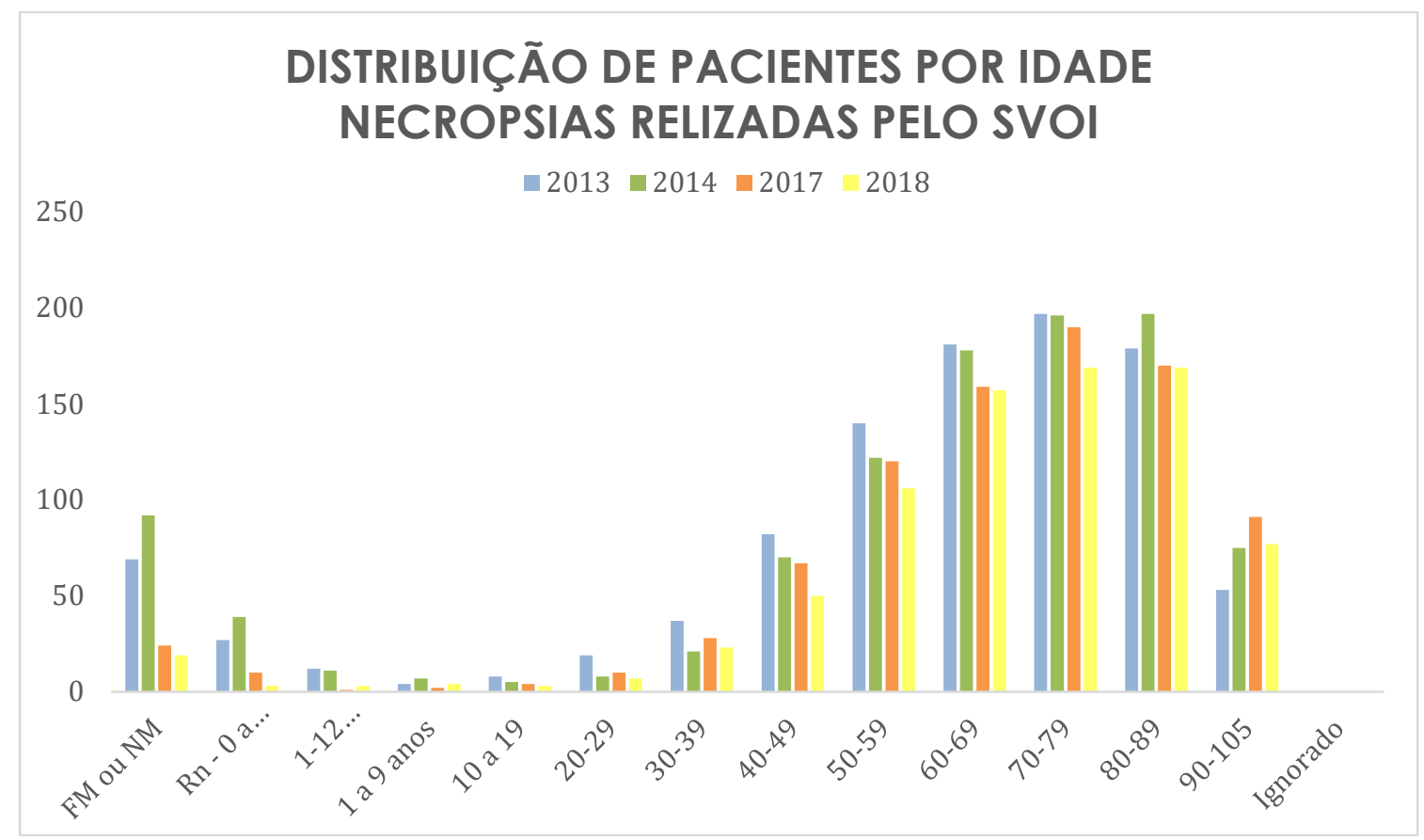

Figura 14. Distribuição por idade do total de necropsias realizadas no SVOI nos anos de 2013, 2014, 2017, 2018.

\begin{tabular}{|c|c|c|c|c|}
\hline $\begin{array}{c}\text { Necropsias Realizadas pelo } \\
\text { SVOI }\end{array}$ & $\begin{array}{l}\text { Média } \\
\text { anterior }\end{array}$ & $\begin{array}{c}\text { Média } \\
\text { subsequente }\end{array}$ & Diferença & Teste T \\
\hline FM ou NM & 80,5 & 21,5 & $-73,29 \%$ & 0,01391 \\
\hline$R n-0$ a $28 d$ & 33 & 6,5 & $-80,30 \%$ & 0,03118 \\
\hline 1-12 meses & 11,5 & 2 & $-82,61 \%$ & 0,00678 \\
\hline 1 a 9 anos & 5,5 & 3 & $-45,45 \%$ & 0,150 \\
\hline 10 a 19 & 6,5 & 3,5 & $-46,15 \%$ & 0,099 \\
\hline $20-29$ & 13,5 & 8,5 & $-37,04 \%$ & 0,236 \\
\hline $30-39$ & 29 & 25,5 & $-12,07 \%$ & 0,358 \\
\hline $40-49$ & 76 & 58,5 & $-23,03 \%$ & 0,117 \\
\hline $50-59$ & 131 & 113 & $-13,74 \%$ & 0,128 \\
\hline $60-69$ & 179,5 & 158 & $-11,98 \%$ & 0,00348 \\
\hline 70-79 & 196,5 & 179,5 & $-8,65 \%$ & 0,124 \\
\hline $80-89$ & 188 & 169,5 & $-9,84 \%$ & 0,088 \\
\hline $90-105$ & 64 & 84 & $31,25 \%$ & 0,132 \\
\hline Ignorado / em branco & 0 & 0 & - & - \\
\hline Total & 1014,5 & 833 & $-17,89 \%$ & 0,02645 \\
\hline
\end{tabular}

Tabela 12. Médias de necropsias realizadas no SVOI nos anos anteriores e subsequentes ao Parecer Consulta, distribuídos por idade. 


\section{DISTRIBUIÇÃO POR IDADE - MÉDIA DE PACIENTES EM NECRÓSPIAS REALIZADAS PELO SVOI}

- média anterior média subsequente

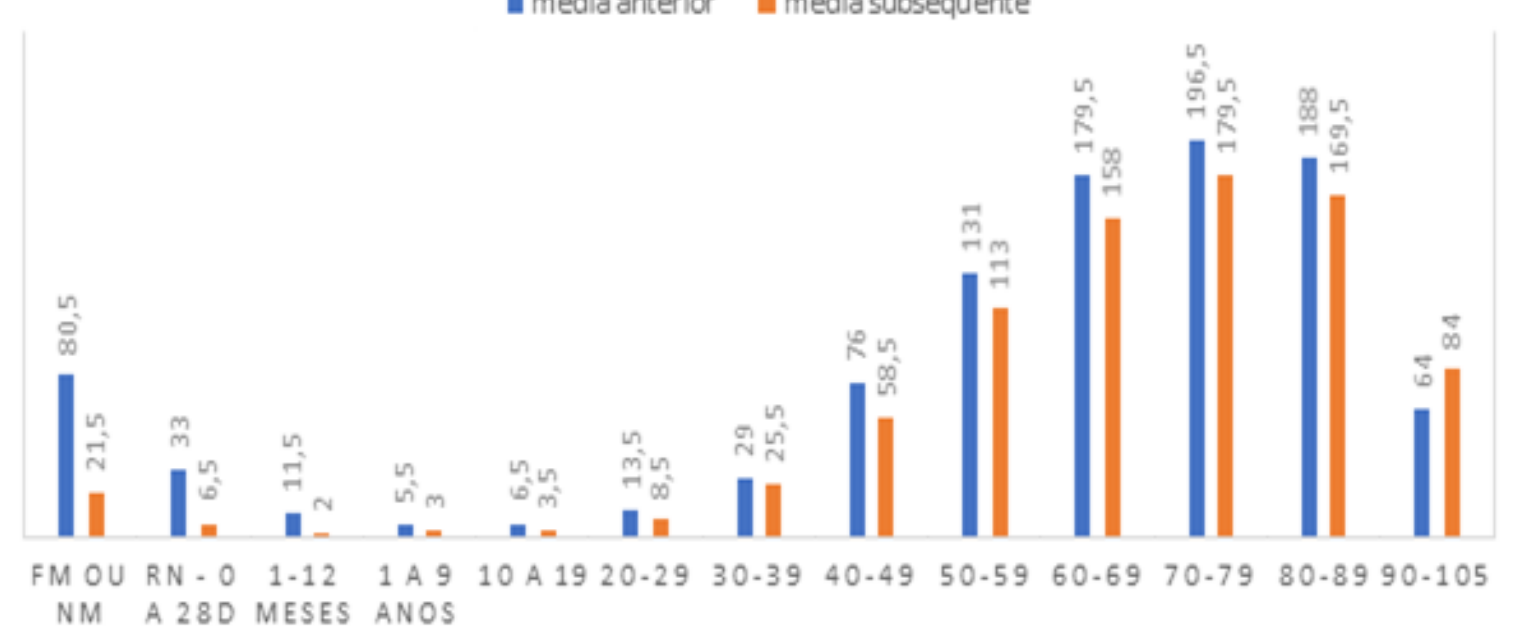

Figura 15. Médias de necropsias realizadas no SVOI nos anos anteriores e subsequentes ao Parecer Consulta, distribuídos por idade.

\begin{tabular}{|l|c|c|c|c|}
\hline \multicolumn{1}{|c|}{ Idade } & $\begin{array}{c}\mathbf{2 0 1 3} \\
\text { transferidos }\end{array}$ & $\begin{array}{c}\mathbf{2 0 1 4} \\
\text { transferidos }\end{array}$ & $\begin{array}{c}\mathbf{2 0 1 7} \\
\text { transferidos }\end{array}$ & $\begin{array}{c}\mathbf{2 0 1 8} \\
\text { transferidos }\end{array}$ \\
\hline FM & 0 & 0 & 0 & 1 \\
\hline $\mathrm{NM}$ & 0 & 0 & 1 & 2 \\
\hline $\mathrm{Rn} .0-28 \mathrm{~d}$ & 1 & 1 & 3 & 0 \\
\hline $1-12$ meses & 0 & 1 & 0 & 2 \\
\hline 1 a 9 anos & 0 & 0 & 2 & 1 \\
\hline 10 a 19 & 0 & 0 & 0 & 0 \\
\hline $20-29$ & 2 & 0 & 1 & 0 \\
\hline $30-39$ & 2 & 2 & 3 & 7 \\
\hline $40-49$ & 2 & 5 & 6 & 5 \\
\hline $50-59$ & 7 & 9 & 7 & 4 \\
\hline $60-69$ & 3 & 6 & 9 & 6 \\
\hline $70-79$ & 12 & 4 & 6 & 9 \\
\hline $80-89$ & 11 & 7 & 2 & 15 \\
\hline $90-105$ & 5 & 4 & 5 & 3 \\
\hline Ignorado / em branco & 10 & 19 & 13 & 0 \\
\hline Total & $\mathbf{5 5}$ & $\mathbf{5 8}$ & $\mathbf{5 8}$ & $\mathbf{5 5}$ \\
\hline
\end{tabular}

Tabela 13. Distribuição por idade do total de necropsias recusadas pelo SVOI nos anos de 2013,2014, 2017, 2018 e redestinadas a outros serviços. 


\section{Distribuição por Idade - Transferências e Exames Redirecionados}

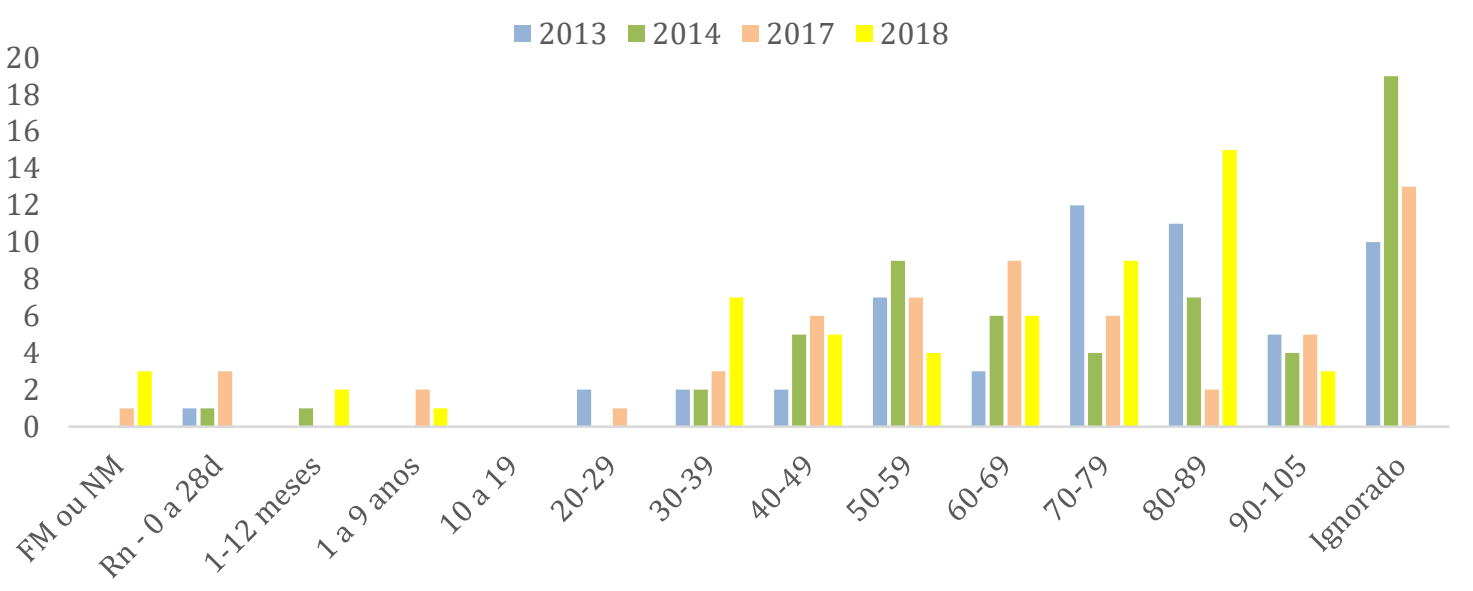

Figura 16. Distribuição por idade do total de necropsias recusadas pelo SVOI nos anos de 2013, 2014, 2017, 2018 e redestinadas a outros serviços.

\begin{tabular}{|c|c|c|c|c|}
\hline $\begin{array}{c}\text { Pacientes } \\
\text { Redestinados }\end{array}$ & $\begin{array}{l}\text { Média } \\
\text { anterior }\end{array}$ & $\begin{array}{c}\text { Média } \\
\text { subsequente }\end{array}$ & Diferença & Teste T \\
\hline FM ou NM & 0 & 2 & - & 0,025 \\
\hline $\mathrm{Rn}-0$ a $28 \mathrm{~d}$ & 1 & 1,5 & $50,0 \%$ & 0,385 \\
\hline $1-12$ meses & 0,5 & 1 & $100,0 \%$ & 0,349 \\
\hline 1 a 9 anos & 0 & 1,5 & $0,0 \%$ & 0,048 \\
\hline 10 a 19 & 0 & 0 & - & - \\
\hline $20-29$ & 1 & 0,5 & $-50,0 \%$ & 0,349 \\
\hline $30-39$ & 2 & 5 & $150,0 \%$ & 0,136 \\
\hline $40-49$ & 3,5 & 5,5 & $57,1 \%$ & 0,167 \\
\hline $50-59$ & 8 & 5,5 & $-31,3 \%$ & 0,150 \\
\hline $60-69$ & 4,5 & 7,5 & $66,7 \%$ & 0,146 \\
\hline 70-79 & 8 & 7,5 & $-6,3 \%$ & 0,459 \\
\hline 80-89 & 9 & 8,5 & $-5,6 \%$ & 0,474 \\
\hline $90-105$ & 4,5 & 4 & $-11,1 \%$ & 0,349 \\
\hline Ignorado / em branco & 14,5 & 6,5 & $-55,2 \%$ & 0,209 \\
\hline Total & 56,5 & 56,5 & $0,0 \%$ & 0,500 \\
\hline
\end{tabular}

Tabela 14. Médias de necropsias recusadas pelo SVOI e redestinadas a outros serviços nos anos anteriores e subsequentes ao Parecer Consulta. 


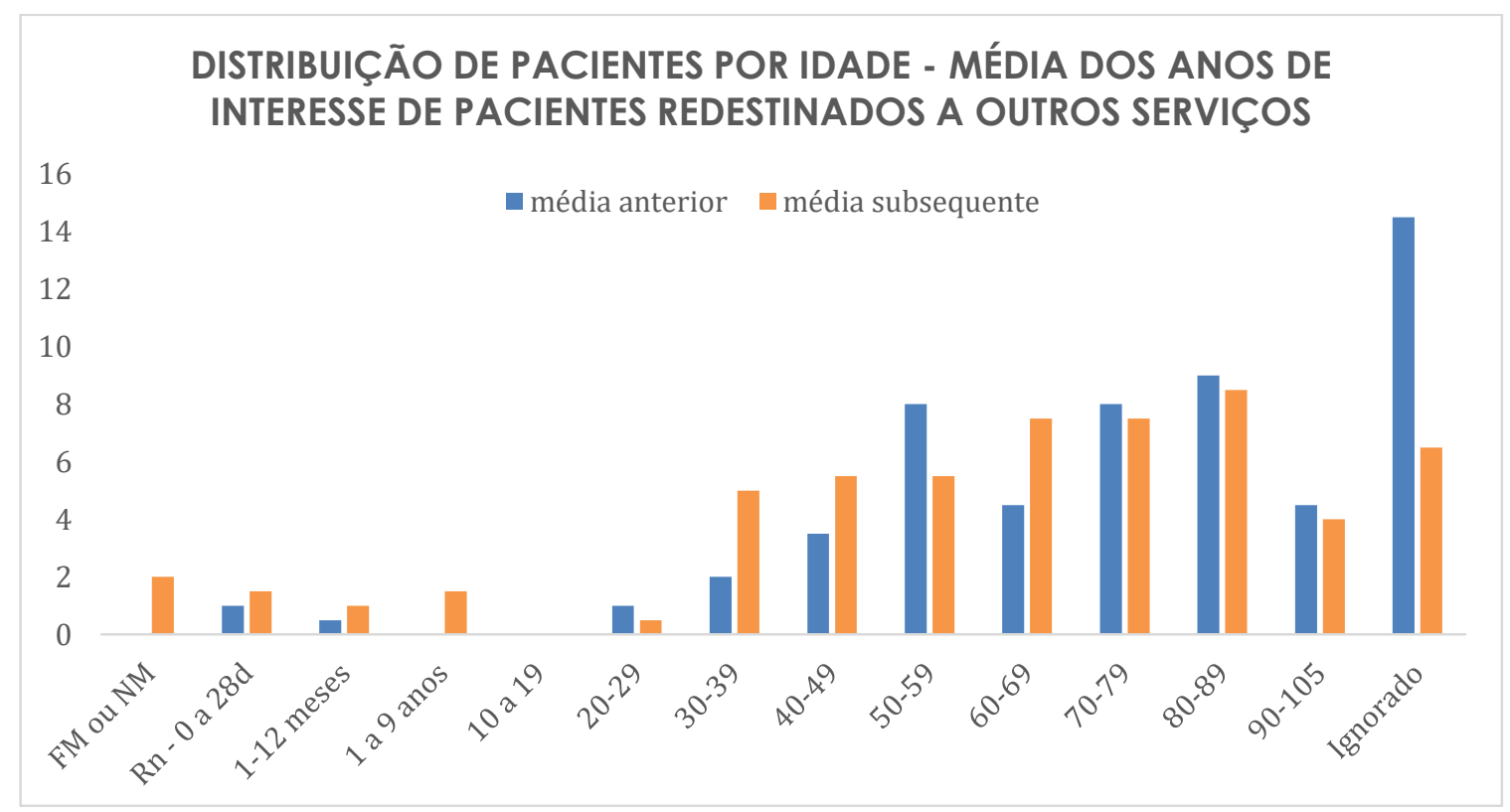

Figura 17. Médias de necropsias recusadas pelo SVOI e redestinadas a outros serviços nos anos anteriores e subsequentes ao Parecer Consulta.

As tabelas de 15 a 20 e figuras de 18 a 23 apresentam a distribuição de pacientes por grupos etários, divididos nas categorias: perinatais compreendendo fetos mortos, natimortos e recém-nascidos; Crianças/ adolescente, compreendendo as crianças maiores de 28 dias de nascimento até jovens de 19 anos (OPAS, 2017; Eisenstein, 2005); adultos - 20 a 59 anos; idosos 60 ou mais anos de vida; e, por fim, idade ignorada ou campo não preenchido.

\begin{tabular}{|l|c|c|c|c|}
\hline Total de Encaminhamentos & $\begin{array}{c}\text { Ano de } \\
\mathbf{2 0 1 3}\end{array}$ & $\begin{array}{c}\text { Ano de } \\
\mathbf{2 0 1 4}\end{array}$ & $\begin{array}{c}\text { Ano de } \\
\mathbf{2 0 1 7}\end{array}$ & $\begin{array}{c}\text { Ano de } \\
\mathbf{2 0 1 8}\end{array}$ \\
\hline Perinatais & 97 & 132 & 38 & 25 \\
\hline Crianças/Adolescentes & 24 & 24 & 9 & 13 \\
\hline Adultos & 291 & 237 & 242 & 202 \\
\hline Idosos & 641 & 667 & 632 & 605 \\
\hline Ignorado / em branco & 10 & 19 & 13 & 0 \\
\hline Total & 1063 & $\mathbf{1 0 7 9}$ & $\mathbf{9 3 4}$ & $\mathbf{8 4 5}$ \\
\hline
\end{tabular}

Tabela 15. Distribuição por grupos etários do total de encaminhamentos nos anos de 2013, 2014, 2017, 2018. 


\title{
DISTRIBUIÇÃO DE PACIENTES POR GRUPOS ETÁRIOS TOTAL DE ENCAMINHAMENTOS
}

\author{
- 2013 Total $\square 2014$ Total $\square 2017$ Total 2018 Total
}

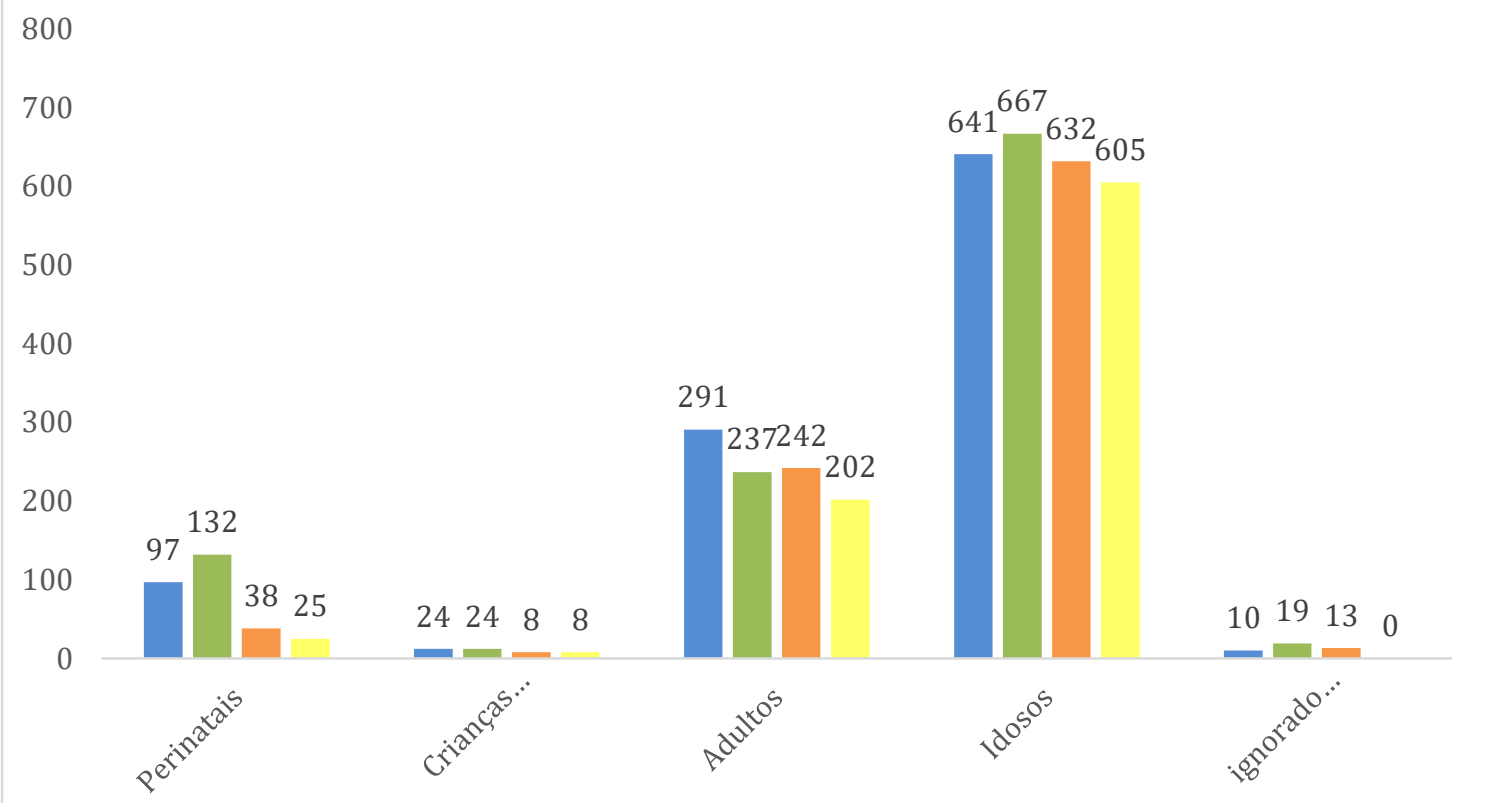

Figura 18. Distribuição por grupos etários do total encaminhadas nos anos de 2013, 2014, 2017, 2018.

\begin{tabular}{|l|c|c|c|c|}
\hline $\begin{array}{l}\text { Total de } \\
\text { Encaminhamentos }\end{array}$ & $\begin{array}{c}\text { Média } \\
\text { anterior }\end{array}$ & $\begin{array}{c}\text { Média } \\
\text { subsequente }\end{array}$ & Diferença & Teste T \\
\hline Perinatais & 114,5 & 31,5 & $-72,49 \%$ & 0,024 \\
\hline $\begin{array}{l}\text { Crianças/Adolescentes } \\
\text { até 19 anos }\end{array}$ & 24 & 11 & $-54,17 \%$ & 0,011 \\
\hline Adultos & 264 & 222 & $-15,91 \%$ & 0,169 \\
\hline Idosos & 654 & 618,5 & $-5,43 \%$ & 0,099 \\
\hline Ignorado / em branco & 14,5 & 6,5 & $-55,17 \%$ & 0,209 \\
\hline Total & 1071 & 889,5 & $-16,95 \%$ & 0,028 \\
\hline
\end{tabular}

Tabela 16. Médias de necropsias realizadas no SVOI nos anos anteriores e subsequentes ao Parecer Consulta, distribuídos por faixa etária. 


\section{Distribuição de Pacientes por Grupos Etários Médias de Encaminhamentos}

700

600

500

400

300

200

100

0
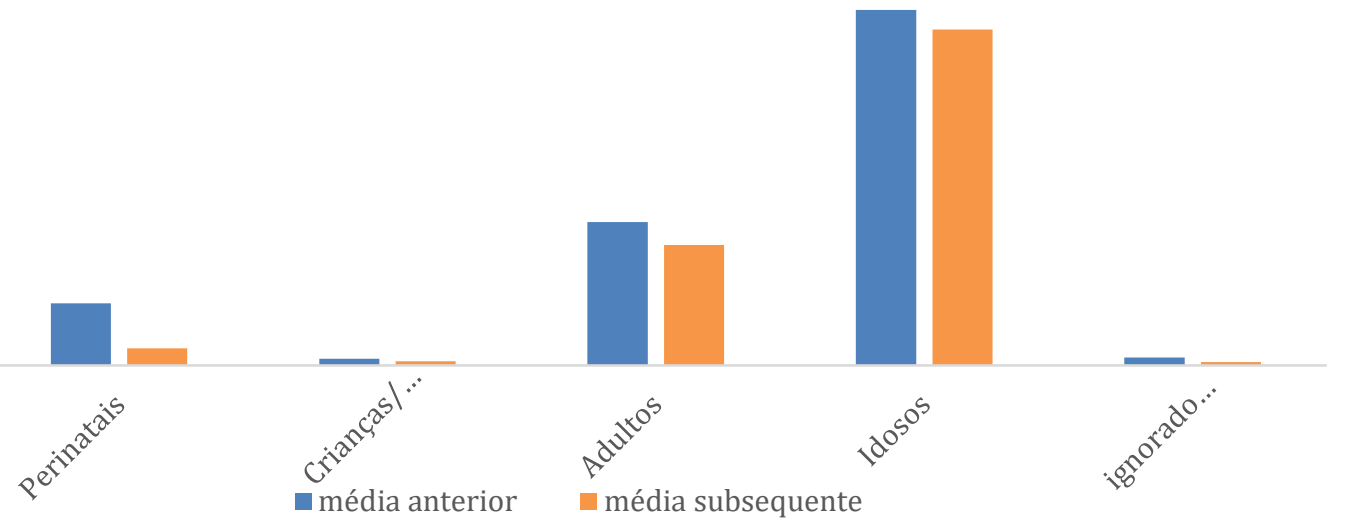

Figura 19. Médias de necropsias realizadas no SVOI nos anos anteriores e subsequentes ao Parecer Consulta, distribuídos por faixa etária.

\begin{tabular}{|l|c|c|c|c|}
\hline Necropsias Realizadas pelo Svol & $\begin{array}{c}\text { Ano de } \\
\mathbf{2 0 1 3}\end{array}$ & $\begin{array}{c}\text { Ano de } \\
\mathbf{2 0 1 4}\end{array}$ & $\begin{array}{c}\text { Ano de } \\
\mathbf{2 0 1 7}\end{array}$ & $\begin{array}{c}\text { Ano de } \\
\mathbf{2 0 1 8}\end{array}$ \\
\hline Perinatais & 96 & 131 & 34 & 22 \\
\hline Crianças/Adolescentes & 24 & 23 & 7 & 10 \\
\hline Adultos & 278 & 221 & 225 & 186 \\
\hline Idosos & 610 & 646 & 610 & 572 \\
\hline Ignorado / em branco & 0 & 0 & 0 & 0 \\
\hline Total & 1008 & $\mathbf{1 0 2 1}$ & $\mathbf{8 7 6}$ & $\mathbf{7 9 0}$ \\
\hline
\end{tabular}

Tabela 17. Distribuição por grupos etários do total de necropsias realizadas pelo SVOI nos anos de $2013,2014,2017,2018$. 


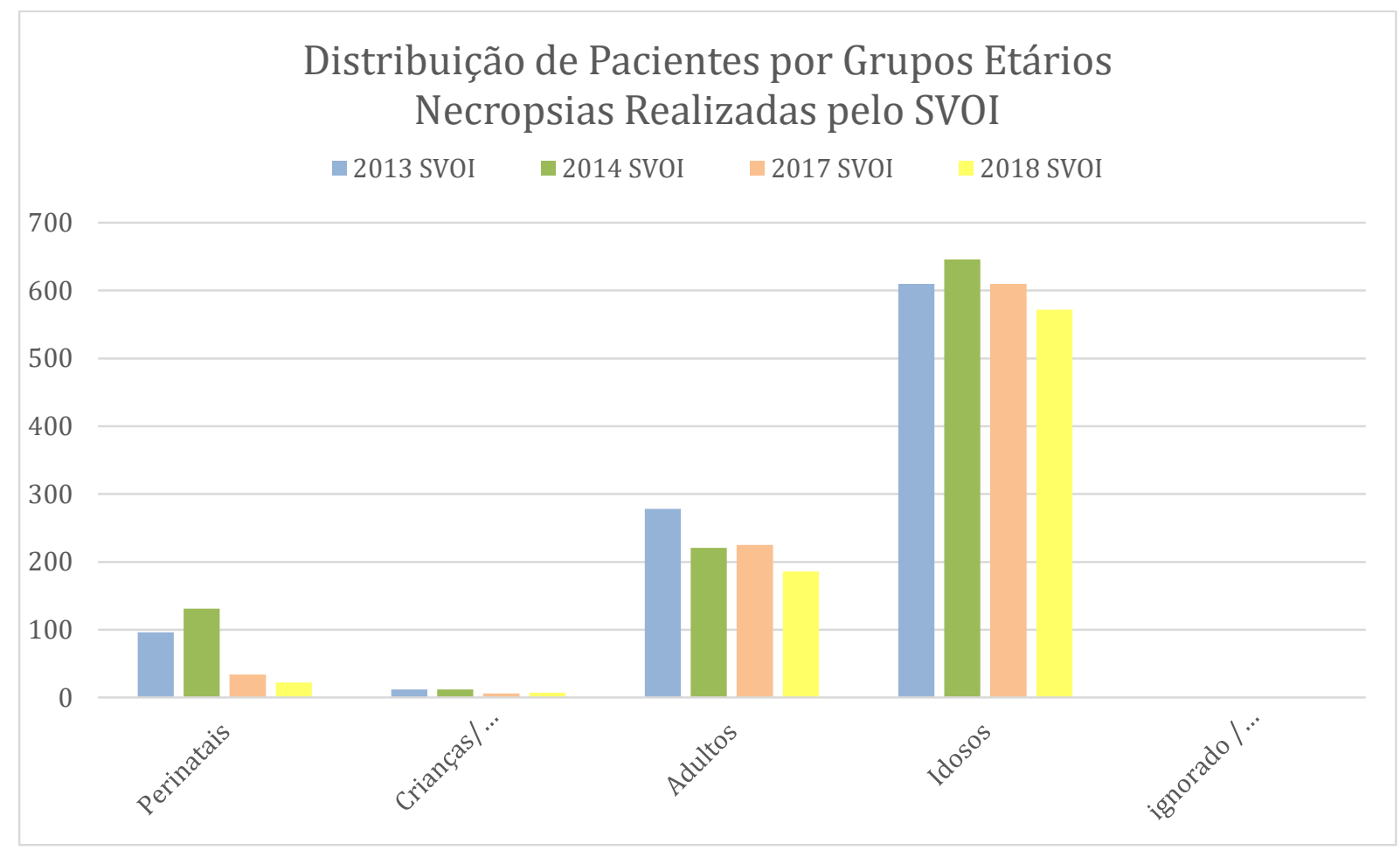

Figura 20. Distribuição por grupos etários do total de necropsias realizadas pelo SVOI nos anos de 2013, 2014, 2017, 2018.

\begin{tabular}{|l|c|c|c|c|}
\hline Necropsias Realizadas pelo SvOI & $\begin{array}{c}\text { Média } \\
\text { anterior }\end{array}$ & $\begin{array}{c}\text { Média } \\
\text { subsequente }\end{array}$ & Diferença & Teste T \\
\hline Perinatais (FM, NM, RN) & 113,5 & 28 & $-75,33 \%$ & 0,022 \\
\hline $\begin{array}{l}\text { Crianças/Adolescentes } \\
\text { até 19 anos }\end{array}$ & 23,5 & 8,5 & $-63,83 \%$ & 0,005 \\
\hline Adultos & 249,5 & 205,5 & $-17,64 \%$ & 0,165 \\
\hline Idosos & 628 & 591 & $-5,89 \%$ & 0,147 \\
\hline Ignorado / em branco & 0 & 0 & & \\
\hline Total & 1014,5 & 833 & $-17,89 \%$ & 0,026 \\
\hline
\end{tabular}

Tabela 18. Médias de necropsias realizadas pelo SVOI nos anos anteriores e subsequentes ao Parecer Consulta, distribuídos por grupos etários. 


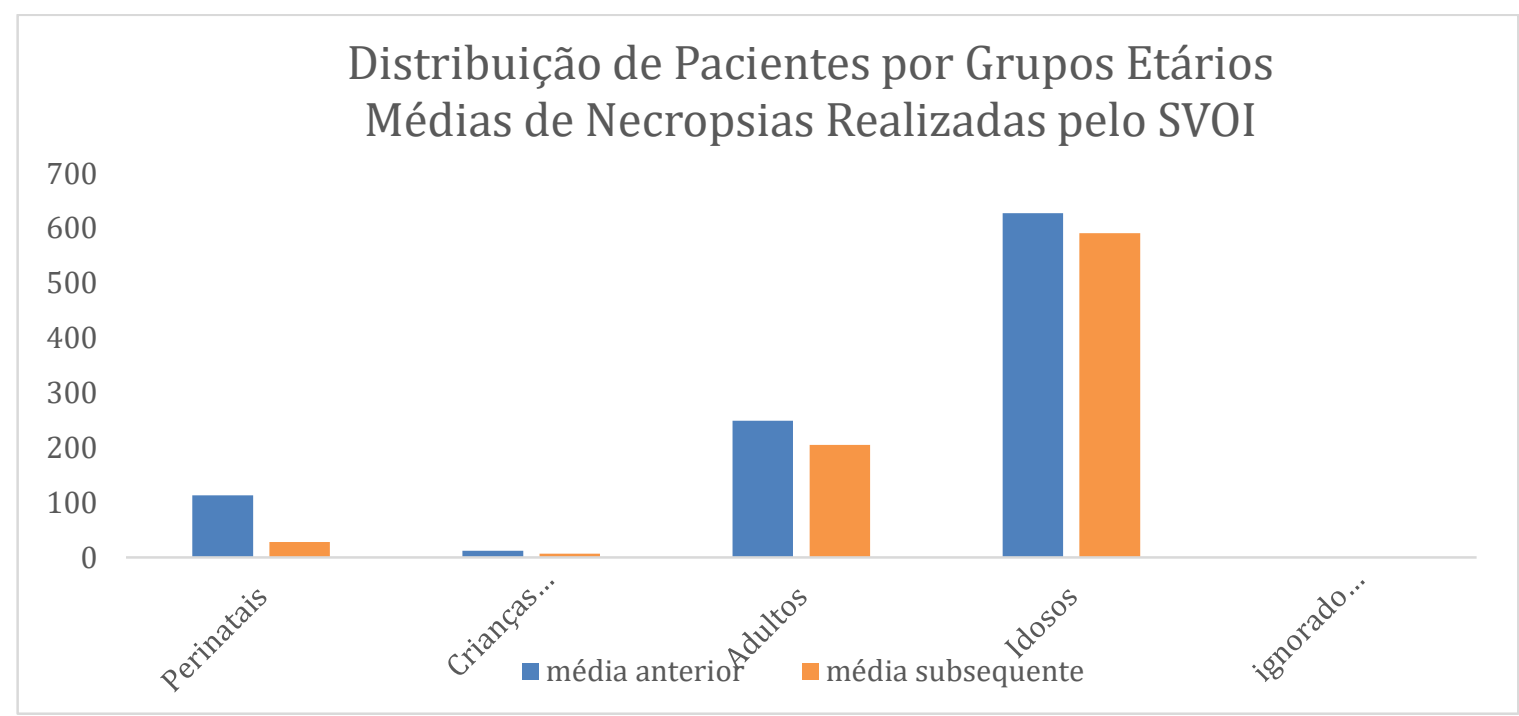

Figura 21. Médias de necropsias realizadas pelo SVOI nos anos anteriores e subsequentes ao Parecer Consulta, distribuídos por grupos etários.

\begin{tabular}{|l|c|c|c|c|}
\hline Pacientes Redestinados & $\begin{array}{c}\text { Ano de } \\
\mathbf{2 0 1 3}\end{array}$ & $\begin{array}{c}\text { Ano de } \\
\mathbf{2 0 1 4}\end{array}$ & $\begin{array}{c}\text { Ano de } \\
\mathbf{2 0 1 7}\end{array}$ & $\begin{array}{c}\text { Ano de } \\
\mathbf{2 0 1 8}\end{array}$ \\
\hline Perinatais (FM, NM, RN) & 1 & 1 & 4 & 3 \\
\hline $\begin{array}{l}\text { Crianças/Adolescentes } \\
\text { até 19 anos }\end{array}$ & 0 & 1 & 2 & 3 \\
\hline Adultos & 13 & 16 & 17 & 16 \\
\hline Idosos & 31 & 21 & 22 & 33 \\
\hline Ignorado / em branco & 10 & 19 & 13 & 0 \\
\hline Total & 55 & 58 & 58 & 55 \\
\hline
\end{tabular}

Tabela 19. Distribuição por grupos etários do total de necropsias recusadas pelo SVOI nos anos de 2013, 2014, 2017, 2018 e redestinadas a outros serviços.

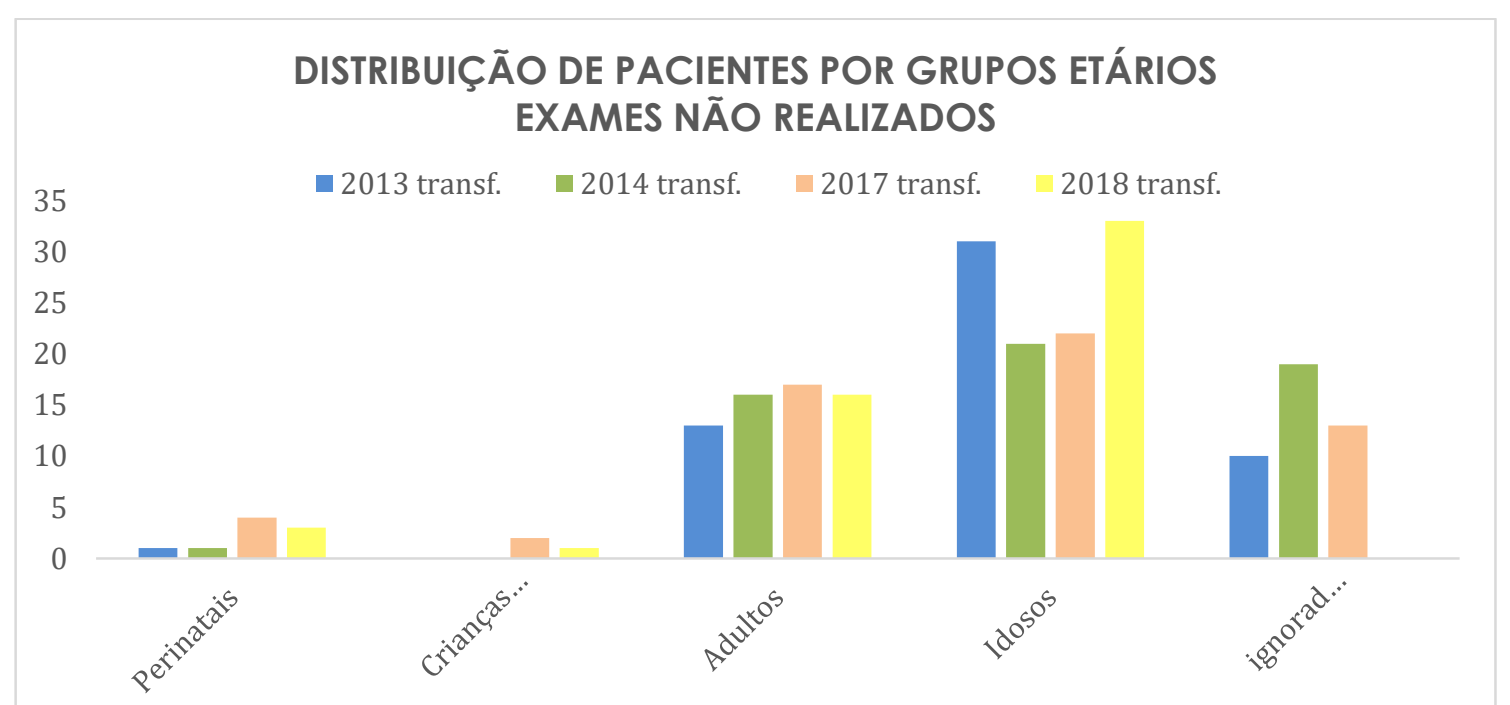

Figura 22. Distribuição por grupos etários do total de necropsias recusadas pelo SVOI nos anos de 
2013, 2014, 2017, 2018 e redestinadas a outros serviços.

\begin{tabular}{|l|c|c|c|c|}
\hline Pacientes Redestinados & $\begin{array}{c}\text { Média } \\
\text { anterior }\end{array}$ & $\begin{array}{c}\text { Média } \\
\text { subsequente }\end{array}$ & Diferença & Teste T \\
\hline Perinatais & 1 & 3,5 & $250 \%$ & 0,0189 \\
\hline $\begin{array}{l}\text { Crianças/Adolescentes } \\
\text { até 19 anos }\end{array}$ & 0,5 & 2,5 & $400 \%$ & 0,0528 \\
\hline Adultos & 14,5 & 16,5 & $13,79 \%$ & 0,1667 \\
\hline Idosos & 26 & 27,5 & $5,77 \%$ & 0,4294 \\
\hline ignorado / em branco & 14,5 & 6,5 & $-55,17 \%$ & 0,2090 \\
\hline Total & 56,5 & 56,5 & $0,00 \%$ & 0,5000 \\
\hline
\end{tabular}

Tabela 20. Médias de necropsias recusadas pelo SVOI e redestinadas a outros serviços nos anos anteriores e subsequentes ao Parecer Consulta, distribuídos por grupos etários.

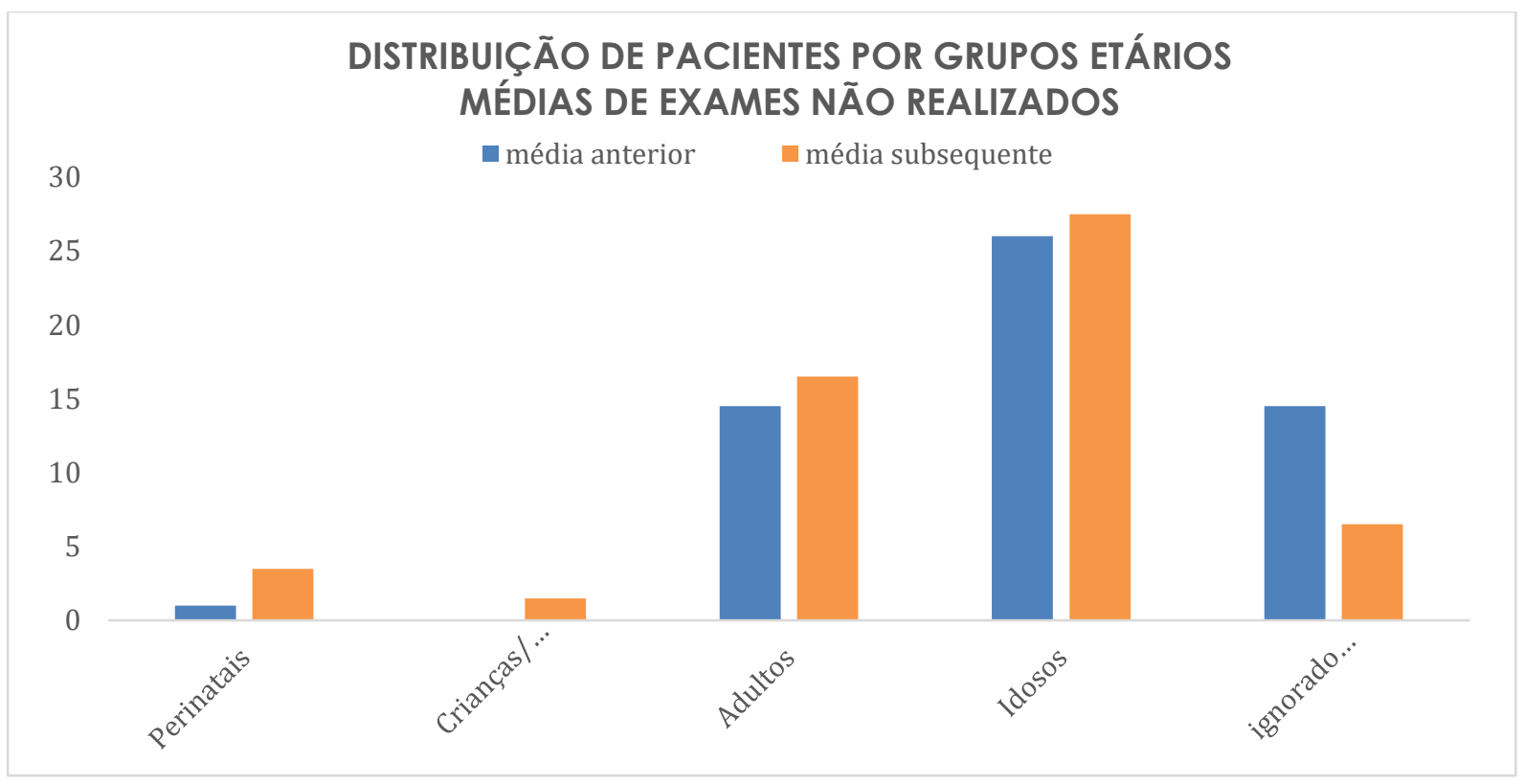

Figura 23. Médias de necropsias recusadas pelo SVOI e redestinadas a outros serviços nos anos anteriores e subsequentes ao Parecer Consulta, distribuídos por grupos etários.

\subsection{Análise de Local de Óbito e Causa Mortis}

A tabela 19 e a figura 22 apresentam os dados referentes ao local de óbito dos cadáveres necropsiados pelo SVOI. São eles: casa de repouso ou Instituição de Longa Permanência (ILP), domicilio, via pública, hospital de financiamento misto (Santas casas e fundações), hospital particular, Unidade Básica de Saúde 
(UBS) ou hospital público, pronto atendimento público, maternidade pública, maternidade particular ou, ainda, outros não especificados no formulário.

$\begin{array}{lcccc} & \text { Ano de } & \text { Ano de } & \text { Ano de } & \text { Ano de } \\ \text { LOCAL DE ÓBITO } & \mathbf{2 0 1 3} & \mathbf{2 0 1 4} & \mathbf{2 0 1 7} & \mathbf{2 0 1 8} \\ \text { Casa de Repouso ou ILP } & 31 & 31 & 38 & 37 \\ \text { Domicilio } & 297 & 295 & 407 & 408 \\ \text { Via Pública } & 7 & 5 & 11 & 5 \\ \text { Hospital de Financiamento Misto } & 212 & 228 & 116 & 110 \\ \text { Hospital Particular } & 83 & 68 & 45 & 34 \\ \text { UBS ou Hospital Público } & 17 & 25 & 13 & 14 \\ \text { Pronto Atendimento publico } & 279 & 260 & 199 & 150 \\ \text { Maternidade Pública } & 24 & 40 & 15 & 11 \\ \text { Maternidade Particular } & 42 & 61 & 9 & 10 \\ \text { Outros } & 16 & 8 & 23 & 11 \\ \text { Total } & \mathbf{1 0 0 8} & \mathbf{1 0 2 1} & \mathbf{8 7 6} & \mathbf{7 9 0}\end{array}$

Tabela 21. Total de necropsias realizadas pelo SVOI nos anos de interesse, distribuídas por local de óbito.

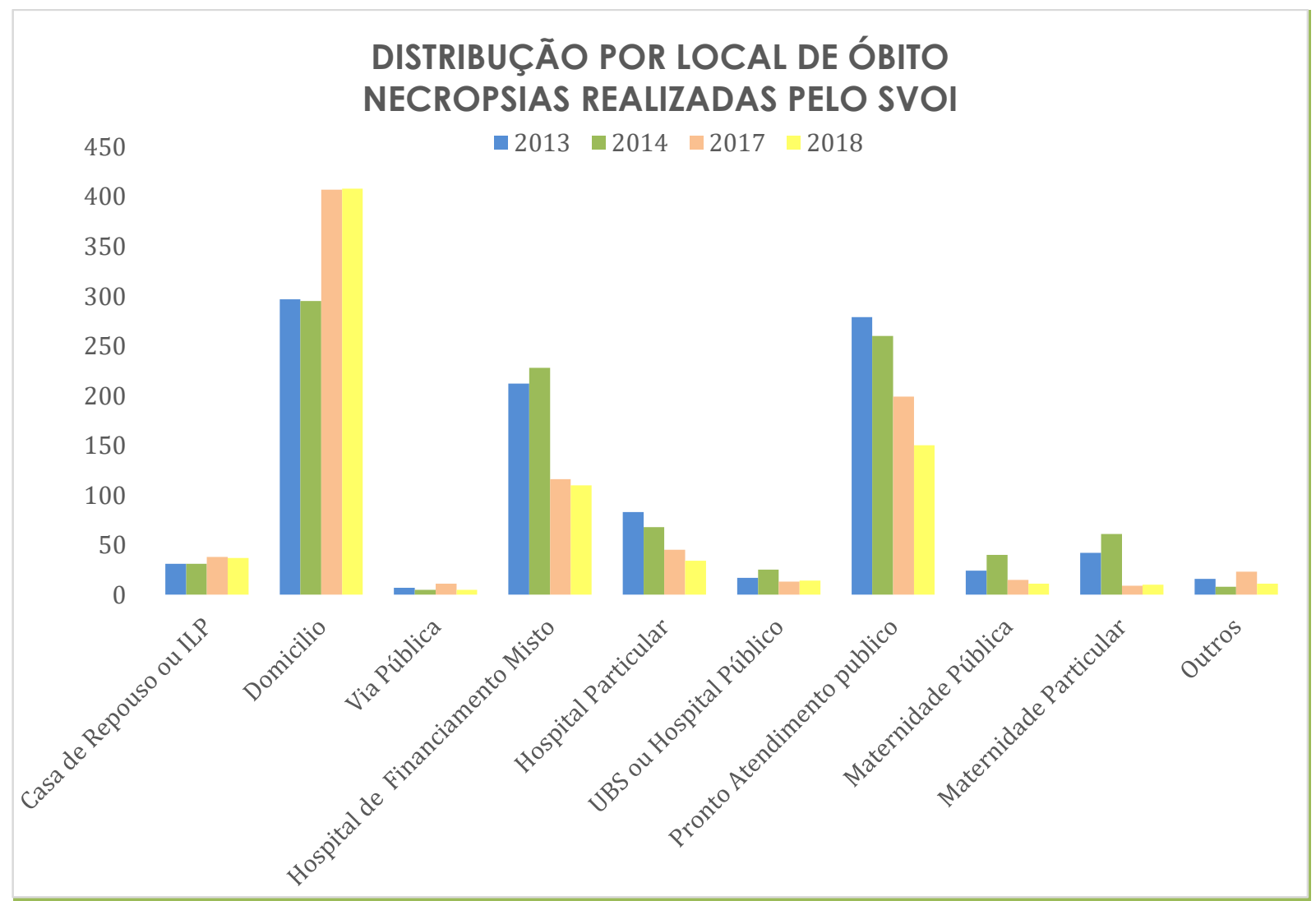

Figura 24. Total de necropsias realizadas pelo SVOI nos anos de interesse, distribuídas por local de 
óbito.

\begin{tabular}{lccccc} 
LOCAL DE ÓBITO & $\begin{array}{c}\text { Média } \\
\text { anterior }\end{array}$ & $\begin{array}{c}\text { Média } \\
\text { subsequente }\end{array}$ & Diferença & Teste T \\
\hline Casa de Repouso ou ILP & 31 & 37,5 & $20,97 \%$ & 0,002933 \\
Domicilio & 296 & 407,5 & $37,67 \%$ & 0,000050 \\
Via Pública & 6 & 8 & $33,33 \%$ & 0,295876 \\
Hospital de Financiamento Misto & 220 & 113 & $-48,64 \%$ & 0,003158 \\
Hospital Particular & 75,5 & 39,5 & $-47,68 \%$ & 0,030364 \\
UBS ou Hospital Público & 21 & 13,5 & $-35,71 \%$ & 0,101941 \\
Pronto Atendimento publico & 269,5 & 174,5 & $-35,25 \%$ & 0,034358 \\
Maternidade Pública & 32 & 13 & $-59,38 \%$ & 0,001781 \\
Maternidade Particular & 51,5 & 9,5 & $-81,55 \%$ & 0,000002 \\
Outros & 12 & 17 & $41,67 \%$ & 0,279887 \\
\hline Total & 1014,5 & 833 & $-17,89 \%$ & 0,026449 \\
\hline
\end{tabular}

Tabela 22. Médias de necropsias realizadas pelo SVOI nos anos anteriores e subsequentes à publicação do Parecer Consulta, distribuídas por local de óbito, salientando a diferença em porcentagem e estatística.

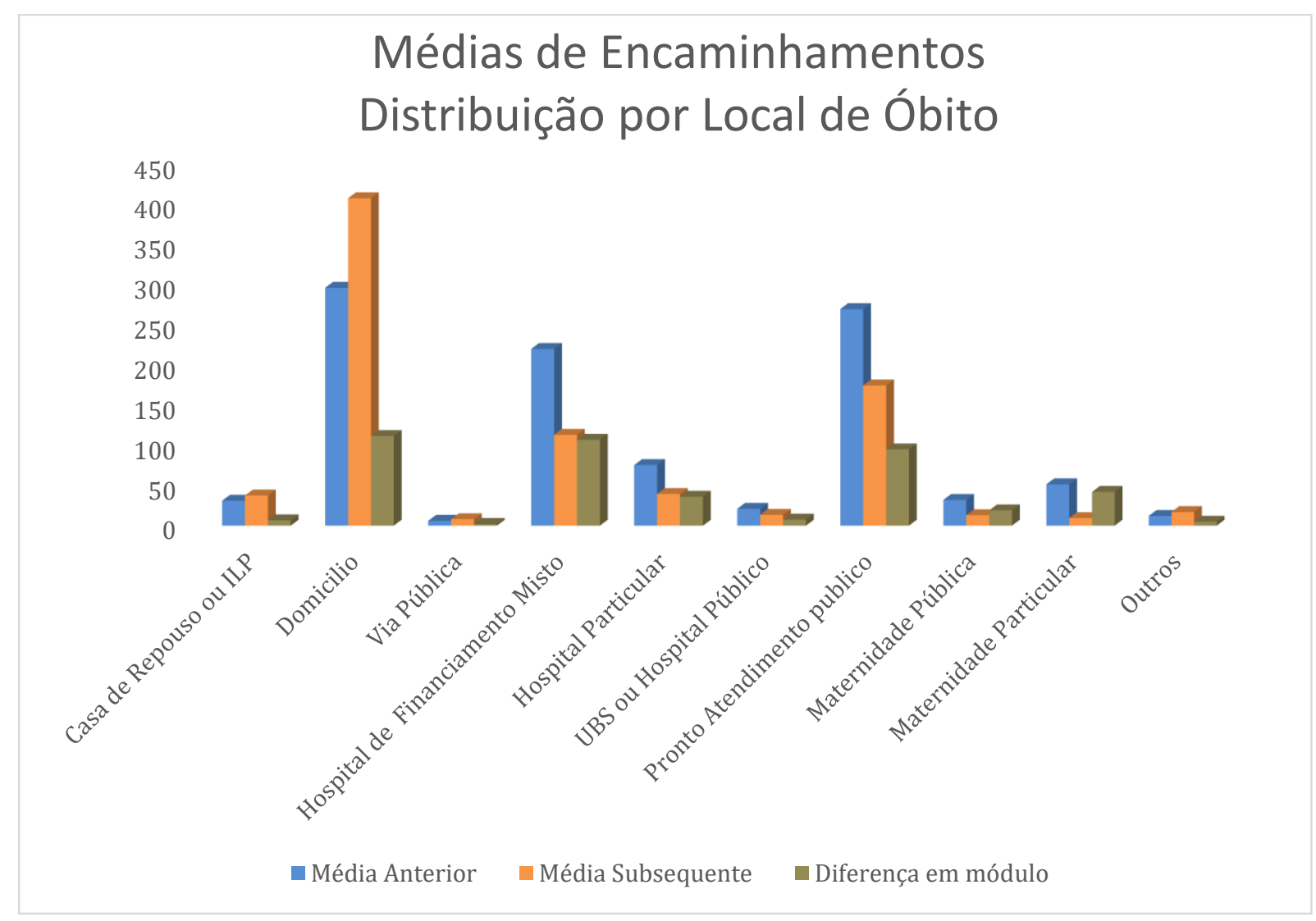

Figura 25. Total de necropsias realizadas pelo SVOI nos anos de interesse, distribuídas por local de óbito.

Com relação aos encaminhamentos feitos por maternidades, nota-se uma 
sazonalidade em nascimentos e óbitos. Assim sendo, a média de encaminhamentos oscila mês a mês. A tabela 21 e a figura 24 apresentam os dados das médias de encaminhamentos feitos por maternidades públicas e particulares em anos anteriores e subsequentes à publicação do Parecer Consulta.

$\begin{array}{lcccc}\text { Janeiro } & \begin{array}{c}\text { Média Anterior } \\ \text { Pública }\end{array} & \begin{array}{c}\text { Média } \\ \text { Subsequente - } \\ \text { Pública }\end{array} & \begin{array}{c}\text { Média Anterior } \\ \text { - Particular }\end{array} & \begin{array}{c}\text { Média } \\ \text { Subsequente - } \\ \text { Particular }\end{array} \\ \text { Fevereiro } & 5,5 & 1,5 & 7 & 0,5 \\ \text { Março } & 2 & 2 & 4 & 2,5 \\ \text { Abril } & 2,5 & 2 & 3,5 & 2,5 \\ \text { Maio } & 5 & 1,5 & 2,5 & 0 \\ \text { Junho } & 1,5 & 0,5 & 2,5 & 1 \\ \text { Julho } & 1 & 0,5 & 5,5 & 0,5 \\ \text { Agosto } & 1 & 0 & 7 & 0 \\ \text { Setembro } & 1,5 & 0,5 & 3,5 & 0,5 \\ \text { Outubro } & 2,5 & 1 & 1 & 0 \\ \text { Novembro } & 2,5 & 2,5 & 5,5 & 0,5 \\ \text { Dezembro } & 3 & 0,5 & 5 & 1 \\ & 4 & 0,5 & 4,5 & 0,5\end{array}$

Tabela 23. Médias de encaminhamentos feitos por maternidades públicas e particulares em anos anteriores e subsequentes à publicação do Parecer Consulta.

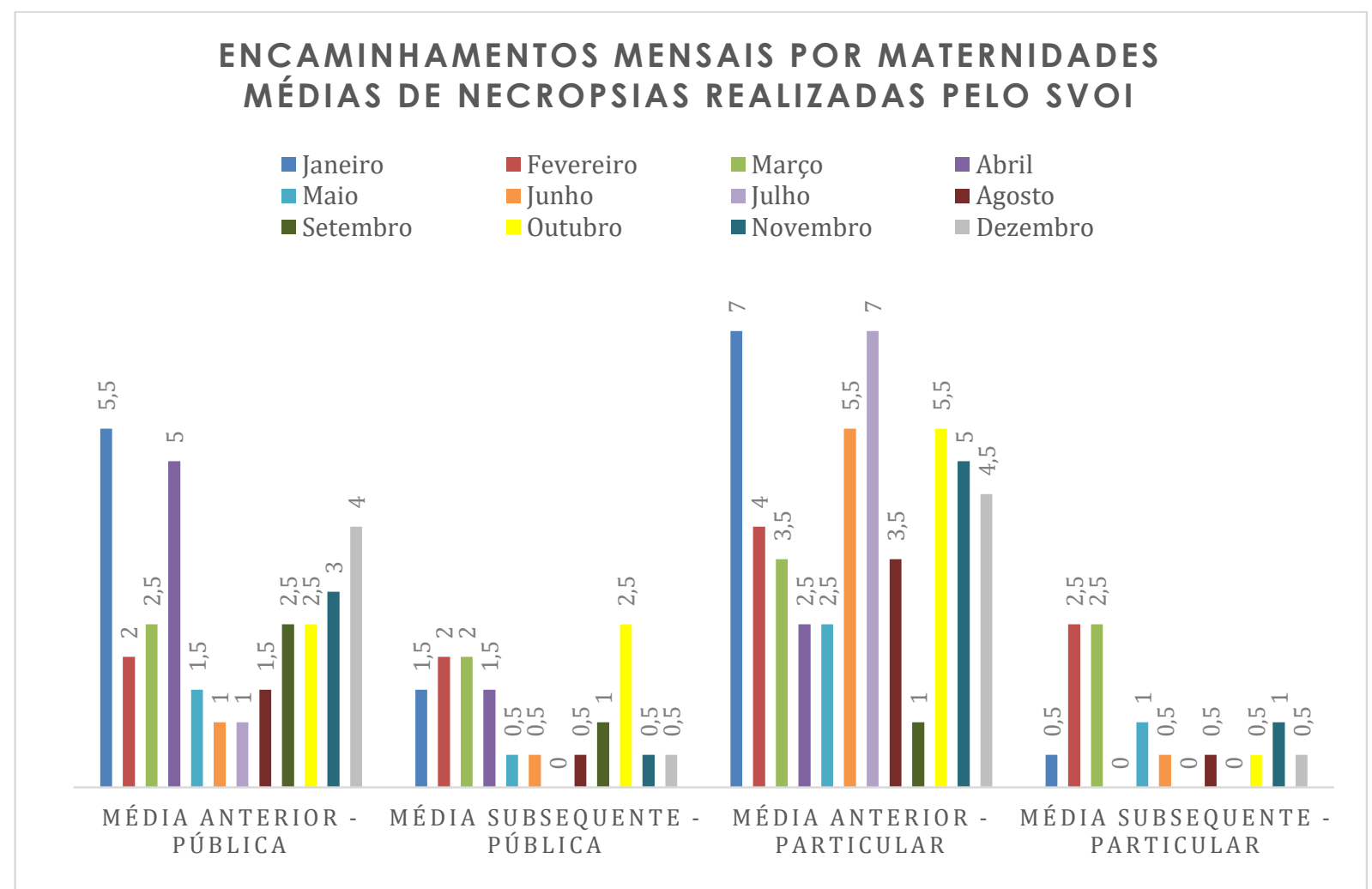

Figura 26. Médias de necropsias realizadas pelo SVOI com encaminhamentos feitos por maternidades públicas e particulares em anos anteriores e subsequentes ao Parecer Consulta. 
Quanto às causas de morte, foram analisadas as causas terminais (imediatas) de morte constantes na Declaração de Óbito das 3695 necropsias realizadas ao longo dos 4 anos de estudo e agrupadas segundo categorias da Classificação Internacional de Doenças e Problemas Relacionados à Saúde Décima Edição (CID-10) e outras que se fizeram necessárias ao longo do estudo, como demonstrado na tabela 21 e na figura 25 .

\begin{tabular}{|l|c|c|c|c|}
\cline { 2 - 5 } \multicolumn{1}{c|}{} & \multicolumn{2}{c|}{ Anterior } & \multicolumn{2}{c|}{ Subsequente } \\
\cline { 2 - 5 } \multicolumn{1}{c|}{} & 2013 & 2014 & 2017 & 2018 \\
\hline $\begin{array}{l}\text { Causa de Morte Indeterminada - exceto } \\
\text { perinatais }\end{array}$ & 20 & 11 & 19 & 13 \\
\hline $\begin{array}{l}\text { Diagnósticos Incongruentes ou de } \\
\text { Preenchimento Equivocado (DIPE) }\end{array}$ & 33 & 38 & 44 & 24 \\
\hline Doenças do aparelho circulatório & 346 & 310 & 312 & 294 \\
\hline Neoplasias & 16 & 15 & 12 & 12 \\
\hline Óbitos Fetais ou Perinatais & 81 & 114 & 18 & 14 \\
\hline Doenças do Aparelho Respiratório & 345 & 383 & 372 & 351 \\
\hline $\begin{array}{l}\text { Doenças Infecciosas e Parasitárias } \\
\text { (sistêmicas ou sem menção de local) }\end{array}$ & 122 & 116 & 72 & 53 \\
\hline Endócrinas, nutricionais e metabólicas & 2 & 5 & 0 & 3 \\
\hline Doenças do Aparelho Digestivo & 22 & 14 & 17 & 14 \\
\hline Doenças do Sistema Nervoso & 15 & 13 & 6 & 9 \\
\hline Doenças do Sistema Urinário & 6 & 2 & 4 & 3 \\
\hline Total & $\mathbf{1 0 0 8}$ & $\mathbf{1 0 2 1}$ & $\mathbf{8 7 6}$ & $\mathbf{7 9 0}$ \\
\hline
\end{tabular}

Tabela 24. Total de necropsias realizadas nos anos de interesse, distribuídas por categorias relacionadas às causas terminais de morte constantes na Declaração de Óbito. 


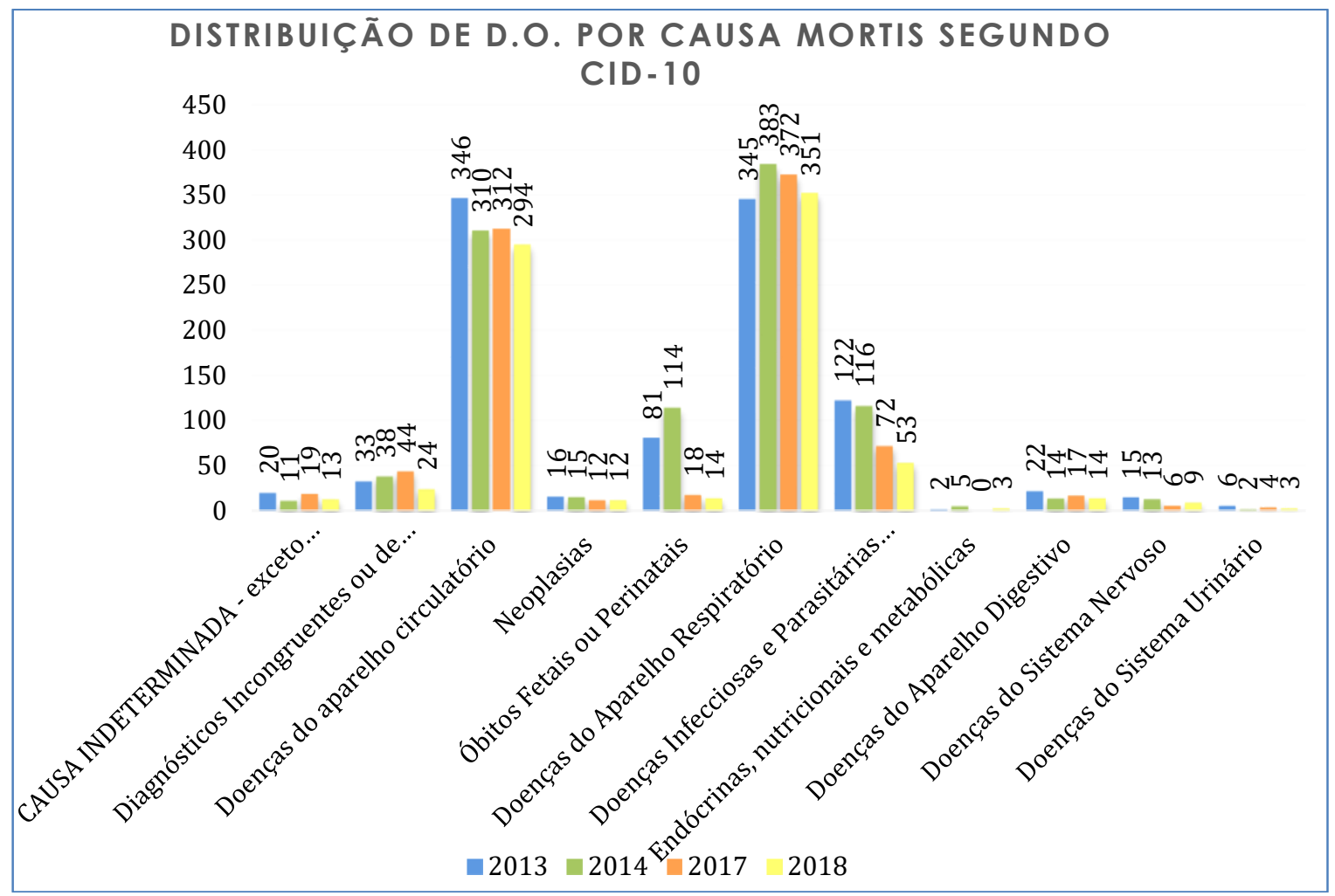

Figura 27. Total de necropsias realizadas nos anos de interesse, distribuídas por categorias relacionadas às causas terminais de morte constantes na Declaração de Óbito.

\begin{tabular}{|l|c|c|c|c|}
\cline { 2 - 4 } \multicolumn{1}{l|}{} & $\begin{array}{c}\text { Média } \\
\text { anterior }\end{array}$ & $\begin{array}{c}\text { Média } \\
\text { subsequente }\end{array}$ & Diferença & TESTE T \\
\hline $\begin{array}{l}\text { CAUSA DE MORTE INDETERMINADA - } \\
\text { exceto perinatais }\end{array}$ & 15,5 & 16 & $3,23 \%$ & 0,4674 \\
\hline $\begin{array}{l}\text { Diagnósticos Incongruentes ou de } \\
\text { Preenchimento Equivocado (DIPE) }\end{array}$ & 35,5 & 34 & $-4,23 \%$ & 0,4488 \\
\hline Doenças do aparelho circulatório & 328 & 303 & $-7,62 \%$ & 0,17 \\
\hline Neoplasias & 15,5 & 12 & $-22,58 \%$ & 0,0099 \\
\hline Óbitos Fetais ou Perinatais & 97,5 & 16 & $-83,59 \%$ & 0,0196 \\
\hline Doenças do Aparelho Respiratório & 364 & 361,5 & $-0,69 \%$ & 0,4594 \\
\hline $\begin{array}{l}\text { Doenças Infecciosas e Parasitárias } \\
\text { (sistêmicas ou sem menção de local) }\end{array}$ & 119 & 62,5 & $-47,48 \%$ & 0,0149 \\
\hline Endócrinas, nutricionais e metabólicas & 3,5 & 1,5 & $-57,14 \%$ & 0,2226 \\
\hline Doenças do Aparelho Digestivo & 18 & 15,5 & $-13,89 \%$ & 0,3088 \\
\hline Doenças do Sistema Nervoso & 14 & 7,5 & $-46,43 \%$ & 0,0345 \\
\hline Doenças do Sistema Urinário & 4 & 3,5 & $-12,50 \%$ & 0,4155 \\
\hline Total & 1014,5 & 833 & $-17,89 \%$ & 0,0264 \\
\hline
\end{tabular}

Tabela 25. Médias de necropsias realizadas nos anos de interesse, distribuídas por categorias relacionadas às causas terminais de morte constantes na Declaração de Óbito. 


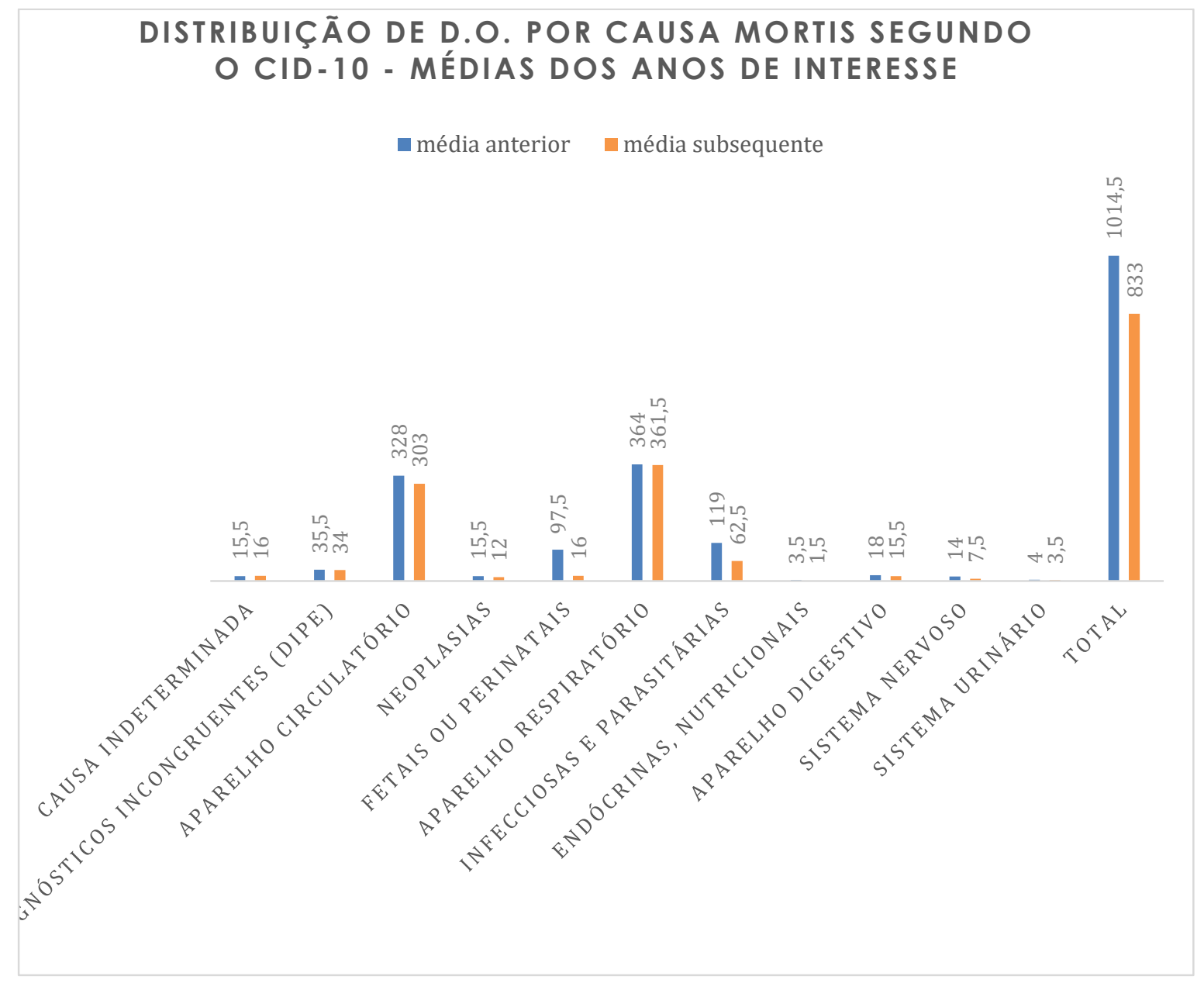

Figura 28. Médias de necropsias realizadas nos anos de interesse, distribuídas por categorias relacionadas às causas terminais de morte constantes na Declaração de Óbito.

A tabela 26 apresenta as categorias que tiveram diferença estatística nas médias de ocorrência nos anos anteriores e subsequentes ao Parecer Consulta, sendo elas: neoplasias, óbitos fetais ou perinatais, doenças infecciosas ou parasitárias, doenças do sistema nervoso.

\begin{tabular}{|l|c|c|c|}
\cline { 2 - 4 } \multicolumn{1}{l|}{} & $\begin{array}{c}\text { média } \\
\text { anterior }\end{array}$ & $\begin{array}{c}\text { média } \\
\text { subsequente }\end{array}$ & TESTE T \\
\hline Neoplasias & 15,5 & 12 & 0,0099 \\
\hline Óbitos Fetais ou Perinatais & 97,5 & 16 & 0,0196 \\
\hline Doenças Infecciosas ou Parasitárias & 119 & 62,5 & 0,0149 \\
\hline Doenças do Sistema Nervoso & 14 & 7,5 & 0,0345 \\
\hline Total & $\mathbf{1 0 1 4 , 5}$ & $\mathbf{8 3 3}$ & $\mathbf{0 , 0 2 6 4}$ \\
\hline
\end{tabular}

Tabela 26. Médias das categorias da CID-10 com redução significativa comparando os anos anteriores e subsequentes ao Parecer Consulta. 


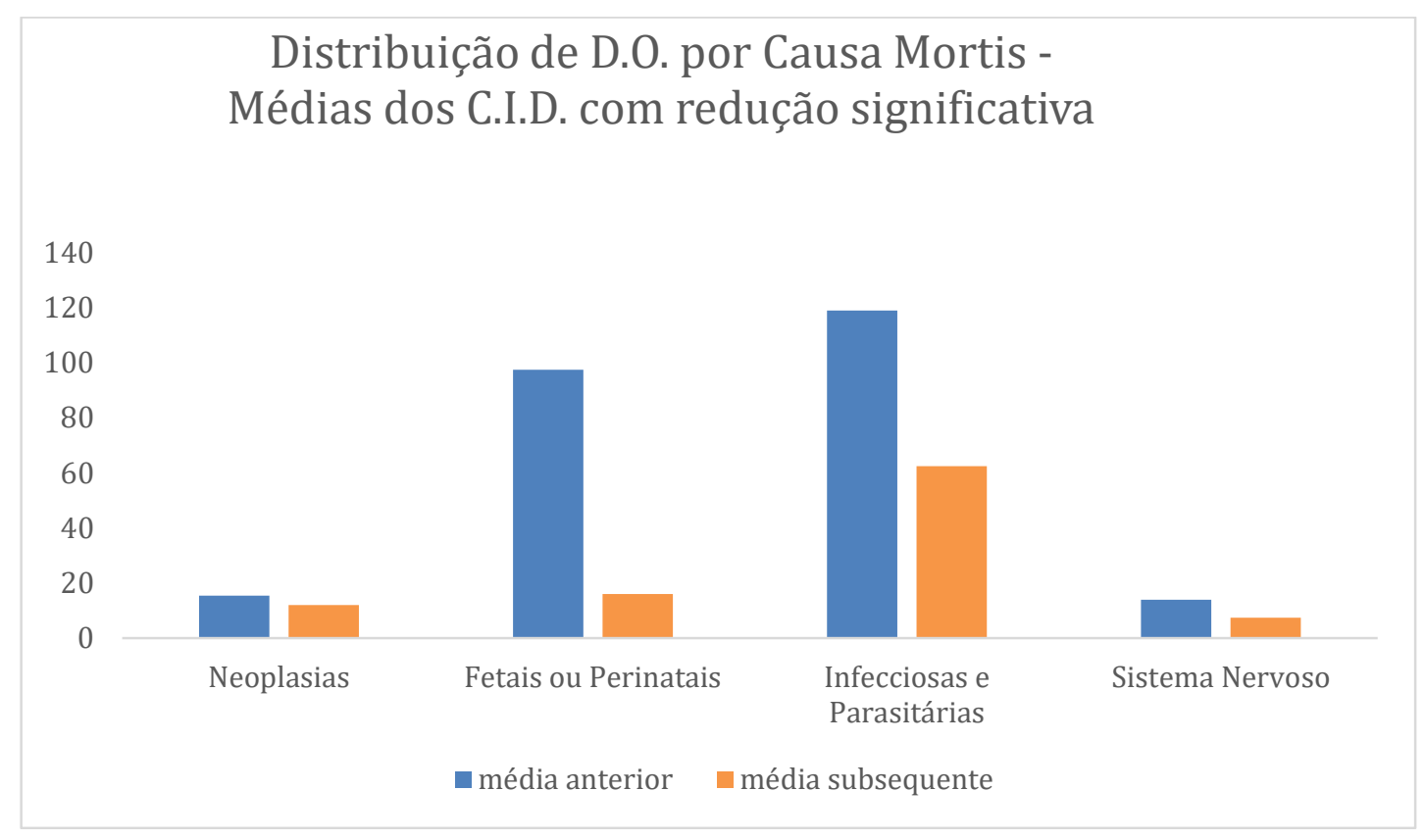

Figura 29. Médias das categorias da CID-10 com redução significativa comparando os anos anteriores e subsequentes ao Parecer Consulta. 


\section{Discussão}

Cabe ao SVOI realizar os exames necroscópicos de pessoas falecidas no município de Ribeirão Preto. Como essas pessoas nem sempre são moradores dessa cidade, o número total de óbitos ocorridos no município segundo o DATASUS é maior do que o número de munícipes falecidos, o que se deve principalmente à rede hospitalar ser referência para a macrorregião de saúde. $O$ total de encaminhamentos e de necropsias realizadas é significativamente diferente comparando-se os anos anteriores e subsequentes ao Parecer Consulta, com diferenças intragrupo.

A média de encaminhamentos dos anos anteriores ao PC de 1071 pacientes caiu para 889,5 nos anos subsequentes, e a média de necropsias realizadas pelo SVOI caiu de 1014,5 para 833, representando diminuições de $16,95 \%$ e 17,89\% respectivamente. Como mostra a Tabela 2, o teste T de 0,026449 indica que essa queda nas médias de necropsias realizadas é significativa. A média de pacientes redestinados foi igual nos dois períodos, 56,5 casos, mas com diferenças significativas intragrupos.

A queda no número de encaminhamentos e de necropsias realizadas antes e depois da publicação do Parecer Consulta tornam-se muito mais expressivos ao verificarmos que houve aumento tanto do número de habitantes de Ribeirão Preto quanto dos óbitos ocorridos na cidade. Ainda, ao compararmos os anos de 2017 e 2018 vemos números menores no último, o que pode indicar uma tendência de queda para anos consecutivos com o aprendizado oriundo da implementação e do reforço das novas regras. Há de se notar também o surgimento das devoluções de casos ao hospital de origem, esporádicas nos anos anteriores ao PC e consolidadas nos anos subsequentes.

Quanto à diminuição de transferências para o IML, não é possível inferir que haja influência do PC sobre a média de casos, sendo necessária para essa conclusão a análise das demais variáveis relacionadas à diminuição de óbitos por causa externa no período e os procedimentos inerentes à polícia civil e científica.

A seguir discutimos as características da população de pacientes necropsiados pelo SVOI. 


\subsection{Características Sociodemográficas dos pacientes examinados}

Quanto ao sexo dos indivíduos, a proporção se manteve estável nos anos de interesse deste estudo, em torno de $55 \%$ de pacientes homens e $45 \%$ de pacientes mulheres em cada ano, com raros casos de pacientes de sexo indeterminado, todos de óbitos fetais.

Embora tenha sido feita a análise sobre cor da pele dos pacientes examinados, pode haver divergência entre o preenchimento do SVOI e autodesignação da pessoa no censo do IBGE. Isso porque, diferentemente do censo, o preenchimento desse campo no SVOI é examinador-dependente. Assim, não podemos afirmar que a diferença em relação à população municipal, de $8 \%$ a mais de pacientes brancos ou a menos de pacientes pretos e pardos, tenha alguma implicação demográfica ou de repercussão social que signifique que as pessoas são mais ou menos encaminhadas para necropsia de acordo com sua cor de pele. Uma outra possibilidade é a de que a população hospitalizada varie demograficamente da população saudável ou não hospitalizada.

Observando as tabelas de distribuição por idade é perceptível a redução do número de pacientes encaminhados em quase todas as faixas etárias, com redução expressiva em algumas (Feto Morto, Natimorto, Recém-nascido, 1-12 meses, 60 a 69 anos) e mantendo valores próximos nas outras. Apenas na faixa etária de 90 a 105 anos houve aumento do número de encaminhamentos. 0 mesmo ocorre na relação de necropsias realizadas. Podemos ver na tabela 12 que a faixa etária de 90 a 105 anos mostra aumento de $31,25 \%$, de necropsias realizadas pelo SVOI, enquanto houve queda em todas as outras faixas.

Para fins de melhor visualização desse fato, reagrupamos as categorias de faixa etária conforme as tabelas 15 a 20 e figuras 18 a 23. Após reagrupadas, todas as categorias relativas à infância tiveram redução com significância estatística, a saber: perinatais (fetos mortos, natimortos, recém-nascidos), até 1 ano (excluindo os recém-nascidos), crianças/adolescentes. Entre adultos e idosos, apenas a faixa etária de 60 a 69 anos foi significativamente menor após análise estatística. 
A diminuição de necropsias realizadas nas faixas etárias relativas à infância se justifica pela maior ocorrência de óbitos intra-hospitalares de bebês e crianças, diferentemente de outras faixas etárias em que grande parte dos óbitos ocorre em domicílio. Os casos de óbito fetal e natimortos (cuja distinção é realizada pelo obstetra), e óbitos perinatais em geral, comumente são oriundos de partos intrahospitalares; crianças doentes costumam ter acompanhamento médico e prontuários extensos, com diagnóstico definido ou em investigação. O Parecer Consulta abrange esses casos de paciente em tratamento com diagnóstico definido, e prevê a recusa do pedido de necropsia pelo SVOI e a devolução do paciente ao hospital de origem. Outrossim, a morte de crianças previamente hígidas em domicílio deve ser investigada pela polícia como morte suspeita.

\subsection{Local de Óbito}

A tabela 22 apresenta a análise estatística de local de óbito dos pacientes necropsiados pelo SVOI, comparando a média anterior ao Parecer Consulta e a média subsequente à publicação do mesmo.

Justifica-se o aumento de necropsias em pacientes falecidos em domicílio $(+37,67 \%$, ) e Instituições de Longa Permanência (+20,97\%) após a publicação do PC por ser tratarem de óbito sem assistência médica, pelo fluxo da constatação do óbito. Também é possível que o aumento da mortalidade geral em Ribeirão Preto, de 13,77\% a mais na média de óbitos por causas naturais (710 indivíduos), tenha influência direta sobre esse número, e que a diminuição de 17,89\% no número de necropsias realizadas tenha se sobreposto a esse aumento de $13,77 \%$ na mortalidade para as demais categorias, de forma que apenas visualizamos o aumento naquelas que não sofreram efeito direto do PC.

Ao estudar os erros de preenchimento em Declarações de Óbito, Silva et al. (2013) concluíram que seus resultados demonstravam negligência no preenchimento ou até mesmo o desconhecimento da fisiopatogenia das doenças. O presente estudo aponta, mais do que isso, a falta de conhecimento do indivíduo enfermo. Uma outra hipótese para o aumento do encaminhamento de pacientes falecidos em domicílio, além do aumento geral da mortalidade, é a má estruturação da estratégia de saúde da família (ESF) do município, que 
embora implantada não abrange a totalidade dos bairros e nem é estruturada de forma a absorver a demanda espontânea, redirecionando os pacientes às unidades de pronto atendimento (UPA), de onde dificilmente o médico plantonista contactará o médico de família para obter informações relativas ao paciente, mesmo que para auxiliar a certificar óbitos de pacientes falecidos no horário de funcionamento dos ESF. Lucena et al (2014) analisaram o preenchimento das DO em um hospital universitário da região sul do Brasil e encontraram 50,18\% com preenchimento incompleto, sendo que, dos médicos participantes, $34,14 \%$ referiram dificuldade no preenchimento de causa mortis dos pacientes falecidos sem assistência médica.

O fluxo de constatação de óbito em domicílio ou Instituição de Longa Permanência (ILP) costuma se dar da seguinte forma: 1- familiar ou cuidador telefona para o SAMU (Serviço de Atendimento Móvel de Urgência) informando que o paciente foi encontrado arresponsivo ou apresentou alteração súbita no nível de consciência; 2- O SAMU dirige-se ao local e transporta o paciente a uma unidade de pronto atendimento. 3- Após constatação do óbito ou tentativa ineficaz de reanimação do paciente, o médico plantonista conversa com familiares e/ou cuidadores e obtém informações para o preenchimento da Declaração de Óbito ou encaminha o paciente ao SVO de sua região. O médico pode solicitar arquivos e exames anteriores do paciente para auxiliar no diagnóstico de causa mortis, e também contactar o médico de família responsável por aquele paciente para obtenção de informações ou até solicitar que o mesmo compareça ao serviço para preenchimento da $D O$, já que o artigo 115 do Código de Ética Médica determina que "é vedado ao médico deixar de atestar óbito de paciente ao qual vinha prestando assistência, exceto quando houver indícios de morte violenta",

Os motivo da falta de comunicação entre médicos, do preenchimento inadequado das DOs e do encaminhamento incorreto de corpos aos SVOs variam entre extremos: do desejo de não impor à família mais uma etapa burocrática ante o seu luto, preenchendo a DO com termos vagos ou com causa indeterminada de morte; do medo do médico de preencher incorretamente o documento e assim destinar o corpo ao SVO; e, principalmente, da má estruturação da ESF regionais, também com médicos plantonistas que não 
conhecem os pacientes ou têm muitas consultas agendadas por hora, limitando sua disponibilidade.

A realização de necropsias de pacientes falecidos em via pública se dá após avaliação do IML. Em Ribeirão Preto as duas instituições estão locadas no mesmo edifício, e uma vez não encontrada lesão traumática ou evidência de morte por causa externa é solicitada a presença de médico ou médica do SVOI para conclusão do exame e preenchimento de formulário específico de transferência do caso e da Declaração de Óbito. Sobre esse tema, Mendo et al. (2019) exploraram as implicações de haver sistemas separados de verificação de óbito no Brasil pela presunção de causa natural ou externa antes da necropsia, que acarretam em transferências entre instituições.

Ainda na tabela 22 vemos a redução de todos os encaminhamentos hospitalares, sendo que em apenas uma categoria não houve significância estatística, a de hospitais públicos e Unidades Básicas de Saúde (UBS). Nessa categoria, apesar da redução de $-35,71 \%$, há dois vieses: 1- O maior hospital público regional, O Hospital das Clínicas da Faculdade de Medicina de Ribeirão Preto, é um hospital terciário com serviço de patologia e necropsias próprio (SERPAT), e encaminha ao SVOI apenas pacientes falecidos pouco após entrada na Unidade de Emergência, portanto sem diagnóstico e com pouco tempo de assistência médica, e raros casos de pacientes ou acompanhantes falecidos dentro das premissas do hospital mas aguardando por consulta ambulatorial, ou seja, não internados; 2- Pode-se inferir que óbitos ocorridos em UBS ocorrem em contexto de urgência, em que o paciente em situação de mal súbito ou piora clínica dirige-se ou é levado por familiar ao local de atendimento médico mais próximo em vez de acionar o SAMU, mas esse conhecimento vem da atuação médica de nossa equipe tanto em Unidades Básicas de Saúde quanto em Unidades de Pronto Atendimento. Portanto, por não serem avaliados os prontuários médicos completos de cada paciente deste estudo, mantivemos essa categoria de análise da forma apresentada.

O grupo Hospital de Financiamento Misto contém as instituições filantrópicas, fundações e hospitais de universidades privadas, nos quais são atendidos tanto pacientes conveniados com planos de saúde, pacientes SUS e paciente atendidos gratuitamente em atividades de ensino e pesquisa dos 
hospitais-escola. Nos hospitais e maternidade particulares são atendidos apenas pacientes conveniados e particulares, e nos hospitais e maternidade públicos são atendidos em sua maioria pacientes SUS, ainda que haja a possibilidade de se pagar por acomodações e serviços diferenciados.

Os encaminhamentos e necropsias de pacientes provenientes de Unidades de Pronto Atendimento públicas representaram a categoria de menor redução entre todas, mas ainda assim com impacto sobre o total, com 35,25\% a menos de exames realizados. Os Hospitais de Financiamento Misto e Hospitais Particulares foram responsáveis por grande parte da queda no número de necropsias, tendo redução de $48,64 \%$ e $47,68 \%$, respectivamente.

Corroborando com as análises de faixa etária, a redução mais expressiva ao compararmos as médias dos anos anteriores ao Parecer Consulta com os anos subsequentes ao Parecer Consulta se deu de maternidades, com 59,38\% na média da maternidade pública e de $81,55 \%$ da maternidade privada, esta com índice de significância do teste T igual a 0,000002.

Por fim, o grupo Outros carece de informações para análise precisa por configurar descrição vaga de local de óbito e que, apesar da diferença de médias, não tem impacto considerável no total anual de pacientes.

\subsection{Causa Mortis}

Para a análise de Causa Mortis fez-se necessária a subdivisão segundo o CID-10, que apesar de ser atualmente usado também para classificação de doenças de pacientes vivos tem sua origem na Lista Internacional de Causas de Morte (International List of Causes of Death) (LAURENTI, 1991; NAGHAVI et al., 2010). Dessa forma, infecções com local definido, como pneumonia ou meningite, foram agrupadas segundo aparelho ou sistema acometido, respectivamente doenças do aparelho respiratório e doenças do sistema nervoso. As causas de morte descritas como "sepse", "septicemia" ou "choque séptico" foram, assim, classificadas na família A- doenças infecciosas e parasitárias. Nas necropsias analisadas quanto à causa imediata (terminal) de 
morte, quase todos os diagnósticos atribuídos a doenças infecciosas e parasitárias foram de sepse, choque séptico ou septicemia, com a exceção de dois casos da Síndrome de Waterhouse-Friderichsen em anos distintos, um caso de escara infectada, um de erisipela e um de tuberculose disseminada. Certamente nos outros 358 casos de sepse e correlatos repetem-se esses diagnósticos, mas divididos entre os campos 1-B, 1-C e 1-D, ou seja, a correlação diagnóstica de moléstia principal (causa básica) e causas intermediárias, que não foram analisados no presente estudo.

Foram analisadas as causas terminais de morte das 3695 necropsias realizadas ao longo dos 4 anos de estudo. As categorias com maior número de óbitos são, em primeiro lugar, Doenças do Aparelho Respiratório, com 1451 pacientes; em segundo lugar Doenças do aparelho circulatório, com 1262 pacientes; em terceiro Doenças Infecciosas e Parasitárias, com 363 pacientes; e em quarto Óbitos Fetais ou Perinatais, com 227 pacientes. Curiosamente, em quinto lugar com mais diagnósticos está o grupo DIPE, criado por nossa equipe para designar os Diagnósticos Incongruentes ou de Preenchimento Equivocado (DIPE), com 139 pacientes, seguido pelo grupo Causa Indeterminada de Morte exceto perinatais, com 63 no total.

Analisando as médias anteriores e subsequentes ao PC, houve redução de pacientes necropsiados em todas as categorias, sendo estatisticamente significativas para os Óbitos Fetais ou Perinatais, Doenças Infecciosas e Parasitárias, Doenças do Sistema Nervoso e Neoplasias.

A categoria com maior redução de exames foi a de óbitos fetais ou perinatais, com queda de 83,59\% necropsias realizadas, e média 81,5 pacientes a menos. A explicação para isso é a mesma da distribuição por faixa etária, uma vez que em Ribeirão Preto os partos são realizados, em sua maioria, em ambiente intra-hospitalar, com assistência médica e causa conhecida ou presumida. As declarações de óbito preenchidas no SVO para natimortos e fetos mortos são vagas, inespecíficas e redundantes, e têm com causa terminal de morte quase sempre "anoxia intrauterina" ou "óbito fetal de causa indeterminada", quando não com termos advindos de informações clínicas, como descolamento de placenta. O preenchimento dessas DO por médico Obstetra ou plantonista que assistiu o parto forneceria dados precisos e úteis para a Vigilância epidemiológica 
municipal e nacional através do DATASUS. O Ministério da Saúde e as Secretarias de Saúde estaduais e municipais pautam suas políticas públicas de saúde nas informações de mortalidade, de nascidos vivos e de óbitos materno-infantis evitáveis, de forma que Declarações de Óbito com a mesma causa terminal de morte fornecem pouca ou nenhuma informação para o Estado. Um exemplo de como esse dado poderia gerar novas políticas públicas de saúde é o diagnóstico de acretismo placentário, que se estiver se elevando nos índices de mortalidade materno-infantil levaria à modificação do protocolo de pré-natal, instituindo a realização de uma ultrassonografia adicional no programa de acompanhamento pré-natal (D'ANTONIO et al, 2018; CLODE et al, 2016; JAUNIAUX et al, 2019; HALL et al, 2014).

A explicação sobre diagnóstico conhecido é válida para os demais casos com redução nos encaminhamentos. Isso por ser visto nas justificativas de devolução de pacientes ao hospital, uma vez que todos os casos devolvidos eram de pacientes internados com diagnósticos definidos. Os seguintes exemplos foram retirados de relatórios reais dos anos de 2017 e 2018: - morte com assistência médica; existência de diagnósticos suficientes para preenchimento da DO; paciente com 44 dias de internação, com vários diagnósticos já estabelecidos e exames complementares feitos; paciente estava internada e recebeu tratamento; paciente assistido com causas de morte definidas.

Com a queda dos encaminhamentos provenientes de hospitais e a redução significativa dos casos de óbitos fetais ou perinatais, doenças infecciosas ou parasitárias, doenças do sistema nervoso e neoplasias, podemos inferir que o aprendizado oriundo da implementação e do reforço das novas regras levou à diminuição de encaminhamento de casos com moléstia principal conhecida em internação hospitalar. A diminuição média de pacientes necropsiados que vieram a óbito por sepse de foco definido é de 56,5, estando atrás apenas dos 81,5 perinatais. Juntos esses dois grupos compõe a maior parte dos 181,5 pacientes a menos na média anual do SVOI.

Quanto a alguns diagnósticos, cabe uma análise simples entre os anos de 2017 e 2018. Os pacientes de óbito fetal ou perinatal tiveram redução de $22,22 \%$ de 2017 para 2018, e entre os de Sepse, choque séptico e septicemia a redução foi de $26,39 \%$. Esses dados são relevantes pois apontam para a maior fonte de 
encaminhamentos desnecessários, já que total de necropsias de 2018 foi 9,82 \% menor que o de 2017, de 876 para 790 pacientes.

Outro dado relevante foi a diminuição de 45,45 \% dos Diagnósticos Incongruentes ou de Preenchimento Equivocado (DIPE), de 44 para 24 pacientes. Esse dado mostra o aprendizado não só dos profissionais médicos atuantes nos hospitais de Ribeirão Preto como um esforço da própria equipe do SVOI em evitar os chamados Garbage Codes.

\subsection{Diagnósticos Incongruentes ou de Preenchimento Equivocado (DIPE)}

A função dos sistemas de informação de saúde pública é prover a comunidade com informações para guiar seus programas (Naghavi, 2010). No Brasil temos um sistema abrangente, o DATASUS, composto por sistemas menores para simplificação do acesso - como o SIM e o SINASC. A completude dos dados de mortalidade é fundamental para o estudo epidemiológico e o desenvolvimento de políticas públicas de saúde, nacionais, estaduais e municipais. Diversos autores abordaram a incompletude e os erros de preenchimento das declarações de óbito na última década, mostrando que esse tema é atual e necessário. Silva et al. (SILVA, 2013) encontraram altos índices de equívocos no preenchimento das declarações de Óbito, com 98,7\% apresentando ao menos um erro em seu preenchimento, sendo $71,5 \%$ no campo causa de morte com uso de termos vagos. Os autores atribuem esses erros a falhas de currículo das escolas médicas e carência de projetos de educação médica continuada com foco nesse tema.

Todos os exemplos aqui contidos foram retirados do banco de dados de declarações de óbito do SVOI, Campo Causa Mortis, linha 1-A, e evidenciaram a necessidade de discutir os Garbage Codes ou, em português, Códigos Lixo ou Códigos Garbage. O termo não é novo, tendo sido cunhado por Murray e Lopez em 1996 (NAGHAVI, 2010; MURRAY e LOPEZ). NAGHAVI et al. Defendem o uso de Garbage Codes (GC) para se referir a todas as mortes cuja descrição deveria ser alterada para aumentar a validade da análise para a Saúde Pública, incluindo 
os termos morte súbita, morte natural, senilidade ou até, em sua região, "visita de Deus" (NAGHAVI, 2010). Essa equipe criou e publicou em 2010 uma lista pública de causa de morte, fornecendo uma estrutura abrangente para identificar e redistribuir os óbitos assinalados com GC. A preferência pelo termo em inglês, além do uso internacional, dá-se por soar menos pejorativo, já que muitos médicos podem se sentir pessoalmente ofendidos com a crítica à escolha de termos epidemiologicamente ineficientes de Causa Mortis. Outro termo com o mesmo propósito ainda não se firmou na literatura médica (NAGHAVI, 2010). Contudo, como o presente trabalho para fins de caracterização dos pacientes encaminhados se pauta na análise somente da linha 1-A da DO, de causa imediata ou terminal de morte, não é possível aplicar integralmente o conceito de Garbage Codes. Seria necessária, para tanto, uma avaliação de todos os campos para definição da causa básica de morte, que será tema de um próximo estudo. Para análise da linha 1-A, dada a existência de incongruências no preenchimento, agregamos esses casos em um novo grupo de análise.

A categoria (DIPE) - Diagnósticos Incongruentes ou de Preenchimento Equivocado foi criada para abarcar os diagnósticos intermediários de causa de morte preenchidos no campo de causa terminal (enfisema pulmonar, etilismo crônico, aderências fibróticas interintestinais, nefrosclerose benigna, aterosclerose coronariana), diagnósticos mal definidos e com uso de termos vagos e ineficientes para as estatísticas de saúde (falência de múltiplos órgãos, morte súbita, senilidade, obesidade) ou ainda os sugestivos de causa externa de óbito.

Alguns diagnósticos constantes de laudos emitidos após as necropsias por médicos patologistas não apontavam, de fato, a causa imediata de morte. Como exemplo temos Hemorragia pulmonar, hemorragia torácica ou hemoptise volumosa, preenchidas no campo 1-A, e que não determina se a morte se deu por insuficiência respiratória por hemotórax impedindo a insuflação pulmonar, insuficiência respiratória por afogamento em sangue ou, ainda, por choque hipovolêmico devido à hemorragia. Além dos termos já citados para exemplificar o preenchimento em campo incorreto, temos causas intermediárias de morte que, sem o seu agravamento, não seriam suficientes para levar a óbito, como hipertrofia do ventrículo esquerdo, esclerose múltipla, doença pulmonar 
obstrutiva crônica, esteatose hepática, sequelas de acidente vascular cerebral, cirrose macro nodular e hérnia umbilical encarcerada. Como exemplo de causas mal definidas ou uso de termos vagos, encontramos ainda: desequilíbrio hidroeletrolítico, pneumonia associada, hepatopatia e insuficiência renal agudas possivelmente de etiologia isquêmica. Por fim, os diagnósticos sugestivos de causas externas escritos na linha 1-A foram: broncoaspiração, obstrução laríngea, estado de choque pós cirúrgico, colectomia com ileostomia prévios e pneumonia aspirativa. Além de descrições vagas e em campo incorreto, a história clínica desses pacientes deveria ser motivo de encaminhamento ao IML.

Corroborando nossa asserção de que o diagnóstico de óbitos intrauterinos ou perinatais devem ser feitos por médicos que assistiram o parto, seja plantonista em unidades de pronto atendimento ou obstetra, temos nessa categoria os diagnósticos morte intrauterina, óbito fetal intraútero e maceração fetal, retirados de nossos registros de 2013 e 2014. Maceração Fetal é uma descrição do corpo do feto em estado de deterioração após óbito intrauterino, muitas vezes inviabilizando a identificação da causa mortis. Dessa forma, o termo deveria constar no laudo de necropsia na parte de características do cadáver, e não como causa de morte, pois é consequência da morte e não causa. Nessa lógica, "morte intrauterina" e "óbito fetal intraútero" são fatos determinados antes do pedido de necropsia, e não configuram causa mortis mas apenas uma obviedade e uma redundância terminológica, já que a causa de morte não pode ser, pura e simplesmente, morte.

Não podemos afirmar que o não encaminhamento desses pacientes resultou no preenchimento adequado das Declarações de Óbito nos demais serviços. Vale salientar que o curso para recodificação de Garbage Codes só pode ser realizado por funcionários da Vigilância Epidemiológica, não estando, portanto, acessível a todos os médicos atuando no Estado. Conforme a tabela 5 , - SVOI foi responsável pela assinatura de, em média, 17,79 \% do total das Declarações de Óbito de Ribeirão Preto antes do Parecer Consulta e de 13,03\% após. As DO não assinadas pelos patologistas do SVOI mas por outros médicos da rede de saúde não foram analisadas e podem ser substrato motivo para pesquisas futuras.

Devido à pandemia de COVID-19, justifica-se em futuro próximo um novo 
estudo sobre o preenchimento de causa de morte em Declarações de Óbito durante o período de suspensão necropsias padrão, que teve início em março de 2020 e perdurou até o momento do encerramento desta tese.

\subsection{Implicações sobre a Gestão de Recursos para a Saúde Pública}

Gonçalves et al. estimaram, em 2016, o custo unitário médio de cada necropsia para o Estado de Minas Gerais em R\$ 809,30 por procedimento, considerando a realização de 4 exames de microscopia habituais (GONÇALVES, 2016). Considerando que essa aproximação seja válida para a cidade de Ribeirão Preto, as 181,5 necropsias a menos na média anual representariam uma economia de $\mathrm{R} \$ 146.887,95$ por ano. Ressaltamos que em 2018 foram realizadas, no total, 86 necropsias a menos do que em 2017, sugerindo uma tendência a progressiva queda de exames e, consequentemente, de gastos públicos. Comparado à média de necropsias dos anos anteriores à publicação do PC, de 1014,5 necropsias, em 2018 foram realizados 224,5 exames a menos, uma economia de $\mathrm{R} \$ 181.687,85$.

Em 2019 aconteceu na Câmara Municipal de Ribeirão Preto uma investigação sobre a demora na liberação de corpos do SVOI, a Comissão Especial de Estudos (CEE) (MATTOS, 2019; ATA da CCE, 2019; G1 RIBEIRÃO PRETO E FRANCA, 2019). Em ata registrada pela CCE consta, em relato de ex-diretor do SVOI, o valor de aproximadamente $\mathrm{R} \$ 3000,00$ como custo unitário médio de cada necropsia, o que acarretaria uma economia mínima de $R \$$ 544.500,00 segundo os cálculos supracitados para a média e R $\$ 673.500,00$ tomando por base apenas o ano de 2018 (Ata da CCE, 2019). O relatório final da CCE conclui que é necessária a contratação de funcionários para que a instituição possa funcionar em tempo integral, 24 horas por dia, e ter presente em cada turno um responsável pela liberação das DO (MATTOS, 2019; G1 RIBEIRÃO PRETO E FRANCA, 2019).

Considerando os recentes e frequentes cortes de gastos na Universidade de São Paulo, incluindo o Centro de Medicina Legal e SVOI que a integram, 
gostaríamos de sugerir com este trabalho o emprego de parte dessa verba economizada a partir da redução do número de necropsias para justificar a contratação de funcionários e retornar ao horário integral de funcionamento do serviço, que hoje se limita a atender das $7 \mathrm{~h}$ às 19h. Até 2014 o recebimento de cadáveres era feito $24 \mathrm{~h}$ por dia, e as necropsias realizadas 18 horas por dia.

O funcionamento integral é limitado pelo déficit de técnicos de necropsia, auxiliares de necropsia e médicos patologistas. Segundo a secretaria de recursos humanos do próprio CEMEL, atualmente estão preenchidas em torno de $60 \%$ das vagas destinadas a cada categoria. As vagas em aberto estão ociosas por aposentadoria, falecimento, afastamento ou desligamento de funcionários antigos, e carecem de autorização da Universidade para contratação. Para técnicos de necropsia, por exemplo, há necessidade de 5 vagas preenchidas para que possam se revezar cobrindo todos os turnos da semana cumprindo a carga horaria prevista na Consolidação das Leis do Trabalho - CLT de 8h por dia, ou seja, 3 técnicos num mesmo dia para o funcionamento integral (CONSOLIDAÇÃO DAS LEIS DO TRABALHO, 2017). Atualmente há apenas 3 técnicos em quadro efetivo, o que mesmo com a redução no horário de funcionamento impossibilita o remanejamento de pessoal em caso de férias ou afastamento por motivos de saúde. De forma similar, o quadro de médicos é composto de 7 vagas, estando apenas 4 delas preenchidas.

O recurso advindo da economia mínima de $\mathrm{R} \$ 146.887,95$ reais por ano possibilita e respalda a contratação de novos funcionários. Faz-se necessário, portanto, um estudo estimativo do custo unitário médio da necropsias realizadas no SVOI, uma vez que os custos operacionais e de materiais em Ribeirão Preto atualmente podem diferir substancialmente dos levantados por Gonçalves et al em 2016. 


\subsection{Implicações legais, bioéticas e de impacto social da realização necropsias desnecessárias}

Discutir a realização de necropsias desnecessárias perpassa aspectos éticos, bioéticos e legais, por vezes análogos à discussão sobre a doação de órgãos, uma vez que o corpo sem vida de um indivíduo pertence à família e não ao Estado (GUIMARÃES, FRANCISCO E SILVEIRA, 2020). Segundo Almeida e Muñoz (2002) o cadáver é considerado res sui generis, uma vez que foge à definição jurídica tanto de pessoa quanto de coisa. Assim, ainda que possam ser respeitadas as diretivas que o indivíduo firmou em vida para a disposição de seus restos mortais, as decisões acerca do tratamento dado ao corpo são de responsabilidade da família, cabendo ao Estado apenas na ausência de quem reclame o corpo.

\subsubsection{Implicações legais}

Nas situações em que os achados de necropsia se configuram de interesse público, ou seja, de toda a sociedade, realização da mesma se torna compulsória, dispensando-se a necessidade de autorização do procedimento e não impossibilitando a sua recusa por familiares (GUIMARÃES, FRANCISCO E SILVEIRA, 2020). Essas podem ser divididas em duas situações: 1- em que o corpo morto constitui prova material de um crime, o que é de interesse para a Segurança Pública; e 2- em que a causa de morte é mal definida ou não esclarecida, sendo que sua elucidação interessa à Saúde Pública. Contudo, poucos são os pacientes que se enquadram na segunda categoria, uma vez que a moléstia principal do enfermo, ou seja, a causa básica de morte, usualmente progride para causa terminal ou imediata de morte no transcorrer de horas, dias, ou anos, geralmente com diagnóstico definido e doença em tratamento, passando por uma ou múltiplas internações hospitalares. Mesmo o temido infarto agudo do miocárdio, exceto quando fulminante, tem horas de progressão entre o sintoma inicial e o edema agudo de pulmão ou instabilidade hemodinâmica, e parte das doenças de acometimento neurológico ou neoplasias evolvem ao longo de anos, inclusive passando pela etapa de cuidados paliativos. 
Transcrevemos novamente um trecho da lei estadual 5.452/86 e também da Portaria $n^{\circ}$ 1405/06 que institui a Rede Nacional de Serviços de Verificação de Óbito e Esclarecimento da Causa Mortis (SVO).

Lei Estadual de São Paulo, 5.452/86

Artigo $2^{\circ}$ - Os Serviços de Verificação de Óbitos têm por finalidade:

I - esclarecer a "causa mortis" em casos de óbito por moléstia mal definida ou sem assistência médica:

II - prestar colaboração técnica, didática e científica aos Departamentos de Patologia das Faculdades de Medicina, órgãos afins ou outros interessados, participando de seus trabalhos e podendo funcionar nas suas dependências e instalações.

\section{Portaria $n^{\circ} 1405 / 06$}

Artigo $8^{\circ}$ - Os SVO serão implantados, organizados e capacitados para executarem as seguintes funções:

I - realizar necropsias de pessoas falecidas de morte natural sem ou com assistência médica (sem elucidação diagnóstica), inclusive os casos encaminhadas pelo Instituto Médico Legal (IML);

II - transferir ao IML os casos: a) confirmados ou suspeitos de morte por causas externas, verificados antes ou no decorrer da necropsia; b) em estado avançado de decomposição; e c) de morte natural de identidade desconhecida;

A segunda e a quinta perguntas formuladas no Parecer Consulta 31 184/15 expõem que, em caso de não haver um diagnóstico de causa de morte, não é necessário termo de consentimento ao solicitar necropsia. Interpreta-se que tais pacientes se enquadram no que é disposto no inciso I. Em casos de pacientes encaminhados com história clínica suficiente para preenchimento da DO, ou seja, havendo um diagnóstico, a realização da necropsia deixa de servir ao interesse legal e epidemiológico e passa a ser realizada por interesse médicoacadêmico, portanto contidas no inciso II da lei 5.452/86, sendo a sua realização facultativa.

Interpreta-se, assim, que é direito da família recusar o exame cadavérico, sendo prudente que as autorizações sejam registradas através de assinatura do termo de consentimento. Se, porventura, a família não autorizar a realização do exame, é dado ao profissional médico a opção de preencher a DO com causa de morte indeterminada, que nesse caso se dá pela inexistência de investigação 
detalhada e não por exame inconclusivo (PARECER CONSULTA 31/2017, CRM-PE 2017). O médico deve atentar para ausência de sinais ou indícios de morte sUspeita ou violenta e, ainda registrar por escrito a recusa ao exame (PARECER CONSULTA 31/2017, CRM-PE 2017).

A redação de qualquer parecer consulta publicado pelos conselhos regionais de medicina é pautada e embasada em leis nacionais, estaduais e também em artigos do Código de Ética Médica, que é revisado e atualizado periodicamente de acordo com a evolução do pensamento científico e o advento de novas modalidades terapêuticas. Transcrevemos aqui três artigos relacionados ao atestado de óbito e à realização de exames, sendo que o Art. 84 está também no texto do Parecer Consulta 31 184/2015 (CÓDIGO DE ÉTICA MÉDICA, 2019):

É vedado ao médico:

Art. 84: Deixar de atestar óbito de paciente ao qual vinha prestando assistência, exceto quando houver indícios de morte violenta.

Art. 31. Desrespeitar o direito do paciente ou de seu representante legal de decidir livremente sobre a execução de práticas diagnósticas ou terapêuticas, salvo em caso de iminente risco de morte.

Art. 14. Praticar ou indicar atos médicos desnecessários ou proibidos pela legislação vigente no País.

Ainda, a resolução do CFM no 1.779/2005, que regulamenta a responsabilidade médica no fornecimento da Declaração de Óbito, indica a possibilidade de encaminhamento de corpos ao SVO caso o médico não consiga correlacionar o óbito com o quadro clínico concernente ao acompanhamento do paciente, caso haja suspeita fundamentada de que a causa de morte difira do quadro de conhecimento prévio e documentado da equipe de saúde em internação hospitalar ou domiciliar com acompanhamento por ESF (CFM, 2005).

A conclusão é que não há respaldo legal ou ético para o encaminhamento de cadáveres para os Serviços de Verificação de Óbito de todo o país após período de internação hospitalar que tenha resultado em 
diagnóstico de causa de morte, ainda que sindrômico ou de foco indeterminado. Propomos que os pedidos de necropsia por interesse médicoacadêmico, além da especificação do questionamento médico e da situação de dúvida que motivou a solicitação do exame, tenham um formulário adicional com informação de endereço eletrônico do médico ou médica solicitante para que seja the seja encaminhado o laudo de necropsia, constando os relatórios de macroscopia, microscopia e correlação diagnóstica. Isso promoveria aprendizado e atualização profissionais, aumentando o substrato para o raciocínio diagnóstico e decisão de condutas médicas futuras, motivo final que justifica a abertura de cadáveres e o exame post mortem.

Assim, a realização de necropsias passaria a ter aplicação imediata na melhoria da saúde pública e não apenas após a elaboração estatística e de planos gestores. Contribuiria, também, com as estatísticas mensais de cada hospital ou estabelecimento de saúde onde ocorram óbitos, realizadas em concordância com a Lei Federal 1 1.976/2009, que dispõe sobre a Declaração de Óbito e a realização de estatísticas de óbitos em hospitais públicos e privados e determina em seu Art. $4^{\circ}$ o aperfeiçoamento dos serviços de saúde e os registros correspondentes (Lei Federal 11.976/2009).

\subsubsection{Implicações bioéticas e de impacto social}

Outro ponto importante a ser discutido é o acolhimento dos familiares e amigos enlutados no aguardo da conclusão de exames, liberação de documentos e demais atividades burocráticas.

O processo do luto que se inicia com a notícia do falecimento e termina meses após o sepultamento, pode e deve ser conduzido por profissionais capacitados, e de forma alguma deve ser agravado pela apreensão causada por uma necropsia desnecessária ou pela demora na liberação do cadáver para os ritos funerários. Diferentemente de outros países, como a Inglaterra, em que a necropsia e o sepultamento podem ser realizados até duas semanas após o falecimento, em nossa cultura procedemos ao velório sepultamento ou cremação logo após o registro do óbito. 
Segundo o guia funerário britânico, o funeral normalmente ocorre após uma ou duas semanas após a morte, podendo ser posposto por períodos maiores caso seja requisitado maior tempo pela família ou pela necessidade de exames (FUNERAL GUIDE, 2021).

Para brasileiros, é inconcebível uma espera tão longa, havendo registros de reclamações quando a liberação pelo SVOI leva mais do 15 horas (MATTOS, 2019; G1 RIBEIRÃO PRETO E FRANCA, 2019). Se considerarmos que, em parte dos casos, o exame necroscópico não era necessário, as famílias foram submetidas a uma angústia adicional no processo de luto, com implicações para a saúde mental, social e econômica desses indivíduos, com perda de dia de trabalho e necessidade de suporte social (alguém para cuidar de filhos, idosos ou outros familiares adoentados).

Para a mãe que abrigou e nutriu o feto durante todo o seu período de gestação e agora tem que lidar com a perda não só daquela vida mas de todas as expectativas geradas quanto a ela, que teve de passar pela dor do parto sem a recompensa de ouvir o choro de seu bebê e acalmá-lo em seus braços, encaminhar o feto para uma necropsia desnecessária é análogo a tortura.

Cada mulher que tem que enterrar seu bebê experiencia a morte de maneira individual, muitas vezes pela realização de ritos funerários íntimos a cada paciente, como banhar, vestir e pentear o bebê, fotografar, pintar mãos e pés para 'carimbo' em folha de recordação, e que poderia ser conduzida pela equipe de saúde que assistiu o parto, complementada quando necessário, de forma a assegurar a devida despedida proteger a puérpera (e sua família) da sensação de culpa, de impotência e de desespero. Esse processo é quebrado com a separação forçada, podendo a necropsia ser interpretada pela família como a mutilação daquele pequeno corpo que nem viveu.

O luto é uma etapa que não pode ser evitada na despedida de um ente querido. É importante para a para saúde mental do indivíduo e para o reestabelecimento e readequação da rotina das famílias. Pessoas ligadas por laços sociais têm saúde interdependente, em que o humor, a saúde física e o estado de espírito de um no estado de saúde do outro (CAREZZATO et al, 2018; ROSTILA ET AL, 2012). 
Não é raro que um cônjuge adoeça física e mentalmente após a enfermidade do parceiro, seja durante o período de internação, de cuidado ou de luto, e isso se aplica também aos demais cuidadores e entes queridos (CAREZZATO et al, 2018; ROSTILA ET AL, 2012; ELWERT E CHRISTAKIS, 2008; ZIVIN E CHRISTAKIS, 2007.).

A prolongação ou exacerbação do luto traz consequências incalculáveis para a saúde, com negação, depressão e isolamento social, fazendo com que a promoção do acolhimento familiar seja uma questão de saúde pública. Para melhor ilustrar isso, transcrevemos um trecho da conclusão de um artigo sobre o assunto publicado pela equipe do Centro de Medicina Legal-FMRP/USP (CAREZZATO et al., 2018):

"O cuidado humanizado e integrado da equipe multidisciplinar de saúde é chave para o renascer saudável (...) esclarecendo e discutindo a obscuridade da morte, na medida do possivel, de modo a facilitar sua compreensão e aceitação. A família é vista como um organismo que necessita tanto de cuidados quanto o doente em si, tanto no trato diário com seus integrantes durante as rotinas hospitalares quanto na participação em grupos de apoio e nos atendimentos pelos profissionais de saúde, educação, apoio religioso e assistentes sociais, antes e depois do óbito. (...) Os que ficaram podem ser ativos participante do desenvolvimento de sua própria resiliência e atuante na dos demais familiares".

Cumprindo seu papel social como instituição abrigada em um departamento de saúde da maior Universidade pública da América Latina, uma vez reequilibrado o quadro de funcionários para as vagas já existentes, é mister a implantação de serviço de acolhimento ao luto no CEMEL, e a destinação de equipe e ambientes adequados para tal fim. Atualmente os familiares aguardam a resolução dos processos burocráticos na recepção do Centro de Medicina Legal, por onde transitam funcionários do SVOI, do IML, docentes e alunos de graduação e pós-graduação, em grupos de até 50 pessoas simultaneamente, podendo gerar por vezes um constrangimento desrespeitoso aos enlutados que ali se encontram. 


\section{Conclusões}

A análise dos dados mostra que o Parecer Consulta 31.184/2015 teve efeito sobre o número de necropsias realizadas no SVOI no que se refere à comparação entre os anos de estudo anteriores à sua implantação, 2013 e 2014, e os dois anos subsequentes à sua implantação, 2017 e 2018, promovendo redução no número de necropsias executadas. O maior impacto foi sobre encaminhamentos de pacientes em internação hospitalar com diagnóstico de septicemia e de óbitos fetais ou perinatais. O preenchimento da DO por médico que acompanhou regularmente o paciente em vida evita diagnósticos irregulares e necropsias desnecessárias.

Não há respaldo legal ou ético para o encaminhamento de cadáveres

para os Serviços de Verificação de Óbito de todo o país após período de internação hospitalar que tenha resultado em diagnóstico de causa de morte, ainda que sindrômico ou de foco indeterminado.

Não é possível afirmar que o não encaminhamento desses pacientes resultou no preenchimento adequado das Declarações de Óbito nos demais serviços da rede municipal de saúde.

É necessário aprimorar o ensino de Medicina Forense e do preenchimento de documentos como laudos e relatórios médicos, entre eles do Questionário de Autópsia Verbal e da Declaração de Óbito.

Faz-se necessária a implantação do preenchimento eletrônico da declaração de óbito, de modo a impedir a colocação de Garbage Codes nos campos de causa da morte e que promova a melhoria da correlação diagnóstica entre campos. Com um sistema nacional de prontuários médicos seria também possível delinear causas básicas e intermediárias de morte com base nas informações de saúde antigas e recentes daquele paciente. Ainda, com o aprendizado de máquina será possível que no prontuário de um indivíduo seja sinalizado o histórico familiar de uma doença, como diabetes ou neoplasias.

Cumprindo seu papel social como instituição abrigada em um departamento de saúde da maior universidade pública da América Latina, é mister a implantação de serviço de acolhimento ao luto no CEMEL e a destinação de equipe e ambiente adequados para tal fim. 


\section{Referências Bibliográficas}

- ATA DA REUNIÃO DA COMISSÃO ESPECIALDE ESTUDOS DESTINADA A ACOMPANHAR A DEMORADA LIBERAÇAODE CORPOS PELO SERVIÇODE VERIFICAÇÃO DE OBITOS EM RIBEIRÃO PRETO. Acessada em 02/01/2021. Disponível em https://publico.camararibeiraopreto.sp.gov.br/sapl_documentos/reuniao_comissao/215_ata.pdf

Atlas do Desenvolvimento Humano no Brasil. Programa das Nações Unidas para o Desenvolvimento. Acessado em 20 de março de 2021, disponível em <http://www.atlasbrasil.org.br>

. BRASIL. Ministério da Saúde. Portaria n 1.405, de 29 de junho de 2006. Institui a Rede Nacional de Serviços de Verificação de Óbito e Esclarecimento da Causa Mortis (SVO). Diário Oficial da república Federativa do Brasil, Brasília, DF, 30 jun. Seção 1, p. 242-244, 2006.

Consolidação das leis do trabalho - CLT e normas correlatas. - Brasília : Senado Federal, Coordenação de Edições Técnicas, 2017. 189 páginas. ISBN: 978-85-7018-891-5. Disponível em <https://www2.senado.leg.br/bdsf/bitstream/handle/id/535468/clt_e_normas_correlatas_led.pdf>

FUNERAL GUIDE. Website britânico para auxílio no processo de luto e preparação de funerais. Acessado em 02/04/2021, disponível em https://www.funeralguide.co.uk/help-resources/arranginga-funeral/when-to-hold-a-funeral

. IBGE - Instituto Brasileiro de Geografia e estatística. Censo Demográfico 2010 por cidades. Acessado em 20 de março de 2021, Disponível em < https://www.ibge.gov.br//brasil/sp/ribeiraopreto.html>

. Lei n. 5.452, de 22 de dezembro de1986.Reorganiza os Serviços de Verificação de Óbitos no Estado de São Paulo. Lex: Diário Oficial, v. 96, n. 245, p. 2, 1986.

. Lei n. 6.015, de 31 de dezembro de 1973. Lei de Registros Publicos. Dispõe sobre os registros públicos, e dá outras providências.

. LEI N 1 1.976, DE 7 DE JULHO DE 2009. Dispõe sobre a Declaração de Óbito e a realização de estatísticas de óbitos em hospitais públicos e privados.

Parecer 31/2017 do Processo Consulta 04/2016. Sobre o Aumento da demanda de corpos no SVO. Disponível em <https://sistemas.cfm.org.br/normas/arquivos/pareceres/PE/2017/31_2017.pdf>

Parecer Consulta 31.184/2015. Sobre o encaminhamento/recebimento de cadáveres para necropsia de verificação de óbitos. CREMESP - Conselho Regional de Medicina do Estado de São Paulo. Aprovado em 14 de maio de 2015, homologado em 17 de julho de 2016. Disponível

Portaria DGP- 14, de 23 de fevereiro de 2005. Disciplina a coleta, registro, processamento, análise e difusão das informações relativas às ocorrências de morte. Lex: Diário Oficial do Estado de São Paulo, v. 115, n. 36, p. 7, 2005.

PORTARIA N 116, DE 11 DE FEVEREIRO DE 2009. Ministério da Saúde - Secretaria de Vigilância em Saúde. Disponível em <http://bvsms.saude.gov.br/bvs/saudelegis/svs/2009/prt0116_11_02_2009.html>

RESOLUÇÃO CFM n 1.779/2005. CONSELHO FEDERAL DE MEDICINA. Regulamenta a 
responsabilidade médica no fornecimento da Declaração de Óbito. Revoga a Resolução CFM n. 1601/2000. Publicada no D.O.U., 05 dez 2005, Seção I, p. 121.

Resolução CNS No 510, de 07 de abril de 2016. Conselho Nacional de Saúde. Publicada no DOU n 98, terça-feira, 24 de maio de 2016 - seção 1, páginas 44, 45, 46.

SÃO PAULO - Lei no 5.452/86, de 22 de dezembro de 1986. Reorganiza os Serviços de Verificação de Óbitos no Estado de São Paulo.

Serviço de Verificação de Óbitos da Capital - Universidade de São Paulo Acessado em 07/04/2021, Disponível em http://www.svoc.usp.br.

SERVIÇO DE VERIFICAÇÃO DE ÓBITOS DO INTERIOR - Universidade de São Paulo. Acessado em 07/04/2021, disponível em https://sites.usp.br/svoi

Serviços de Verificação de óbito: após 10 anos, Brasil não cumpre meta, diz CFM. Portal Médico - CFM, 2016. Acessado em 05 set. 2018. Disponivel em: <https://portal.cfm.org.br>.

SIM - Sistema de Informação sobre Mortalidade do Ministério da Saúde. Brasília: GIAE/Secretaria de Vigilância em Saúde. Acessado em 20 de Março de 2021. Dados disponibilizados através dos sites http://www2.datasus.gov.br/DATASUS e http://tabnet.datasus.gov.br/

Website G1 Ribeirão Preto e Franca - CEE sobre demora em liberação de corpos pede mais técnicos e SVO aberto $24 \mathrm{~h}$ por dia em Ribeirão. Reportagem assinada por Gl Ribeirão Preto e Franca, 23 de setembro de 2019. Acessado em 02/06/2020, disponível em https://gl.globo.com/sp/ribeirao-preto-franca/noticia/2019/09/23/cee-sobre-demora-emliberacao-de-corpos-pede-mais-tecnicos-e-svo-aberto-24h-em-ribeirao-preto.ghtml

Worldometers.info. Estatísticas atualizadas em tempo real. Dover, Delaware, E.U.A. Acessado em 21 de Março de 2021. Disponível em < https://www.worldometers.info/coronavirus> Almeida e Muñoz, In: Bioética $3^{a}$ ed. - Segre, Marco; Cohen, Claudio. 3. ed. São Paulo : EDUSP, 2002. 218p. ISBN 85-314-0304-9.

ARAÚJO, C.L.F et al. O quesito cor/raça em formulários de saúde: a visão dos profissionais de saúde. Rev. enferm. UERJ, Rio de Janeiro, v. 18, n. 2, p. 241-246, 2010.

ATHANÁZIO, D. A. et al. O ensino de Patologia nas escolas médicas está em crise? Uma revisão sobre a experiência internacional. Rev. Bras. Educ. Med., Rio de Janeiro, v. 33, n. 1, p. 49-54, 2009.

BARBEIRO, F.M.S. et al. Óbitos fetais no Brasil: Revisão Sistemática. Rev Saúde Pública, São Paulo, v. 49, n. 22, p. 1-15, 2015.

BELZEBERG H, RIVKIND Al. It always pays to make a diagnosis: to autopsy or not to autopsy? Crit Care Med 1998;26:1299-1300.

BIERIG, JR. A potpourri of legal issues relating to the autopsy. Arch Pathol Lab Med 1996;120:759-762.

BLOSSER AS, ZIMMERMAN HE, STAUFFER JL. Do autopsies of critically ill patients reveal important findings that were clinically undetected? Crit Care Med 1998;26(8):1332-1336.

CAMPOS, D. et al. Uso da autópsia verbal na investigação de óbitos com causa mal definida em Minas Gerais, Brasil. Cad. Saúde Pública, Rio de Janeiro, v. 26, n. 6, p. 1221-1233, jun. 2010.

CARDOSO, A.B.C. Serviços de Verificação de óbitos: Características e contribuições para o 
esclarecimento de causas de morte. 2007. 103 f. Dissertação (Mestrado em Microbiologia, Parasitologia e Patologia). Universidade Federal do Paraná, Curitiba, 2007.

CAREZZATO, C. L.; PIRES, L. A.; CARVALHO, A. M. P; SANTOS, P. L. dos S. (2018). O LUTO DOS IRMÃOS: CONSEQUÊNCIAS PARA A SAÚDE DE CRIANÇAS APÓS A PERDA DE UM IRMÃO E COMO AMENIZÁLAS. Revista De Enfermagem Da UFJF, 2(2). Disponível em <https://periodicos.ufjf.br/index.php/enfermagem/article/view/3878>

CAREZZATO, C.L. Estudo da relação entre os diagnósticos clínicos e necroscópicos de causa mortis de pacientes que vieram a óbito no HC-FMRP/USP nos anos de 2010 e 2014. Dissertação de mestrado. Universidade de São Paulo, Brasil. 2016

CARMO, L.F.S. et al. Gerenciamento do risco de broncoaspiração em pacientes com disfagia orofaríngea. Revista CEFAC. v. 20, n. 4, p. 532-540, Jul-Ago. 2018.

CHERNOF D. The role of managed health care organizations in autopsy reimbursement. Arch Pathol Lab Med 1996;120(8):771-772.

CHUTE CG, BALLARD DJ, NEMETZ PN. Contribution of autopsy to population - based cancer epidemiology: target intervention to improve ascertainment. IARC Sci Publ 1991;1 12:207-216.

CID-10: Classificação Estatística Internacional de Doenças e Problemas Relacionados à Saúde Décima revisão. Trad. do Centro Colaborador da OMS para a Classificação de Doenças em português. $3^{a}$. Ed. São Paulo: EDUSP; 2008.

CLODE, N.; JORGE, C.C; GRAÇA, M.G.. Normas de Atuação na Urgência de Obstetricia e de Ginecologia. Edição: Hospital Santa Maria, Portugal, 2016. P.87. Disponível em <http://www.fspog.com//fotos/editor2/normas_de_urgencia_2016.pdf>

CORDNER, S.M. Deciding the cause of death after necropsy. Lancet 1993;341:1458-1460.

CROCE, D.; CROCE JUNIOR, D. Manual de Medicina Legal. 8ª. Ed. São Paulo: Saraiva, 2012.

D'ANTONIO F, TIMOR-TRITSCH IE, PALACIOS-JARAQUEMADA J, MONTEAGUDO A, BUCA D, FORLANI F, MINNECI G, FOTI F, MANZOLI L, LIBERATI M, ACHARYA G, CALÌ G. First-trimester detection of abnormally invasive placenta in high-risk women: systematic review and meta-analysis. Ultrasound Obstet Gynecol. 2018 Feb;51 (2):176-183. doi: 10.1002/vog.18840. PMID: 28833750.

EISENSTEIN, E. Adolescência: definições, conceitos e critérios . Adolesc Saude. 2005;2(2):6-7

ELWERT, F.; CHRISTAKIS, N.A. The effect of widowhood on mortality by the causes of death of both spouses. Am J Public Health. 2008 Nov;98(1 1):2092-8. doi: 10.2105/AJPH.2007.1 14348. Epub 2008 May 29.

FEINSTEIN, A.R. Epidemiological and clinical challenges in reviving the necropsy. Arch Pathol

FERNANDEZ-SEGOVIANO P, ESTEBAN A. The autopsy as a tool to monitor diagnostic error. Intensive Care Med, 1999; 25:343-344.

FRANÇA, G.V. Medicina Legal. 10ª. Ed. São Paulo: Guanabara Koogan, 2015.

GAMBINO, S.R. The autopsy - the ultimate audit. Arch Pathol Lab Med 1984;108:444-445.

GELLER, S.A. Religious attitudes and the autopsy. Arch Phatol Lab Med 1984;108(6):494-496. 
GONÇALVES, M.A., FE, B.P., CUNHA, Y.F.F., ALEMÃO, M.M., GONÇALVES, F.M.V., BRAGA, L.C. A aplicação do Custeio Baseado em Atividades para conhecimento do Serviço de Verificação de Óbitos no Estado de Minas Gerais. Anais do XXIII Congresso Brasileiro de Custos - Porto de Galinhas, PE, Brasil, 16 a 18 de novembro de 2016

GUIDUGLI, R. B. et al. Causa de mortes de indivíduos encontrados em decomposição na cidade de São Paulo. Diagn Tratamento. v. 14, n. 3, p. 105-107, 2009.

GUIMARÃES, FRANCISCO E SILVEIRA. O corpo Humano Morto, em Cohen \& Oliveira - Bioética, Direito e Medicina. Cap 20, p.196. Ed. Manole. Barveri -SP, 2020.

GUT, A.L.; FERREIRA, A.L.A; MONTENEGRO, M.R. Autopsy: quality assurance in the ICU. Intensive Care Med 1999;25:360-363.

HALL, T.; WAX, J.R; LUCAS, F.L.; CARTIN, A.; JONES, M.; PINETTE, M.G. Prenatal sonographic diagnosis of placenta accreta-impact on maternal and neonatal outcomes. J Clin Ultrasound. Outubro de 2014;42(8):449-55.

HASUO Y, UEDA K, KIYOHARA Y, WADA J, KAWANO H, KATO I, et al. Accuracy of diagnosis on death certificates for underlying causes of death in a long-term autopsy-based population study in Hisayama, Japan; with special reference to cardiovascular diseases. J Clin Epidemiol 1989;42(6):577584.

HÉRCULES, H. C. Medicina Legal: Texto e Atlas. 2a. Ed. São Paulo: Atheneu, 2014.

HILL RL, ANDERSON RE. The recent history of the autopsy. Arch Pathol Lab Med 1996;120:702-712. (A condensed description of the evolution of autopsy pathology during the last 400 years.)

JAUNIAUX ERM, ALFIREVIC Z, BHIDE AG, BELFORT MA, BURTON GJ, COLLINS SL, et al. Placenta Praevia and Placenta Accreta: Diagnosis and Management. BJOG: An International Journal of Obstetrics \& Gynaecology. 2019;126(1):e1-48.

JUVIN, P, Teissiere F, Brion F, Desmonts JM, Duringon M. Postoperative death and malpractice suits: is autopsy useful? Anesth Analg 2000;91 (2):344-346.

KAJIWARA JK, ZUCOLOTO S. A Autópsia na História. Medicina, Ribeirão Preto 1991; 24(2):55-69.

KING LS, MEEHAN MC. A history of autopsy. Am J Pathol 1973;73:514-544.

KING, DW. Potential of the autopsy. Arch Pathol Lab Med 1984;108:439-443.

Lab Med 1996;120:749-752.

LARDENOYE JW, KAPPETEIN AP, PEETERS MP, SPAANDER PJ, BRESLAU PJ. Valve of keeping records of mortality. Eur J Surg 2002;168:436-440.

LAURENTI R, MELO JORGE M.H.P. O ATESTADO DE ÓBITO: Aspectos médicos, estatísticos, éticos e jurídicos. CREMESP - Conselho Regional de Medicina do Estado de São Paulo, 2015. Disponível em https://www.cremesp.org.br/pdfs/atestado_de_obito.pdf

LAURENTI, R., 1991. Análise da informação em saúde: 1893 - 1993, cem anos da Classificação Internacional de Doenças. Revista Saúde Pública, 25:407-417

LAURENTI, R.; MELLO JORGE, M.H.P.; GOTLIEB, S.L.D. A confiabilidade dos dados de mortalidade e morbidade por doenças crônicas não-transmissíveis. Ciênc. Saúde Coletiva, Rio de Janeiro, v. 9, n. 
4, p. 909-920, Dec. 2004.

LUCENA, Luan et al . Declaração de óbito: preenchimento pelo corpo clínico de um hospital universitário. Rev. Bioét., Brasília, v. 22, n. 2, p. 318-324, Aug. 2014 . Available from $<\mathrm{http}$ ///www.scielo.br/scielo.php?script=sci_arttext\&pid=\$1983-

$80422014000200014 \&$ Ing=en\&nrm=iso>. access on 22 Apr. 2021. https://doi.org/10.1590/198380422014222013.

LUNDBERG GD. Medicine without the autopsy. Arch Pathol Lab Med 1984;108(6):449-454.

MATTOS, ALINE. Comissão Especial de Estudos (CEE) do SVO ouve diretora sobre atrasos na liberação de corpos na cidade. Website da Câmara Municipal de Ribeirão Preto, 22 de Agosto de 2019. Acessado em 02/06/2020. Disponível em http://www.camararibeiraopreto.sp.gov.br/JW34/noticiaWeblmprimir.xhtml;jsessionid=bc6ec79e96 4409539 d8e l db 1 bbbf; jsessionidversion=2f4a573334:0?id $=5062$

MCPHEE SJ. The autopsy: an antidote to misdiagnosis. Medicine 1996b;76:41-43.

MELLO JORGE, M.H.P; LAURENTI, R.; GOTLIEB, S.L.D. Análise da qualidade das estatísticas vitais brasileiras: a experiência de implantação do SIM e do SINASC. Ciênc. Saúde Coletiva, Rio de Janeiro, v. 12, n. 3, p. 643-654, jun. 2007 . Disponível em $<$ http://www.scielo.br/scielo.php?script=sci_arttext\&pid=S1413-

$81232007000300014 \&$ Ing=pt\&nrm=iso>. Acessado em 21 abr. 2021. https://doi.org/10.1590/S141381232007000300014 .

MENDO, C.T.M.; TERADA, A.S.S.D.; GARCIA, S.B; GUIMARÃES, M.A. Transfers of necropsy cases: the paradox of the Brazilian Medico-legal System and repercussions in mortality data. International Journal of Scientific Research, Gujarat, India, v. 8, n. 1, p. 9-10, 2019.

MINISTÉRIO DA SAÚDE. A declaração de óbito: documento necessário e importante. Ministério da Saúde, Conselho Federal de Medicina, Centro Brasileiro de Classificação de Doenças. Brasília: Ministério da Saúde, 2009, 3.ed.

MURRAY, C. J. L., AND A. D. LOPEZ. 1996a. "Estimating Causes of Death: New Methods and Global and Regional Applications for 1990." In The Global Burden of Disease, ed. C. J. L. Murray and A. D. Lopez, 117-200. Vol. 1 of Global Burden of Disease and Injury Series. Cambridge, MA: Harvard University Press.

NADROUS HF, AFESSA B, PFEIFER EA, PETERS SG. The role of autopsy in the intensive care unit. Mayo Clin Proc 2003;78:947-950.

NAGHAVI, M., MAKELA, S., FOREMAN, K. et al. Algorithms for enhancing public health utility of national causes-of-death data. Popul Health Metrics 8, 9 (2010). https://doi.org/10.1 186/1478-79548-9

NEWTON D, COFFIN CM, CLARK EB, LOWICHIK A. How the pediatric autopsy yields valuable information in a vertically integrated health care system. Arch Pathol Lab Med 2004;128:1239-1246.

ORGANIZAÇÃO PAN-AMERICANA DA SAÚDE. Saúde e sexualidade de adolescentes. Construindo equidade no SUS. Ministério da Saúde. Brasília, DF: OPAS, MS, 2017.

ROCHA, L.O.S. Necropsia e educaçao médica. Revista Médica de Minas Gerais, volume: 24.1, 2014. DOI: http://www.dx.doi.org/10.5935/2238-3182.20140024 
ROSTILA M, SAARELA J, KAWACHI I. The forgotten griever: a nationwide follow-up study of mortality subsequent to the death of a sibling. Am J Epidemiol. 2012 Aug 15;176(4):338-46. doi: 10.1093/aje/kws163. Epub 2012 Jul 19.

SETLOW, V.P. The need for a national autopsy policy. Arch Pathol Lab Med 1996ç 120:773-777.

SHOJANIA KG, BURTON EC. The persistent value of the autopsy. Am Fam Physician 2004;69(1 1):25402542.

SILVA, José Antônio Cordero da et al . Declaração de óbito, compromisso no preenchimento: avaliação em Belém - Pará, em 2010. Rev. Assoc. Med. Bras., São Paulo, v. 59, n. 4, p. 335340, Aug. 2013. Disponível em <http://www.scielo.br/scielo.php?script=sci_arttext\&pid=\$010442302013000400011\&lng=en\&nrm=iso>. Acessado em 21/04/2021. https://doi.org/10.1016/j.ramb.2013.03.001.

SINARD, J.H.; BLOOD, D.J. Quality Improvement on an academic autopsy service. Arch Pathol Lab Med 2001;125:237-245.

TRELSTEAD RL, AMENTA PS, FORAN DJ, SMILOW PC. The role for regional autopsy centers in the evaluation of covered deaths - survey of opinions of US and Canadian chairs of pathology and major health insurers in the United States. Arch Pathol Lab Med 1996;120:753-758.

WORLD HEALTH ORGANIZATION (WHO). Verbal autopsy standards: ascertaining and attributing cause of death. Geneva: World Health Organization; 2016.

ZARBO RJ, BAKER PB, HOWANITZ PJ. The autopsy as a performance measurement tool - diagnostic discrepancies and unresolved clinical questions. Arch Pathol Lab Med 1999;123:191-198.

ZIVIN, K.; CHRISTAKIS, N.A. The emotional toll of spousal morbidity and mortality. Am J Geriatr Psychiatry. 2007 Sep; 15(9):772-9. 


\title{
Anexo 1 - Parecer Consulta CREMESP 31.184/2015
}

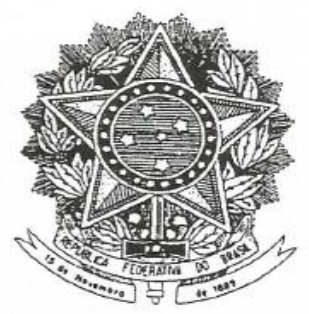

CONSELHO REGIONAL DE MEDICINA DO ESTADO DE SÃO PAULO

FONE: ( 011 ) 3017-9300 - FAX: (011) 3231-1745

http : // www . cremesp . org . br

Rua da Consolação, 753 - Centro

01301-910 São Paulo - SP

\section{CONSULTA No $31.184 / 2015$}

\begin{abstract}
Assunto: Sobre o encaminhamento/recebimento de cadáveres para necropsia de verificação de óbitos. O sistema de verificação de óbitos tem recebido com frequência casos que não seriam da competência ou real necessidade.
\end{abstract}

Relatores: Conselheiro Aizenaque Grimaldi de Carvalho e Dr. Luiz Frederico Hoppe, Membro da Câmara Técnica de Medicina Legal.

Ementa: Deve constar do encaminhamento, de
forma clara, qual e a situação de dúvida sobre
o diagnóstico da causa de morte, incluindo
descrição do caso clínico e exames
complementares demonstrando que não é
possível o preenchimento da Declaração de
Óbito pelo médico responsável pela assistência,
e, principalmente, o motivo da real necessidade
da necropsia.

O consulente Prof. Dr. M.A.G., solicita parecer do CREMESP sobre exame do encaminhamento/recebimento de cadáveres para necropsia de verificação de óbitos. O sistema de verificação de óbitos tem recebido com frequência casos que não seriam da competência ou real necessidade.

Frente ao exposto questiona-se:

"É ético, por parte da direção do SVO, passar a exigir que, nos casos de óbitos provenientes de situação com atendimento médico $e$ internação hospitalar, para a execução das necropsias:

1. Conste de encaminhamento, de forma clara, qual é a situação de dúvida sobre o diagnóstico da causa da morte, incluindo descrição do caso clínico e exames complementares demonstrando que não é possível o preenchimento da Declaração de Óbito pelo médico responsável pela assistência ao paciente quando em vida; $e$

2. Nos casos em que o médico patologista do SVOI constatar que o preenchimento da Declaração de Óbito seja possível com os dados obtidos no atendimento hospitalar, a necropsia somente seja realizada mediante o encaminhamento de termo de consentimento livre e esclarecido assinado por familiar da pessoa falecida (indicando o grau de parentesco) ou pelo responsável legal? 


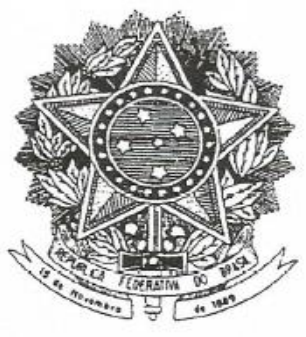

CONSELHO REGIONAL DE MEDICINA DO ESTADO DE SÃO PAULO

\author{
FONE: ( 011 ) 3017-9300 - FAX: (011) 3231-1745 \\ http : // www . cremesp . org . br \\ Rua da Consolação, 753 - Centro \\ 01301-910 São Paulo - SP
}

médica materna hospitalar:

Em relação aos óbitos fetais com assistência

É ético, por parte da direção do SVO, passar a exigir que, nos casos de óbitos fetais com assistência médica materna hospitalar, para a execução das necropsias fetais:

3. Conste do encaminhamento do caso, de forma clara, qual é a situação de dúvida sobre o diagnóstico da causa da morte fetal que esteja enquadrada nos itens III e IV do art 19 da Portaria MS 116/2009, incluindo descrição clínica do parto (normal ou cesariana), suas possíveis intercorrências $e$ exames complementares demonstrando que não é possível o preenchimento da Declaração de Óbito pelo médico que assistiu o parto;

4. Seja encaminhado juntamente com o corpo do feto tanto placenta quanto cordão umbilical para exame, assim como quaisquer outros elementos atípicos que possam estar associados; $e$

5. Nos casos em que o médico patologista do SVOI constatar que o preenchimento da Declaração de Óbito seja possível com os dados obtidos no atendimento hospitalar, em analogia aos casos de necropsia anatomopatológica ou hospitalar, a necropsia somente seja realizada mediante $o$ encaminhamento de termo de consentimento livre e esclarecido, assinado por familiar (um dos genitores ou outro familiar indicando o grau de parentesco) ou pelo responsável legal".

\section{PARECER}

Respostas as dúvidas questionadas:

"É ético por parte da direção do SVO, passar a exigir que, nos casos de óbitos provenientes de situação com atendimento médico $e$ internação hospitalar, para execução de necropsias:

Pergunta $n^{\circ} 1$. Conste do encaminhamento, de forma clara, qual e a situação de dúvida sobre o diagnóstico da causa de morte, incluindo descrição do caso clínico e exames complementares demonstrando que não é possivel o preenchimento da Declaração de Óbito pelo médico responsável pela assistência;

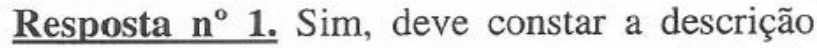
adequada do caso, assim como exames e principalmente o motivo da real necessidade da necropsia. 


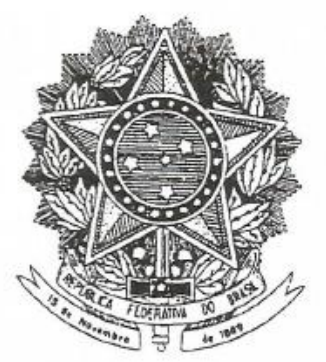

CONSELHO REGIONAL DE MEDICINA DO ESTADO DE SÃO PAULO

\author{
FONE: ( 011 ) 3017-9300 - FAX: (011) 3231-1745 \\ http : // www . cremesp . org . br \\ Rua da Consolação, 753 - Centro \\ 01301-910 São Paulo - SP
}

de Ética Médica:

Segundo o Artigo 84 do Capítulo X do Código

\title{
CAPÍTULOX
}

DOCUMENTOS MÉDICOS

É vedado ao médico:

Art. 84. Deixar de atestar óbito de paciente ao qual vinha prestando assistência, exceto quando houver indicios de morte violenta.

Pergunta $n^{\circ}$ 2. Nos casos em que o médico patologista do SVOI constatar que o preenchimento da Declaração de Óbito seja possivel com os dados obtidos no atendimento hospitalar, a necropsia seja realizada mediante o encaminhamento de termo de consentimento livre e esclarecido assinado por familiar da pessoa falecida (indicando o grau de parentesco) ou pelo responsável legal?

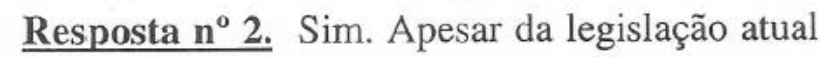
não estabelecer previsão legal relativa à exigência de autorização dos familiares ou do representante legal do falecido para a realização de necropsia nos casos de mortes naturais, é recomendável que seja solicitado tal consentimento, para se evitar questionamentos futuros.

médica materna hospitalar:

Em relação aos óbitos fetais com assistência

É ético, por parte da direção do SVO, passar a exigir que, nos casos de óbitos fetais com assistência médica materna hospitalar, para a execução das necropsias fetais:

Pergunta $n^{\circ} 3$. Conste do encaminhamento do caso, de forma clara, qual é a situação de dúvida sobre o diagnóstico da causa da morte fetal que esteja enquadrada nos itens III e IV do art 19 da portaria MS 116/2009. incluindo descrição clínica do parto (normal ou cesariana), suas possiveis intercorrências e exames complementares demonstrando que não e possível o preenchimento da Declaraşão de Óbito pelo médico que assistiu o parto. 


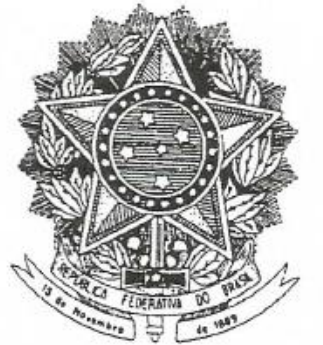

respondida no item anterior 1 .
CONSELHO REGIONAL DE MEDICINA DO ESTADO DE SÃO PAULO

\author{
FONE: ( 011 ) 3017-9300 - FAX: (011) 3231-1745 \\ http : // www . cremesp . org . br \\ Rua da Consolação, 753 - Centro \\ 01301-910 São Paulo - SP
}

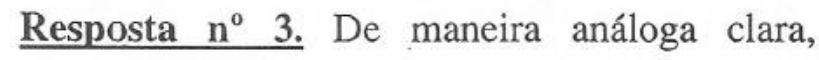

Pergunta $n^{\circ}$ 4. Seja encaminhado juntamente com o corpo do feto tanto placenta quanto cordão umbilical para exame, assim como quaisquer outros elementos atipicos que possam estar associados:

Resposta $\mathrm{n}^{\circ}$ 4. Sim, para propiciar um melhor alcance diagnóstico, a análise dos anexos fetais é relevante.

Pergunta $n^{\circ}$ 5. Nos casos em que o médico patologista do SVOI constatar que o preenchimento da Declaração de Óbito seja possível com os dados obtidos no atendimento hospitalar, em analogia aos casos de necropsia anatomopatológica ou hospitalar, a necropsia somente seja realizada mediante o encaminhamento de termo de consentimento livre e esclarecido, assinado por familiar (um dos genitores ou outro familiar indicando o grau de parentesco) ou pelo responsável legal.

$\underline{\text { Resposta } \mathbf{n}^{\circ} \text { 5. Sim, vide resposta à pergunta } 2 .}$

Este é o nosso parecer, s.m.j.

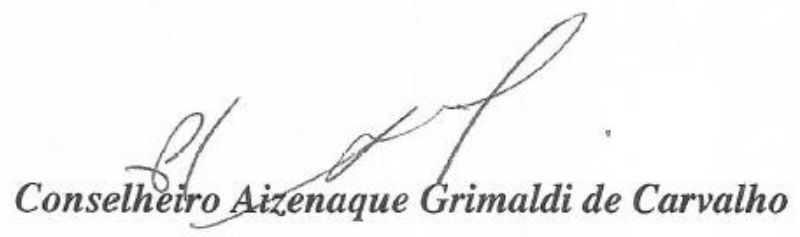

PARECER APROVADO NA REUNIÃO DA CÂMARA TÉCNICA DE MEDICINA LEGAL, REALIZADA EM 14/05/2015.

APROVADO NA REUNIÃO DA CÂMARA DE CONSULTAS, REALIZADA EM 01.07.2016. HOMOLOGADO NA 4.732 ${ }^{\circ}$ REUNIÃO PLENÁRIA, REALIZADA EM 12.07.2016. 


\section{Anexo 2 - Declaração de Óbito fornecida pelo Ministério da Saúde (MINISTÉRIO DA SAÚDE, 2009).}

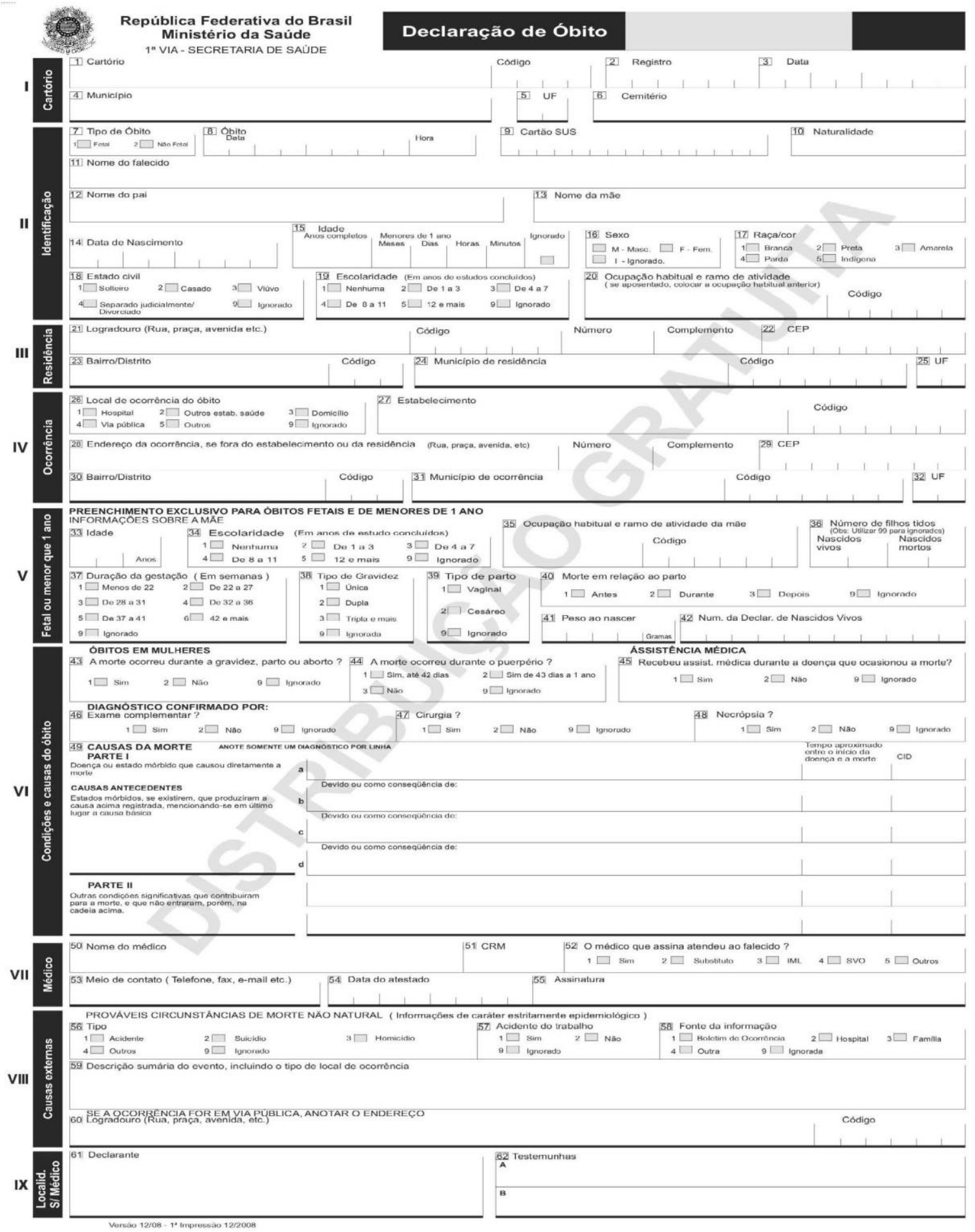




\section{Anexo 3 - Carta de Aceite do Projeto de Pesquisa pelo Comitê de Ética em Pesquisa do HC-FMRP.}

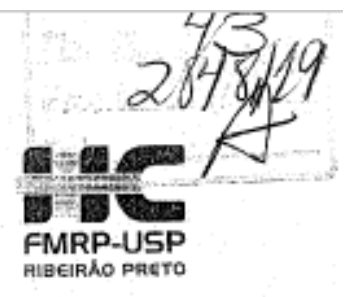

Ribeirẫo Preto, 16/07/2018

\section{COMITÊ DE ÉTICA EM PESQUISA}

Recebido em 03 de julho de 2018, documentação enviada pelos pesquisadores Professor Doutor Marco Aurélio Guimarães (Professor Associado da FMRP-USP CEMEL) e pela Doutoranda no CEMEL/FMRP-USP, Professora Ms. Carolina Lindemann Carezzato, solicitando avaliação sobre a necessidade de submissão à apreciação do Comitê de Ética do HCRP e da Faculdade de Medicina de Ribeirão PretoUSP do trabalho intitulado "Estudo sobre o encaminhamento/recebimento de cadáveres para o Serviço de Verificação de Óbitos do Interior (SVOI): efeitos do parecer consulta CREMESP $31184 / 2015 "$ ". O presente projeto de pesquisa foi elaborado, de acordo com os pesquisadores, como projeto de doutorado junto ao Centro de Medicina Legal do Departamento de Patologia e Medicina Legal da Faculdade de Medicina de Ribeirão Preto da Universidade de São Paulo (CEMEL/FMRP-USP).

O presente projeto de pesquisa propõe:

1) Realizar o levantamento retrospectivo do número de autopsias no SVOI para os anos de 2014, 2015 e 2016, assim como as características sociodemográficas dos casos (sem identificação individual) e diagnósticos finais para emissão das Declarações de Óbito

2) Realizar o levantamento retrospectivo do número de necropsias no SVOI para o ano de 2017 e prospectivo para 2018 e 2019, assim como as características sociodemográficas dos casos (sem identificação individual) e diagnósticos finais para emissão das Declarações de Óbito

3) Realizar a comparação dos dados anteriores e posteriores a 2017, para verificar possíveis diferenças entre o número de necropsias, perfil sociodemográfico e de diagnósticos nos casos de necropsias realizadas no SVOI para avaliação da interferência do Parecer Consulta 31184/2015 nas atividades do serviço

4) Analisar e discutir criticamente os aspectos medico-legais e bioéticos dos resultados a serem obtidos, indicando possíveis falhas dos processos e consequências para a gestão de recursos públicos.

HOSPITAL DAS CLINICAS DA FACULDADE DE MEDICINA OE RIBEIRÃO PRETO DA UNIVERSIDADE DE SÃO PAULO Campus Universitário - Monte Alegre

14048-900 Ribeiråo Preto SP 